$$
\begin{gathered}
\text { Universidade de São Paulo } \\
\text { Faculdade de Medicina de Ribeirão Preto } \\
\text { Departamento de Genética }
\end{gathered}
$$

\title{
DINÂMICA DA MISTURA ÉTNICA EM COMUNIDADES REMANESCENTES DE QUILOMBO BRASILEIRAS
}

\author{
Marcelo Rizzatti Luizon
}


Marcelo Rizzatti Luizon

\section{DINÂMICA DA MISTURA ÉTNICA EM COMUNIDADES REMANESCENTES DE QUILOMBO BRASILEIRAS}

Tese apresentada à Faculdade de Medicina de Ribeirão Preto da Universidade de São Paulo para obtenção do título de Doutor

Área de concentração: Genética.

Orientador: Prof. Dr. Aguinaldo Luiz Simões 
AUTORIZO A REPRODUÇÃO E DIVULGAÇÃO TOTAL OU PARCIAL DESTE TRABALHO, POR QUALQUER MEIO CONVENCIONAL OU ELETRÔNICO, PARA FINS DE ESTUDO E PESQUISA, DESDE QUE CITADA A FONTE.

FICHA CATALOGRÁFICA

Luizon, Marcelo Rizzatti.

Dinâmica da mistura étnica em comunidades remanescentes de quilombo Brasileiras / Marcelo Rizzatti Luizon ; orientador Aguinaldo Luiz Simões. - Ribeirão Preto, 2007.

115 f. : fig.

Tese (Doutorado - Programa de Pós-Graduação em Genética.) - Faculdade de Medicina de Ribeirão Preto da Universidade de São Paulo.

1. Mistura étnica. 2. Comunidades remanescentes de quilombo. 3. Marcadores informativos de ancestralidade. 4. Genética de populações humanas. I. Titulo. 


\section{FOLHA DE APROVAÇÃO}

Marcelo Rizzatti Luizon

Dinâmica da mistura étnica em comunidades remanescentes de quilombo Brasileiras

Tese apresentada à Faculdade de Medicina de Ribeirão Preto da Universidade de São Paulo para obtenção do título de Doutor Área de concentração: Genética.

Aprovado em:

Banca Examinadora

Prof. Dr.

Instituição: Assinatura:

Prof. Dr.

Instituição: Assinatura:

Prof. Dr.

Instituição: Assinatura:

Prof. Dr. Instituição: Assinatura:

Prof. Dr.

Instituição: Assinatura: 


\section{Dedicatória}

A toda minha familia, sem dúvida o bem mais precioso que possuo. Em especial aos meus pais e irmãos, pela força que sempre me transmitem, que me mantém firme em minha caminhada.

Agradeço imensamente. 


\section{Agradecimentos}

Ao Dr. Aguinaldo Luiz Simões, pela oportunidade, confiança, amizade, e pela contribuição para o meu crescimento científico.

Às Profas. Dras. Ana Angélica Leal Barbosa, Kiyoko Abé Sandes, Sandra Mara Bispo Sousa e Ilíada Rainha de Souza pela grande colaboração neste trabalho.

Aos professores membros da banca examinadora, pela disponibilidade em avaliar este trabalho e, dessa forma, contribuir com minha formação.

Ao professores e funcionários do Departamento de Genética da Faculdade de Medicina de Ribeirão Preto, pelos ensinamentos e acolhida.

Ao Prof. Mark D. Shriver, da Universidade da Pennsylvania, por ter compartilhado seus dados, o que permitiu enriquecer o nosso trabalho.

Ao Conselho Nacional de Desenvolvimento Científico e Tecnológico pela concessão da bolsa de Doutorado para a realização desta pesquisa.

Aos amigos do Laboratório de Genética Bioquímica e do Bloco C deste Departamento, pela agradável convivência durantes estes anos.

Às amigas Maria e Ana Lúcia, pela atenção que sempre me dispensaram na discussão das dúvidas sobre a parte laboratorial do trabalho.

Aos amigos Cláudia, Celso e Sandra pela ajuda nas análises estatísticas, nas discussões e na revisão do texto.

À Yara pelo companheirismo durante todos estes anos, pela ajuda na revisão do texto e pela diagramação desta Tese. 


\section{Resumo}

LUIZON, M. R. Dinâmica da mistura étnica em comunidades remanescentes de quilombo Brasileiras. 2007. 115 f. Tese (Doutorado) Faculdade de Medicina de Ribeirão Preto, Universidade de São Paulo, Ribeirão Preto, 2007.

Apesar da intensa mistura étnica na formação da população Brasileira, pequenos grupos isolados ainda podem ser encontrados, principalmente representados pelas tribos indígenas e comunidades remanescentes de quilombo. As comunidades de Barra (BA), São Gonçalo (BA) e Valongo (SC) apresentam diferentes histórias demográficas de formação. Os AIMs (Marcadores Informativos de Ancestralidade) são capazes de revelar essas diferenças pois apresentam grandes diferenciais de freqüência $(\delta)$ entre os principais grupos populacionais parentais (africanos, amerindios, europeus) e, por esta razão, constituem polimorfismos com maior poder discriminante em estimativas de mistura étnica. No presente trabalho, foram testados oito AIMs na análise de três remanescentes de quilombo, comparados a duas amostras de população urbana brasileira. Um destes marcadores, o alelo CYP1A1*2C, foi testado em sete aldeias de quatro tribos da Amazônia Central Brasileira, completando a análise dos outros sete marcadores previamente realizados nestas populações ameríndias. Os objetivos, além da descrição formal de tais populações, incluiam comparar eventuais diferenças entre as comunidades quilombolas e verificar a eficiência relativa destes marcadores em estudos deste tipo. A comparação das freqüências do alelo CYP1A1*2C entre os ameríndios e populações mundiais confirma este alelo como um excelente AIM para diferenciar amerindios de europeus e africanos, informação importante em estimativas de mistura em populações trihíbridas Brasileiras. As freqüências de oito AIMs (FY-Null, RB, LPL, AT3, Sb19.3, APO, PV92 e CYP1A1*2C) foram então estimadas nas comunidades remanescentes de quilombo de Barra $(n=47)$, São Gonçalo $(n=51)$ e Valongo $(n=25)$ e nas populações urbanas de Jequié $(n=47)$ e Hemosc (Hemocentro de 
Santa Catarina, $n=25$ ) a partir dos fenótipos determinados por PCR e PCRRFLP. As análises estatísticas empregaram programas já descritos (GENEPOP, DISPAN, GDA, STRUCTURE, MVSP e ADMIX 2 e 3). As freqüências alélicas e genotípicas diferenciam todas as comunidades remanescentes e urbanas, fato corroborado pelos valores de $F_{S T}(\mathrm{p}<0,01)$ par a par entre elas. Outros valores de $F_{S T}$ mostram similaridades da comunidade de Barra com africanos e da amostra Hemosc com Europeus, o que é confirmado pelas estimativas do componente africano em Barra (95\%) e europeu no Hemosc (83\%), como também pelas análises de componente principal. Nestas últimas, o locus FY foi a variável de maior peso ('loading') sobre o primeiro componente principal e o PV92 o locus de maior peso sobre o segundo componente principal. Este método demonstrou-se particularmente adequado, pois, em ambas as análises, os dois componentes principais explicaram mais do que $95 \%$ da variância total. As estimativas dos componentes africano, europeu e ameríndio em São Gonçalo (68\%, 22\% e $10 \%)$ e JQ $(52 \%, 31 \%$ e $17 \%)$ mostram que os AIMs geram estimativas de contribuição africana maiores do que as obtidas por STRs autossômicos, YSTRs e marcadores clássicos nas mesmas populações. A estimativa do componente africano em Valongo (68\%) foi menor que a obtida a partir dos marcadores clássicos. Isto poderia ser considerado como evidência da maior eficiência destes marcadores na quantificação do componente africano, uma vez que o aumento das estimativas não foi generalizado e, portanto, provavelmente não viciado. Conclui-se que os AIMs seriam mais eficientes para o cálculo da proporção relativa dos diferentes componentes formadores destas populações, pois conduziriam a estimativas mais realistas.

Palavras-chave: Mistura étnica. Comunidades remanescentes de quilombo. Marcadores informativos de ancestralidade. 


\section{Abstract}

\section{LUIZON, M. R. Inter-ethnic admixture dynamics in Brazilian quilombo} remnant communities. 2007. 115 f. Thesis (Doctoral) - Faculdade de Medicina de Ribeirão Preto, Universidade de São Paulo, Ribeirão Preto, 2007

In spite of the high degree of inter-ethnic admixture that characterizes the formation of the Brazilian population, small isolated groups, mainly represented by indigenous Amerindian tribes and communities known as quilombo remnants, can still be found. Barra (BA), São Gonçalo (BA) and Valongo (SC) are communities that presented different demographic histories during their formations. The AIMs (Ancestry Informative Markers) are capable of disclosing such differences due to the fact that they present large frequency differentials $(\delta)$ between the major ethnic groups that gave origin to the Brazilian population. This provides more reliable information for interethnic admixture estimates. Given that, the present study aimed at establishing the differences regarding inter-ethnic admixture between these three quilombo remnants, which present different demographic histories. The CYP1A1*2C allele frequencies were established in four indigenous tribes from the Brazilian Amazon, which are characterized by low admixture degrees with non-Amerindian people (2-3\%), and were compared with frequencies obtained in worldwide populations. This comparison evidenced that such allele is extremely useful for setting Amerindians apart from Europeans and Africans, which is an outstanding feature for estimation of admixture proportions in Brazilian tri-hybrid populations. Allele frequencies of eight AIMs (FY-Null, RB, LPL, AT3, Sb19.3, APO, PV92 and CYP1A1*2C) were obtained in three quilombo remnant communities, Barra $(n=47)$, São Gonçalo $(n=51)$ and Valongo $(n=25)$, and in urban population samples from Jequié $(n=47)$ and Hemosc $(n=25)$, by means of PCR and PCR-RFLP. Statistical analysis were carried out employing the GENEPOP, DISPAN, GDA, STRUCTURE, MVSP and ADMIX 2 and 3 softwares. Allele and genotype 
frequencies are able to differentiate all quilombo remnant and urban samples, an aspect corroborated by the pair-wise $F_{S T}(\mathrm{p}<0.01)$ values. Other $F_{S T}$ estimates reveal similarities between Barra and Africans and between Hemosc and Europeans, which are supported by the respective African and European admixture estimates in Barra (95\%) and Hemosc (83\%) and by the Principal Component Analysis. In the latter analysis, the FY locus consisted in the variable with greatest influence ("loading") over the first component. On the other hand, the variable PV92 exhibited the highest influence over the second component analysis. This method has proven to be very reliable, given that, in both analyses, the first two principal components explained more than 95\% of the total variance. African, European and Amerindian inter-ethnic admixture estimates in São Gonçalo (68\%, 22\% and 10\%) and JQ $(52 \%, 31 \%$ and 17\%) emphasize the fact that the AIMs provides higher African contribution estimates than the ones obtained by means of autosomal and Y-linked STRs and classical markers in the same populations. African contribution estimated in Valongo (68\%) was lower than the one obtained by means of classical markers. Taken together, these estimates may be an evidence of higher effectiveness of this set of markers in quantifying the African component, as long as the increase in African contribution was not generalized and, hence, probably unbiased. In conclusion, the AIMs are more effective in estimating the admixture proportions of the different ethnic components that gave origin to these populations, given that they resulted in more reliable estimates.

Keywords: Ethnic admixture. Remnant quilombo communities. Ancestry informative markers. 
INTRODUÇÃO

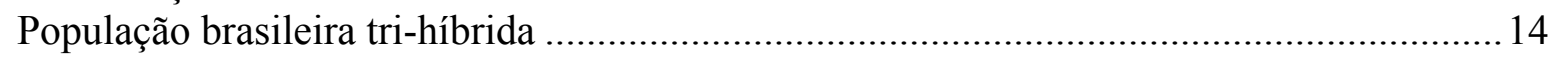

Afro-descendentes e Comunidades Remanescentes de Quilombo........................................15

Atualização do Conceito de Quilombo............................................................................. 18

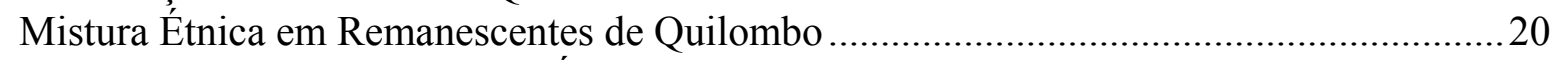

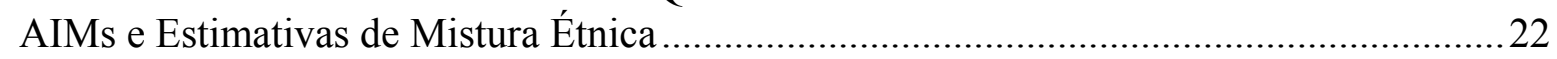

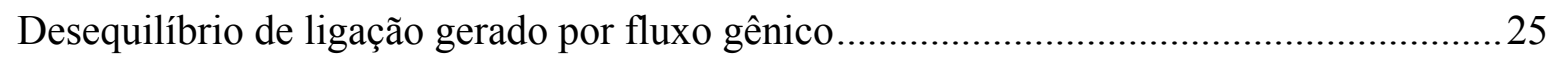

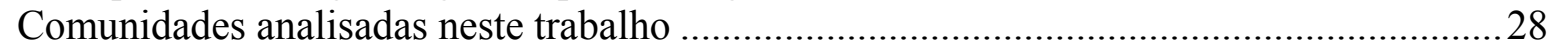

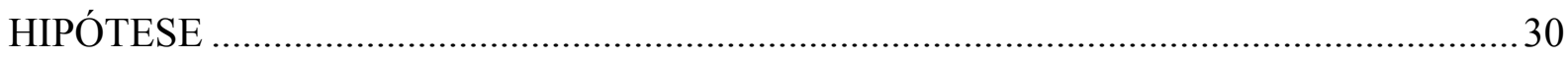

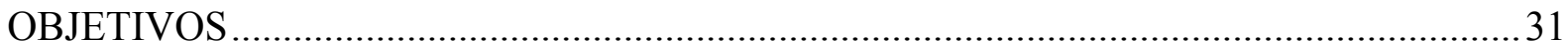

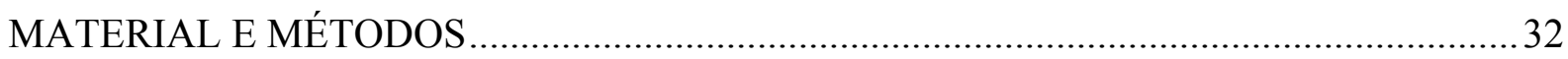

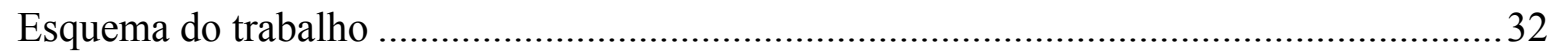

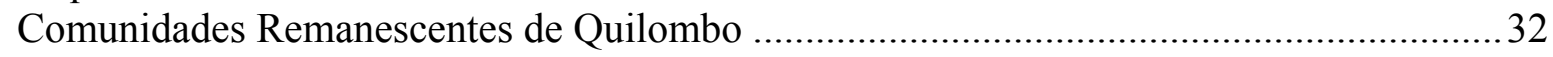

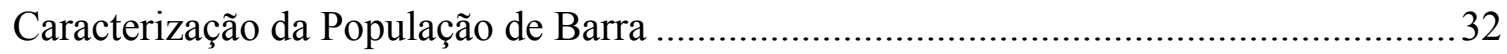

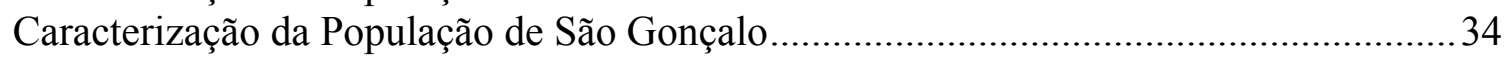

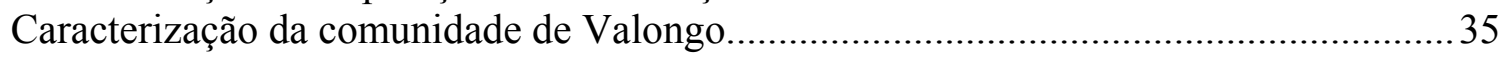

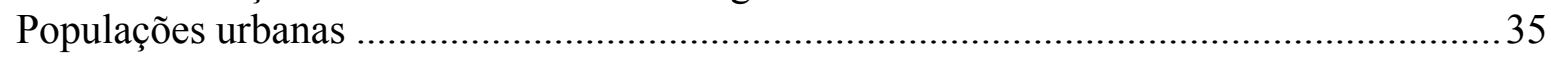

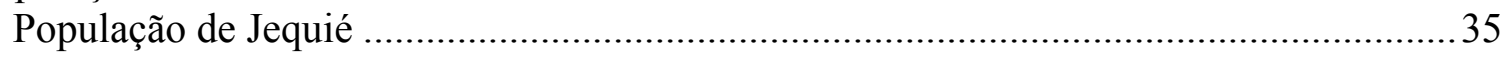

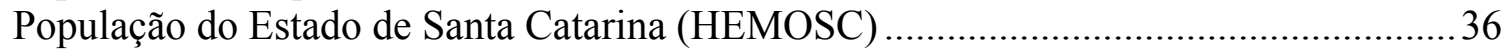

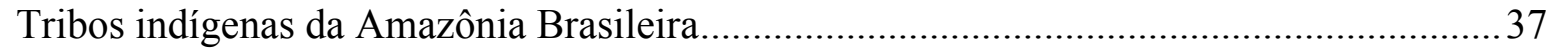

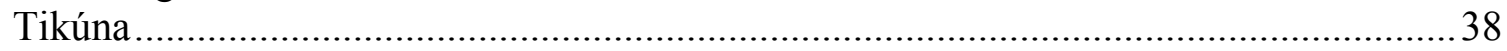

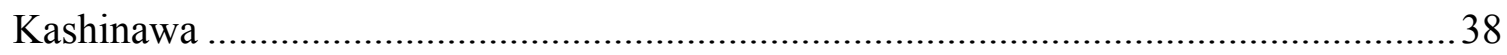

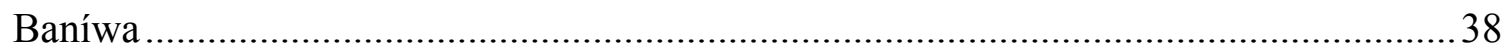

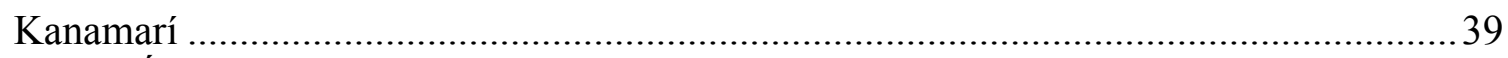

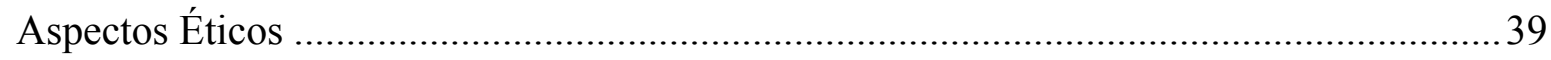

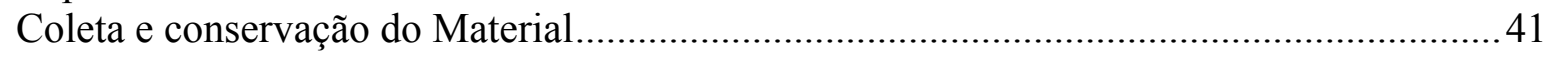

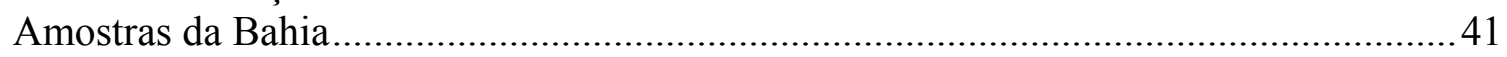

Amostras de Santa Catarina (HEMOSC) ................................................................ 42

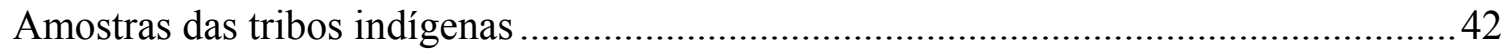

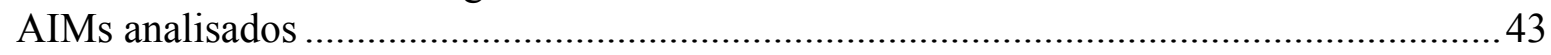

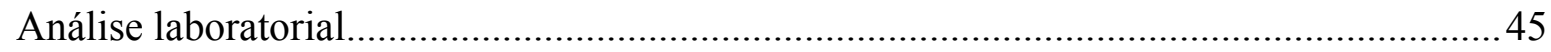

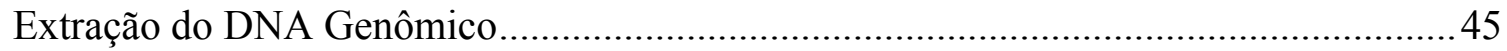

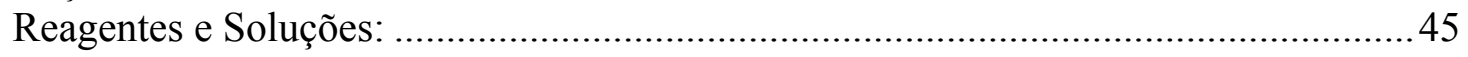

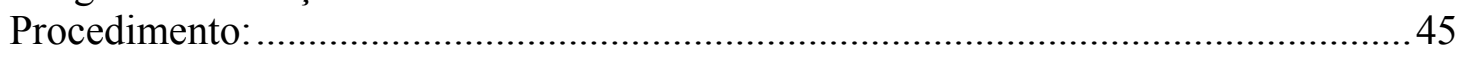

Reação em Cadeia da Polimerase (PCR) ............................................................... 46

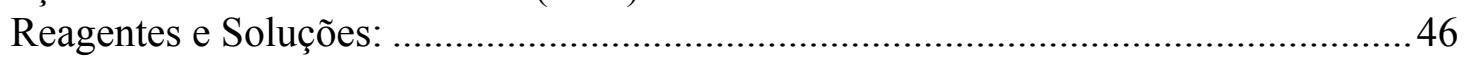

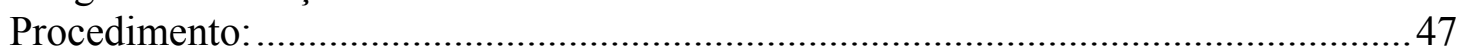

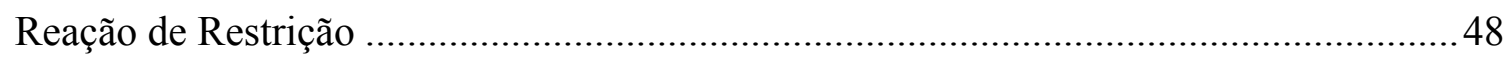




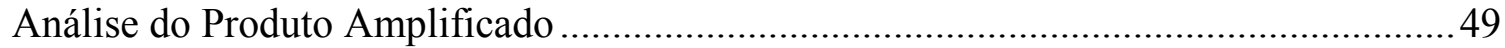

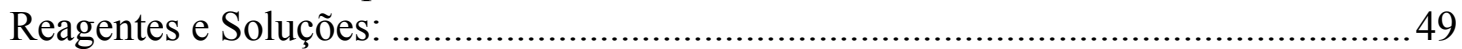

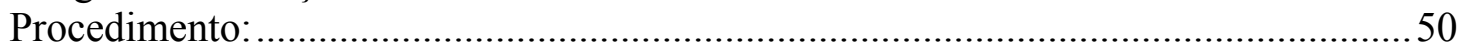

Coloração com Nitrato de Prata e Secagem do Gel........................................................ 51

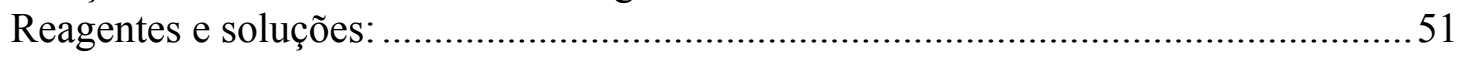

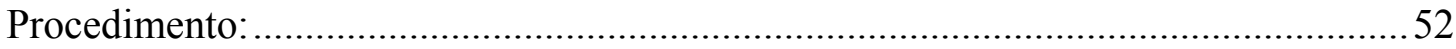

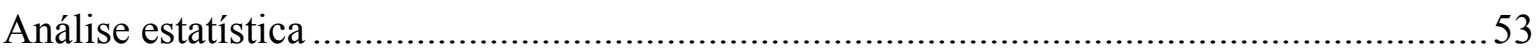

Freqüências Gênicas em Populações Ancestrais .................................................................53

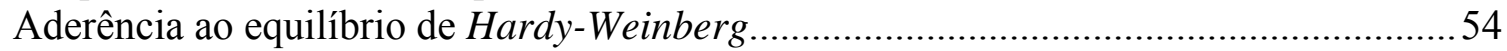

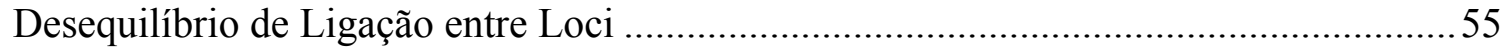

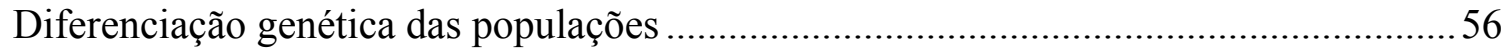

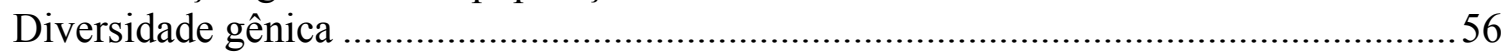

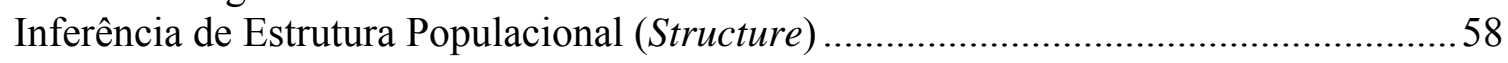

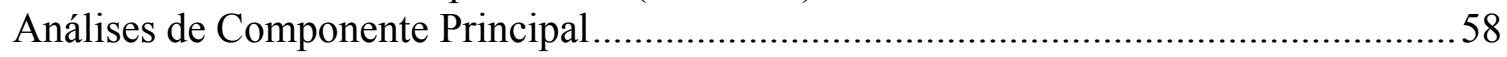

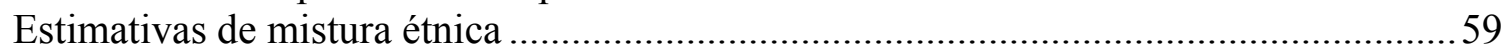

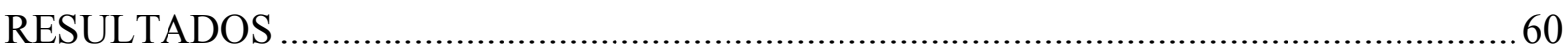

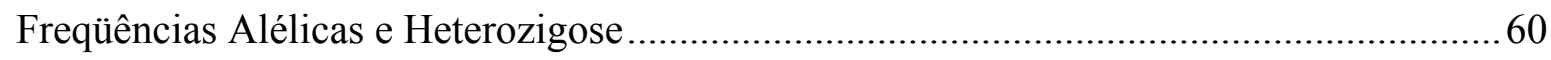

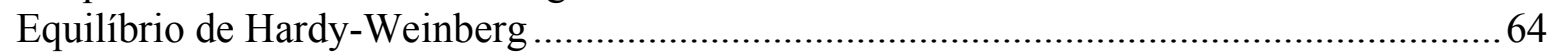

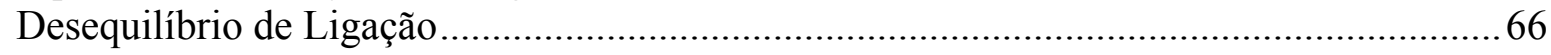

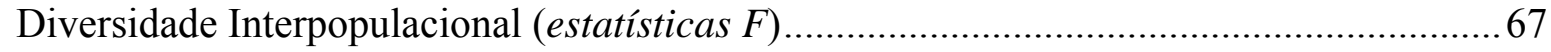

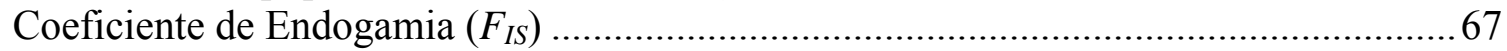

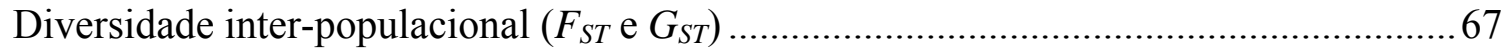

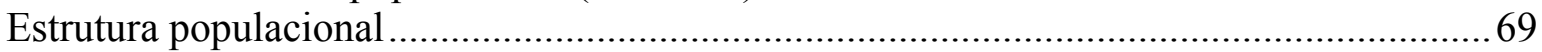

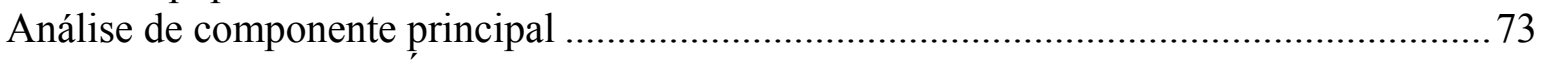

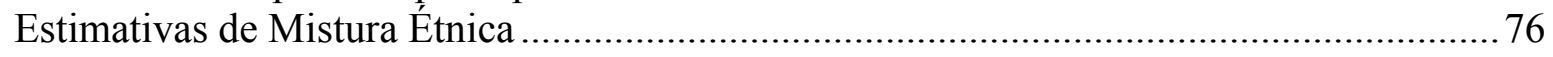

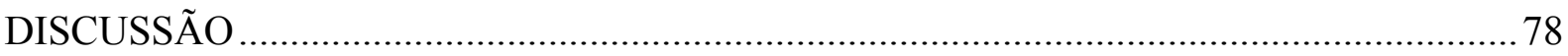

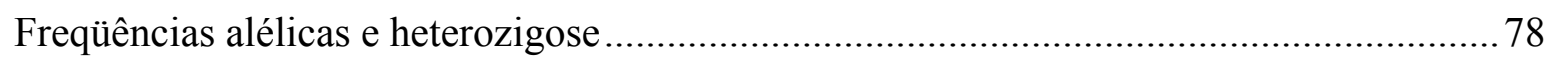

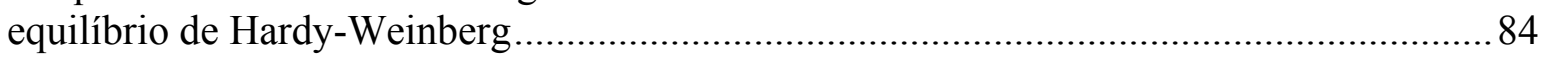

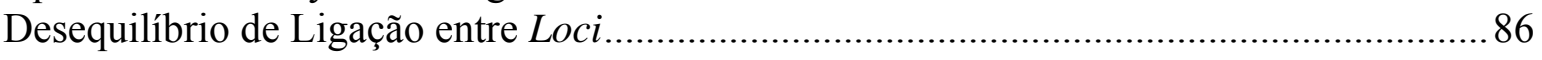

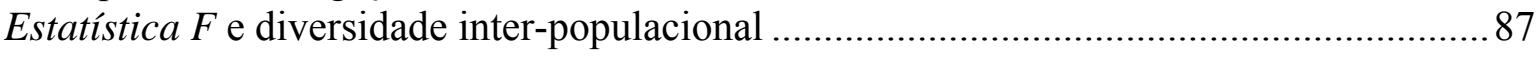

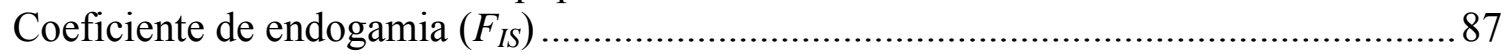

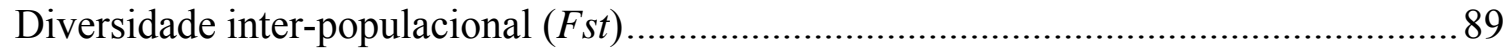

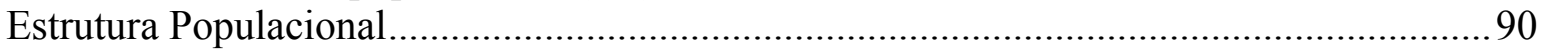

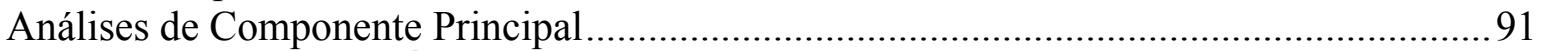

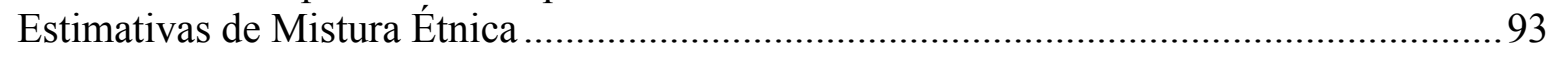

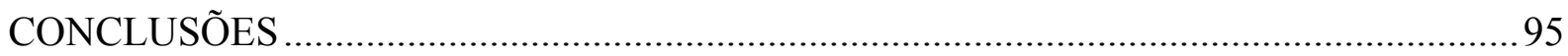

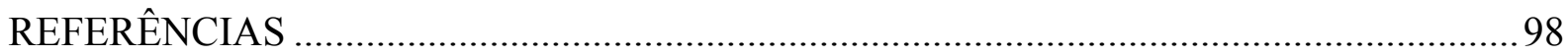

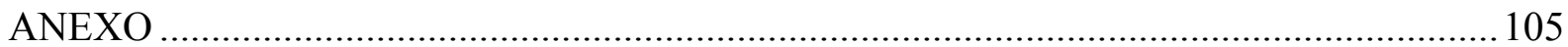




\section{Lista de Tabelas}

TABELA 1: Mistura étnica em comunidades afro-derivadas Brasileiras.

.21

TABELA 2. Estimativas de mistura africana (Afr), européia (Eur) e ameríndia (Amer) obtidas a partir de diferentes conjuntos de AIMs em populações Americanas.

TABELA 3: Localização citogenética, enzimas de restrição, seqüência dos primers e condições de PCR dos oito AIMs analisados.

TABELA 4: Condições de PCR para os AIMs analisados. Quantidade em $\mu 1$ suficiente para uma reação.

TABELA 5. Freqüências alélicas dos oito AIMs e diversidade genética $\left(H_{S}\right)$ nas comunidades remanescentes de quilombo, populações urbanas e ameríndias analisadas. As freqüências se referem ao alelo CYP1A1*2C e aos alelos $* 1$ dos demais loci.

TABELA 6. Diferenciação das frequencias gênicas e genotípicas entre os pares de populações analisadas. Os valores significativos $(\mathrm{p}<0,05)$ após a correção de Bonferroni $\left(\alpha_{\text {Bonf. }}<0,007\right)$ estão destacados em negrito.

TABELA 7. Diversidade genética $\left(H_{S}\right)$ obtidas a partir dos AIMs FY, RB, LPL, AT3, Sb19.3 e APO entre diferentes populações mundiais.

TABELA 8. Probabilidade de desvio casual segundo teste exato (Guo e Thompson, 1992) para a verificação do equilíbrio de Hardy-Weinberg. Os valores significativos antes da correção de Bonferroni estão destacados em itálico e sublinhado e os valores significativos após a correção $\left(\alpha_{\text {Bonf. }}<0,0005\right)$ estão destacados em negrito ...65

TABELA 9. Valores de $F_{I S}$ e seus intervalos de confiança (IC) para as populações analisadas. Valores significativos em negrito, pois seus IC não incluem o valor zero.

TABELA 10. Valores de $F_{S T}$ e intervalos de confiança (IC) para diferentes conjuntos e pares de populações. Valores significativos em negrito, pois seus IC não incluem o valor zero.

TABELA 11. Valores de $F_{S T}$ e intervalos de confiança (IC) entre as populações analisadas e populações mundiais. Valores significativos em negrito, pois seus IC não incluem o valor zero......

Tabela 12. Características dos componentes principais baseados nas freqüências alélicas de seis AIMs (FY, RB, LPL, AT3, Sb19.3 e APO).

Tabela 13. Pesos (loadings) das variáveis na resolução dos componentes principais na análise baseada em seis AIMs (FY, RB, LPL, AT3, Sb19.3 e APO).

Tabela 14. Características dos componentes principais baseados nas freqüências alélicas de sete AIMs (FY, RB, LPL, AT3, Sb19.3, APO e PV92).

Tabela 15. Pesos (loadings) das variáveis na resolução dos componentes principais na análise baseada em sete AIMs (FY, RB, LPL, AT3, Sb19.3, APO e PV92).

TABELA 16. Contribuição dos componentes africano, europeu e ameríndio obtidos a partir dos oito AIMs para as comunidades remanescentes de quilombo e populações urbanas analisadas.

Tabela 17. Freqüências (\%) do alelo CYP1A1*2C em populações mundiais. 79

TABELA 18. Comparação das contribuições africana, européia e ameríndias obtidas a partir dos oito AIMs com marcadores previamente analisados nas comunidades de São Gonçalo e Valongo e na população urbana de Jequié. 


\section{Lista de Figuras}

FIGURA 1. Principais rotas do tráfico de escravos para o Brasil. Crédito: Antonio Sérgio Bento Moreira. 16

FIGURA 2. Esquema apresentando dois modelos extremos de mistura; isolamento híbrido (HI) e fluxo gênico contínuo (CGF; modificado de Pfaff et al., 2001).

FIGURA 3. Localização das comunidades remanescentes de quilombo (Barra, São Gonçalo e Valongo) e das populações urbanas (Jequié e Florianópolis, ou Hemosc) analisadas. Crédito: Antonio Sérgio Bento Moreira... 33

FIGURA 4. Localização geográfica das aldeias pertencentes às tribos Tikúna, Kashinawa, Baníwa e Kanamarí e número de amostras analisadas.

FIGURA 5. Comparação das freqüências dos AIMs entre as comunidades remanescentes de quilombo de São Gonçalo, Barra e Valongo, as populações urbanas de Jequié e HEMOSC, e as tribos da Amazônia Brasileira, Tikúna, Baníwa, Kashináwa e Kanamarí.

FIGURA 6. (A) Estrutura populacional nas comunidades remanescentes de quilombo e nas populações urbanas, em comparação com populações parentais Africanas, Européias e Ameríndios da Amazônia Brasileira, obtido a partir de sete AIMs (com exceção do CYP1A1). Foram admitidas $k=3$ populações, 30.000 interações para o período burn-in e 100.000 interações para as estimativas dos parâmetros. (B) Proporção de associação de cada população a cada um dos três clusters.

FIGURA 7. Agrupamento dos indivíduos (círculos) das comunidades de (A) Barra, Valongo e São Gonçalo e de (B) Jequié e do HEMOSC, de acordo a contribuição dos grupos étnicos parentais: africano, europeu e ameríndio.

FIGURA 8. Componentes principais obtidos a partir de seis AIMs (FY, RB, LPL, AT3, Sb19.3 e APO) que relacionam as freqüências alélicas das populações analisadas com populações mundiais. Populações africanas e européias (Parra et al., 2001; Tomás et al., 2002), afro- e euro-americanas (Parra et al., 1998), euro-brasileiros (Zembrzuski et al., 2006), e populações indígenas da América do Norte (dbSNP, PSU-ANTH) e da Amazônia Brasileira (Luizon et al., 2007a).

FIGURA 9. Componentes principais obtidos a partir da adição do locus PV92 aos seis AIMs da Figura 8, que relacionam as freqüências alélicas das populações analisadas com populações mundiais. Populações africanas e européias (Parra et al., 2001; Tomás et al., 2002), afro- e euro-americanas (Parra et al., 1998), euro-brasileiros (Zembrzuski et al., 2006), e populações indígenas da América do Norte (dbSNP, PSU-ANTH) e da Amazônia Brasileira (Luizon et al., 2007a). 


\section{INTRODUÇÃO}

\section{POPULAÇÃO BRASILEIRA TRI-HÍBRIDA}

A população Brasileira é resultado do processo de mistura entre Amerindios, Europeus, Africanos e, mais recentemente, indivíduos de outras nacionalidades. Os Ameríndios autóctones representavam uma população de aproximadamente 2,4 milhões de individuos (IBGE, 2000) quando a colonização Européia se iniciou, em 1500, com a chegada de aproximadamente 500.000 Portugueses, quase todos homens (Ribeiro, 1995). O tráfico de escravos começou na metade do século XVI e, até 1855 , aproximadamente 4 milhões de Africanos foram trazidos ao Brasil (IBGE, 2000). Eles eram oriundos de diferentes regiões Africanas sub-saarianas, predominantemente de regiões hoje pertencentes a Angola, Congo e Moçambique (Curtin, 1969). Dessa maneira, a população Brasileira trihíbrida inicial se originou da mistura entre homens Europeus e mulheres Amerindias ou Africanas. Por fim, aproximadamente 6 milhões de imigrantes chegaram ao Brasil entre 1820 e 1975, em sua maioria Portugueses e Italianos (70\%), e números reduzidos de Espanhóis, Alemães, Sírios, Libaneses e Japoneses (IBGE, 2000).

Graus variáveis de contribuição amerindia, européia e africana foram observados em indivíduos auto-declarados como brancos, de quatro diferentes regiões brasileiras. Tais indivíduos, aleatoriamente selecionados a partir de casos de paternidade, foram analisados quanto a marcadores informativos de ancestralidade do DNAmt (Alves-Silva et al., 2000), 
cromossomo Y (Carvalho-Silva et al., 2001) e autossômicos (Parra et al., 2003).

A contribuição diferencial dos grupos parentais também pode ser evidenciada por outros estudos envolvendo marcadores de DNAmt e do cromossomo $\mathrm{Y}$ em populações de diferentes regiões brasileiras (Ferreira et al., 2006; Marrero et al., 2005; Ribeiro-dos-Santos et al., 2007).

Apesar da intensa mistura étnica na formação da população Brasileira, pequenos grupos isolados ainda podem ser encontrados, principalmente representados pelas aldeias Amerindias e comunidades Afro-derivadas remanescentes de quilombos, que conservam muitas características de suas populações ancestrais.

\section{AFRO-DESCENDENTES E COMUNIDADES REMANESCENTES DE QUILOMBO}

Apesar da discussão quanto aos números totais, cerca de 9 a 13 milhões de africanos foram trazidos para as Américas (Matoso, 1982). Os 4 milhões de escravos que o Brasil teria recebido a partir da metade do século XVI (Curtin, 1969) foram introduzidos para trabalhar como escravos nas lavouras de cana-de-açúcar e café, além da mineração de ouro (Calmon, 1959). O período do tráfico de escravos pode ser dividido em quatro grandes ciclos, caracterizados por rotas que apresentam diferentes origens geográficas na África e locais de desembarque no Brasil (Figura 1). 


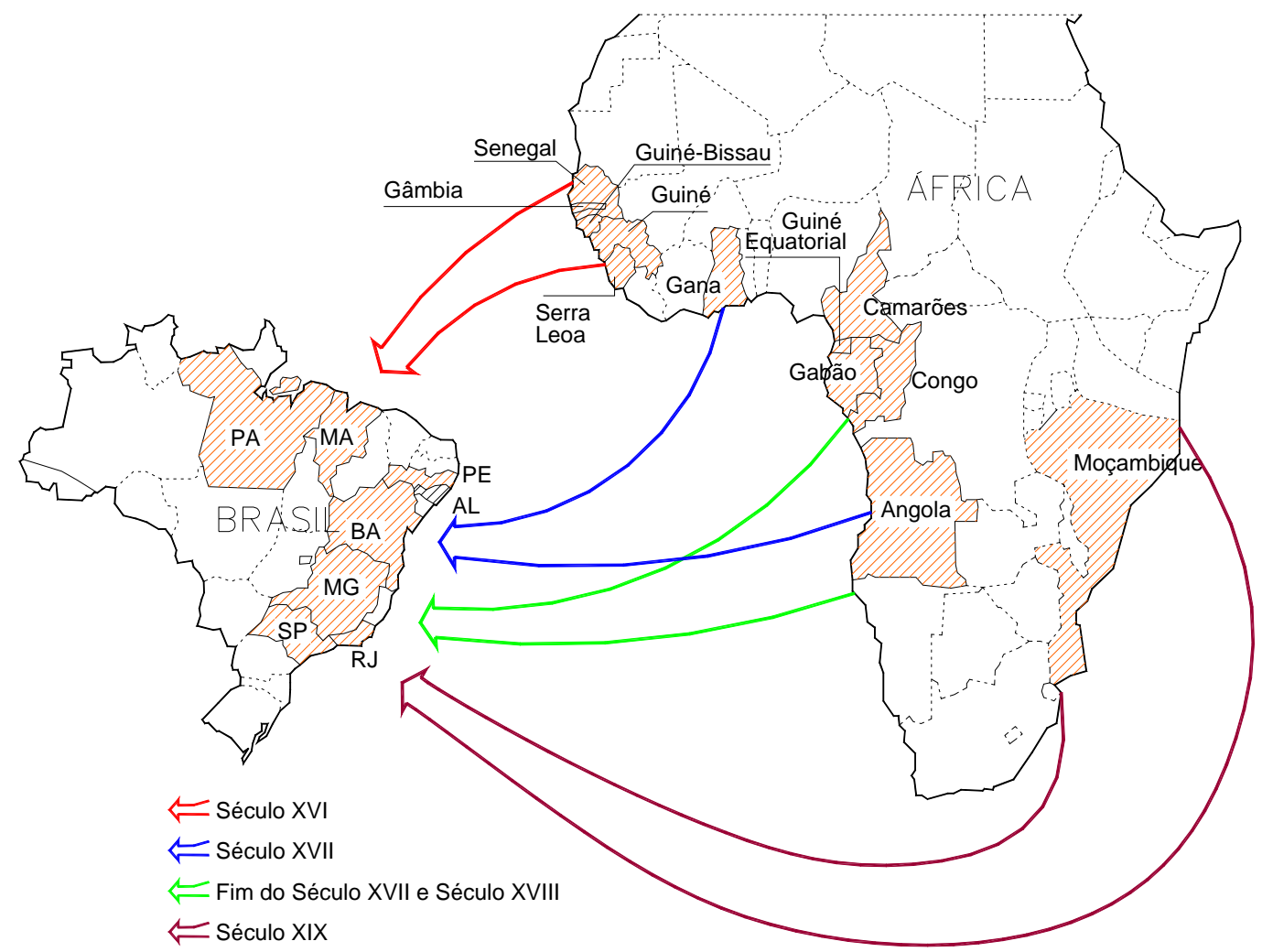

FIGURA 1. Principais rotas do tráfico de escravos para o Brasil. Crédito: Antonio Sérgio Bento Moreira.

No século XVI (ciclo da Guiné), os escravos eram trazidos em sua maioria de Serra Leoa, Senegal, Guiné, Guiné Bissau e Gâmbia, e chegavam nos estados do Pará, Maranhão e Bahia para trabalhar na cultura da canade-açúcar (Goulart, 1975; Matoso, 1982; Viana, 1988). No século XVII (ciclo do Congo e de Angola), os africanos eram trazidos do Congo, Gabão, Angola, Gana, Guiné Equatorial e Camarões, e chegavam à Bahia, Pernambuco e Alagoas, nesta que foi a principal rota de tráfico por 300 anos (Matoso, 1982). No final do século XVII e começo do XVIII (ciclo da Costa da Mina), os africanos eram trazidos do Congo e de Angola.

A partir de 1850 o tráfico de escravos foi proibido, entretanto os mesmos eram trazidos ilegalmente a Bahia, Rio de Janeiro e São Paulo 
(Goulart, 1975; Matoso, 1982; Salzano, 1986). No século XIX, o Brasil recebeu escravos de diferentes localidades, como Costa da Mina, Congo e principalmente de Moçambique (Goulart, 1975; Matoso, 1982).

A distribuição dos africanos no território brasileiro foi bastante heterogênea (Viana, 1988). Os estados que receberam os maiores contingentes foram o Rio de Janeiro (38\%), Bahia (25\%), Pernambuco (13\%), São Paulo (12\%), Maranhão (7\%) e Pará (5\%).

Durante o período da escravidão no Brasil, os africanos que conseguiam escapar se refugiavam com outros em igual situação em áreas afastadas dos centros de colonização ou em locais de dificil acesso, escondidos e fortificados, no meio das matas. Os núcleos se transformaram em aldeias, dedicando-se à economia de subsistência e, às vezes, ao comércio. Esta fuga representou uma das mais importantes formas de resistência à escravidão. A palavra quilombo (kilombo), que possui origem banto e significa acampamento ou fortaleza, foi usada pelos portugueses para designar estas comunidades formadas por escravos fugidos do cativeiro.

O Quilombo dos Palmares foi a maior manifestação de rebeldia e organização política, militar e econômica contra o escravismo na América Latina. Organizado por quilombolas no território atualmente pertencente ao estado de Alagoas, teve início aproximadamente em 1630, perdurou por quase cem anos e, durante esse longo período, desestabilizou regionalmente o sistema escravista. Paradoxalmente, não existem documentos escritos pelos palmarinos durante a sua existência. Certamente seguiam, como em outros quilombos, a tradição africana de comunicação oral (Moura, 2004). 
A maior parte dos quilombos originados durante o período da escravidão teve uma formação heterogênea dependendo da região geográfica e dos grupos fundadores. Por exemplo, como relatado para o próprio Quilombo dos Palmares: "Além das fugas sistemáticas de escravos, contribuía para aumentar sua população o ingresso de indios, "salteadores", fugitivos da justiça e elementos de outras etnias ou camadas que se sentiam oprimidos pelo sistema escravista” (Moura, 2004).

\section{ATUALIZAÇÃo DO CONCEITO DE QUILOMBO}

Os grupos que hoje são considerados remanescentes de comunidades de quilombos se constituíram a partir de uma grande diversidade de processos, que incluem as fugas com ocupação de terras livres e geralmente isoladas, mas também as heranças, doações, recebimento de terras como pagamento de serviços prestados ao Estado, a simples permanência nas terras que ocupavam e cultivavam no interior das grandes propriedades, bem como a compra de terras, tanto durante a vigência do sistema escravocrata quanto após a sua extinção. Exemplos incluem o caso do quilombo Frechal, no Maranhão, localizado a cem metros da casa grande, ou casos onde o quilombo esteve na própria senzala, representado por formas de produção autônoma dos escravos que poderiam ocorrer, sobretudo em épocas de decadência de ciclos econômicos, fossem agrícolas ou de mineração (Carvalho, 2002).

Portanto, não se deve imaginar que estes grupos camponeses negros tenham resistido em suas terras até os dias de hoje porque ficaram isolados, à margem da sociedade. Pelo contrário, sempre se relacionaram intensa e 
assimetricamente com a sociedade brasileira, resistindo a várias formas de violência para permanecerem em seus territórios ou, ao menos, em parte deles (Carvalho, 2002).

Conforme registros junto a Fundação Cultural Palmares (2007), 1.000 comunidades remanescentes dos quilombos estão espalhadas por todos os estados brasileiros. As maiores concentrações destas comunidades estão nos estados da Bahia e Maranhão.

O direito à titulação dos territórios que as comunidades remanescentes de quilombos historicamente reconhecem como seus está previsto no artigo no 68 do Ato das Disposições Constitucionais Transitórias da Constituição Federal de 1988, sob o enunciado: "Aos remanescentes das comunidades de quilombos que estejam ocupando suas terras é reconhecida a propriedade definitiva, devendo o Estado emitir-lhes os títulos respectivos" (Carvalho, 2002).

O Decreto no 4.887, de 20 de novembro de 2003, em seu artigo $2^{\circ}$, considera os remanescentes das comunidades dos quilombos, "os grupos étnico-raciais, segundo critérios de auto-atribuição, com trajetória histórica própria, dotados de relações territoriais específicas, com presunção de ancestralidade negra, relacionada com a resistência à opressão histórica sofrida" (Fundação Cultural Palmares, 2007). A legislação também estabelece o conceito de terra ocupada por quilombos, que seriam aquelas "utilizadas para a garantia de sua reprodução física, social, econômica e cultural". O processo de demarcação de terras quilombolas é de competência 
do INCRA (Instituto Nacional de Colonização e Reforma Agrária). Neste caso, a terra é propriedade coletiva de toda a comunidade.

\section{MISTURA ÉTNICA EM REMANESCENTES DE QUILOMBO}

Apesar do processo de miscigenação existente, as comunidades afrobrasileiras constituem-se em um grande estoque dos genes africanos fundadores da população brasileira, os quais são importantes para o estudo da origem e caracterização não só dos negros brasileiros, como de toda a população do Brasil (Arpini-Sampaio et al., 1999).

A contribuição genética dos grupos europeu, africano e amerindio foi estimada em muitas comunidades remanescentes de quilombos, a partir de vários tipos de marcadores genéticos (Tabela 1). Embora exista uma predominância do componente africano na maioria destas comunidades, graus variáveis de ancestralidade européia e ameríndia são observados a depender da região, do tipo do marcador analisado e da história demográfica da população.

A maioria destes marcadores genéticos utilizados previamente, excetuando-se os bialélicos do cromossomo $\mathrm{Y}$ e do DNAmt, apresentam freqüências polimórficas tanto nas populações híbridas como naquelas representativas das populações ancestrais. Entretanto, existem marcadores genéticos que exibem diferenciais de freqüência alélica $(\delta)$ superiores a $30 \%$ entre quaisquer duas populações parentais, primeiramente chamados de PSAs (do inglês Population-Specific Alleles; Shriver et al., 1997), e atualmente 
denominados por AIMs (do inglês Ancestry Informative Markers; Bonilla et al., 2004).

TABELA 1: Mistura étnica em comunidades afro-derivadas Brasileiras.

\begin{tabular}{|c|c|c|c|c|c|}
\hline \multirow[b]{2}{*}{ Comunidades } & \multicolumn{5}{|c|}{ Contribuição (\%) } \\
\hline & Marcador & Europeu & Africano & Ameríndio & Referências \\
\hline \multicolumn{6}{|l|}{ Norte } \\
\hline Trombetas-PA & Clássico & 27 & 62 & 11 & (1) \\
\hline Trombetas-PA & Clássico & 23,8 & 56,4 & 19,8 & (2) \\
\hline Trombetas-PA & STR/VNTR & 32,5 & 57,6 & 9,9 & (3) \\
\hline Trombetas-PA & DNAmt & 7 & 80 & 13 & (3) \\
\hline Trombetas-PA & STR-Y & 13 & 84 & 3 & (3) \\
\hline Cametá-PA & Clássico & 18 & 49,6 & 32,3 & (4) \\
\hline Cametá-PA & Clássico & 17,9 & 48 & 34,1 & (2) \\
\hline Cametá-PA & STR/VNTR & 24,2 & 53,4 & 22,4 & (3) \\
\hline Cametá-PA & DNAmt & 17 & 59 & 24 & (3) \\
\hline Cametá-PA & STR-Y & 54 & 28 & 18 & (3) \\
\hline Pacoval-AM & Clássico & 27,4 & 44,3 & 28,3 & (5) \\
\hline Curiaú-AM & Clássico & 26,4 & 73,6 & 0 & (5) \\
\hline Curiaú-AM & DNA-Y & 37 & 57 & 6 & (6) \\
\hline Curiaú-AM & DNAmt & 0 & 53 & 47 & (6) \\
\hline \multicolumn{6}{|l|}{ Nordeste } \\
\hline Muquém-AL & Clássicos & 14 & 73 & 13 & (7) \\
\hline Quilombo-AL & Clássicos & 30 & 64 & 6 & (7) \\
\hline Cajueiro-MA & Clássicos & 32,6 & 67,4 & 0 & (8) \\
\hline Cajueiro-MA & STR/VNTR & 26,2 & 48,8 & 25 & (3) \\
\hline Cajueiro-MA & DNAmt & 17 & 59 & 24 & (3) \\
\hline Cajueiro-MA & STR-Y & 24 & 78 & 0 & (3) \\
\hline Mimbó-PI & Clássicos & 22 & 61 & 17 & (9) \\
\hline Sítio Velho-PI & Clássicos & 16 & 72 & 12 & (9) \\
\hline São Gonçalo-BA & Clássicos/STR & 32,39 & 53,49 & 14,12 & (10) \\
\hline São Gonçalo-BA & STR-Y & 40,28 & 59,72 & 0 & (10) \\
\hline \multicolumn{6}{|l|}{ Sul } \\
\hline Paredão-RS & Clássicos & 18,1 & 79,1 & 2,8 & (4) \\
\hline Paredão-RS & Clássicos & 19,8 & 80,2 & 0 & (2) \\
\hline Paredão-RS & STR/VNTR & 38 & 49,2 & 12,8 & (3) \\
\hline Paredão-RS & DNAmt & 15 & 58 & 27 & (3) \\
\hline Paredão-RS & STR-Y & 35 & 65 & 0 & (3) \\
\hline
\end{tabular}

Referências: (1) Schneider et al., 1997; (2) Bortolini et al., 1995; (3) Bortolini et al., 1999; (4) Bortolini et al., 1992; (5) Guerreiro et al., 1999; (6) Ribeiro-dos Santos et al., 2002; (7) Pedrosa 1998; (8) Bortolini et al., 1998; (9) Arpini-Sampaio et al., 1999; (10) Sousa 2001; (11) Silva Jr. et al., 1999.

A precisão nas estimativas de mistura étnica é diretamente dependente do valor de $\delta$ dos marcadores utilizados, portanto os AIMs são os marcadores ideais para estimativas eficazes de mistura populacional (Parra et al., 1998; 
Parra et al., 2001), e na detecção de associações alélicas entre loci não ligados (Pfaff et al., 2001). O nível destas associações pode explicar as diferentes histórias de mistura étnica experienciadas por diferentes populações, assim como o seu grau de estrutura genética.

\section{AIMS E ESTIMATIVAS DE MISTURA ÉTNICA}

Os AIMs já foram empregados em estimativas de mistura étnica em populações das Américas do Norte, Central e do Sul (Tabela 2). As estimativas de contribuição gênica européia em populações Afro-americanas dos EUA variaram de 3,5\% (Gullah) a 22,5\% (New Orleans). O baixo nivel de contribuição européia entre os Gullah corrobora evidências históricas, culturais e antropológicas prévias que indicam seu maior isolamento (Parra et al., 2001).

A mistura africana foi preponderante nestas populações Afroamericanas, enquanto a mistura Ameríndia praticamente não foi considerada (Parra et al., 1998, Parra et al., 2001). Por outro lado, a mistura Européia é preponderante nas estimativas de Mexicanos-americanos e Portoriquenhos, denominados como Hispânicos (Salari et al., 2005, Choudhry et al., 2006), e a ancestralidade Amerindia é maior dentre os Mexicanos (Martinez-Marignac et al., 2007) e quase completa dentre os Nativos Americanos do México (Bonilla et al., 2005) e da Amazônia Brasileira (Luizon et al., 2007a). 
TABELA 2. Estimativas de mistura africana (Afr), européia (Eur) e amerindia (Amer) obtidas a partir de diferentes conjuntos de AIMs em populações Americanas.

\begin{tabular}{lcccc}
\hline & \multicolumn{3}{c}{ mistura (\%) } & \\
\cline { 2 - 4 } \multicolumn{1}{c}{ Populações } & Afr & Eur & Amer & Refs.* \\
\hline Jamaica & & 6,8 & & $(1)$ \\
Afro-americanos (EUA) & & 11,6 a 22,5 & $(1)$ \\
Afro-americanos de Gullah (EUA) & & 3,5 & & $(2)$ \\
Afro-americanos (Carolina do Sul, EUA) & & 11,8 & & $(2)$ \\
Afro-americanos (Columbia, EUA) & & 17,7 & & $(2)$ \\
Hispânicos (San Luis Valley, Colorado) & 3,2 & 62,7 & 34,1 & $(6)$ \\
Mexicanos-americanos & 3,4 & 44,9 & 51,7 & $(7)$ \\
Mexicanos-americanos (San Francisco) & 3,7 & 45,4 & 51 & $(11)$ \\
Mexicanos & 5 & 30 & 65 & $(12)$ \\
Porto-riquenhos & 16,2 & 65,5 & 18,3 & $(7)$ \\
Porto-riquenhos (NY city) & 29,1 & 53,3 & 17,6 & $(8)$ \\
Porto-riquenhos & 21,3 & 65,5 & 18,3 & $(11)$ \\
Afro-caribenhos (Tobago) & 94.0 & 4.6 & 1.4 & $(9)$ \\
Argentinos & 1,7 & 80,2 & 18,1 & $(4)$ \\
Argentinos (La Plata) & 6,5 & 67,6 & 25,9 & $(12)$ \\
Colombianos (Antioquia) & 6 & 79 & 16 & $(5)$ \\
Tlapa (Nativos Americanos, México) & & & $\sim 98$ & $(10)$ \\
Indígenas da Amazônia Brasileira & & & $\sim 98$ & $(13)$ \\
Brasileiros brancos (S, N, NE e SE) & 13 a 32 & & & $\left(14^{\mathrm{a}}\right)$ \\
Brasileiros brancos, intermediários e negros & 31 a 51 & & & $\left(14^{\mathrm{b}}\right)$ \\
Euro-brasileiros (RS) (n=101 e 102) & 2 a 6 & & & $(3)$ \\
\hline Reforinnnn
\end{tabular}

Referências: (1) Parra et al., 1998; (2) Parra et al., 2001; (3) Zembrzuski et al., 2006; (4) Seldin et al., 2007; (5) Bedoya et al., 2006; (6) Bonilla et al., 2004a; (7) Salari et al., 2005; (8) Bonilla et al., 2004b; (9) MiljkovicGacic et al., 2005; (10) Bonilla et al., 2005; (11) Choudhry et al., 2006; (12) Matinez-Marignac et al., 2007; (13) Luizon et al., 2007; (14) Parra et al., 2003: ${ }^{a}$ Auto-declarados e ${ }^{\mathrm{b}}$ Queixadinha (MG).

No Brasil, a ancestralidade genômica africana foi estimada em 173 individuos da comunidade rural de Queixadinha (MG) a partir dos nove AIMs descritos por Parra et al. (1998). Estes individuos também foram classificados quanto ao fenótipo conforme a cor da pele, forma do nariz e dos lábios e cor e forma dos cabelos. Os resultados indicam que, no Brasil, a cor da pele é um pobre indicador de ancestralidade genômica africana (Parra et al., 2003). Por outro lado, a análise de 34 AIMs em amostras de afroamericanos e afro-caribenhos revelou correlações significantes entre as 
estimativas de ancestralidade individual e a pigmentação da pele (Shriver et al., 2003).

Dentre homens Brasileiros auto-declarados como brancos os índices de mistura africana foram maiores no Sudeste e menores no Sul (Parra et al., 2003), e corroboram dados de mtDNA obtidos nestas mesmas amostras (Alves-Silva et al., 2000). No entanto, em Euro-brasileiros da região Sul classificados de acordo com a cor da pele e outras características morfológicas, a contribuição Africana foi bem inferior em comparação com o estudo anterior (Zembrzuski et al., 2006; Tabela 2).

Tais estimativas de mistura obtidas a partir dos AIMs em populações Brasileiras foram inicialmente realizadas utilizando-se freqüências parentais amerindias de somente 10 indivíduos Karitiana, Suruí, Tikuna (Parra et al., 2003). Os dados disponiveis para ameríndios Sul-americanos também eram restritos às tribos Pehuenche, Tikuna e Quechua (Shriver et al., 1997; Collins-Schramm et al., 2004; Weber et al., 2002).

No intuito de gerar freqüências parentais para estimativas de mistura na população brasileira, a distribuição de freqüências de sete AIMs selecionados por Parra et al. (1998) e Shriver et al. (2003) foi investigada em 309 indivíduos de quatro tribos indigenas da Amazônia Brasileira. Como salientado por Parra et al. (2003), quando empregados em análises de populações miscigenadas, os valores de $\delta$ dos AIMs deste conjunto não permitem a discriminação de europeus e amerindios (Luizon et al., 2007).

Por outro lado, um dendrograma Neighbor-Joining separou africanos e europeus dos ameríndios com um alto suporte estatístico (valor de bootstrap 
$=0,989)$. A baixa diversidade $\left(G_{S T}=0,042\right)$ entre Nativos norte-americanos e ameríndios da Amazônia Brasileira corrobora os achados prévios de ausência de variação intra-étnica para os AIMs (Tomás et al., 2002). Portanto, apesar dos efeitos da deriva genética, as freqüências alélicas médias apresentadas podem ser usadas como parentais em estimativas de mistura em populações urbanas brasileiras (Luizon et al., 2007a).

\section{DESEQUILÍBRIO DE LIGAÇÃO GERADO POR FLUXO GÊNICO}

O desequilíbrio de ligação (LD, do inglês Linkage Disequilibrium) entre genes proximamente ligados pode ser causado pela existência de LD na população fundadora, o qual ainda não teve tempo de dissipar-se devido a uma baixa freqüência de recombinação. No entanto, O LD também pode surgir como um artefato da mistura de sub-populações que diferem em suas freqüências alélicas (Hartl \& Clark, 2007). A estratificação existe quando a população foi formada pela mistura entre sub-populações, e quando as proporções de mistura variam entre os indivíduos (Hoggart et al., 2003).

O fluxo gênico entre populações geneticamente distintas gera desequilíbrio de ligação (ALD, do inglês admixture linkage disequilibrium) entre os loci (ligados e não ligados) que possuem freqüências alélicas diferentes.

O efeito da dinâmica da mistura no padrão de LD foi avaliado por simulações de dois modelos extremos de mistura: (1) isolamento híbrido (HI, do inglês Hybrid Isolation), no qual a mistura ocorre em uma única geração 
e, (2) fluxo gênico contínuo (CGF, Continuous Gene Flow), no qual a mistura ocorre a uma taxa paulatina a cada geração (Figura 2; Pfaff et al., 2001).

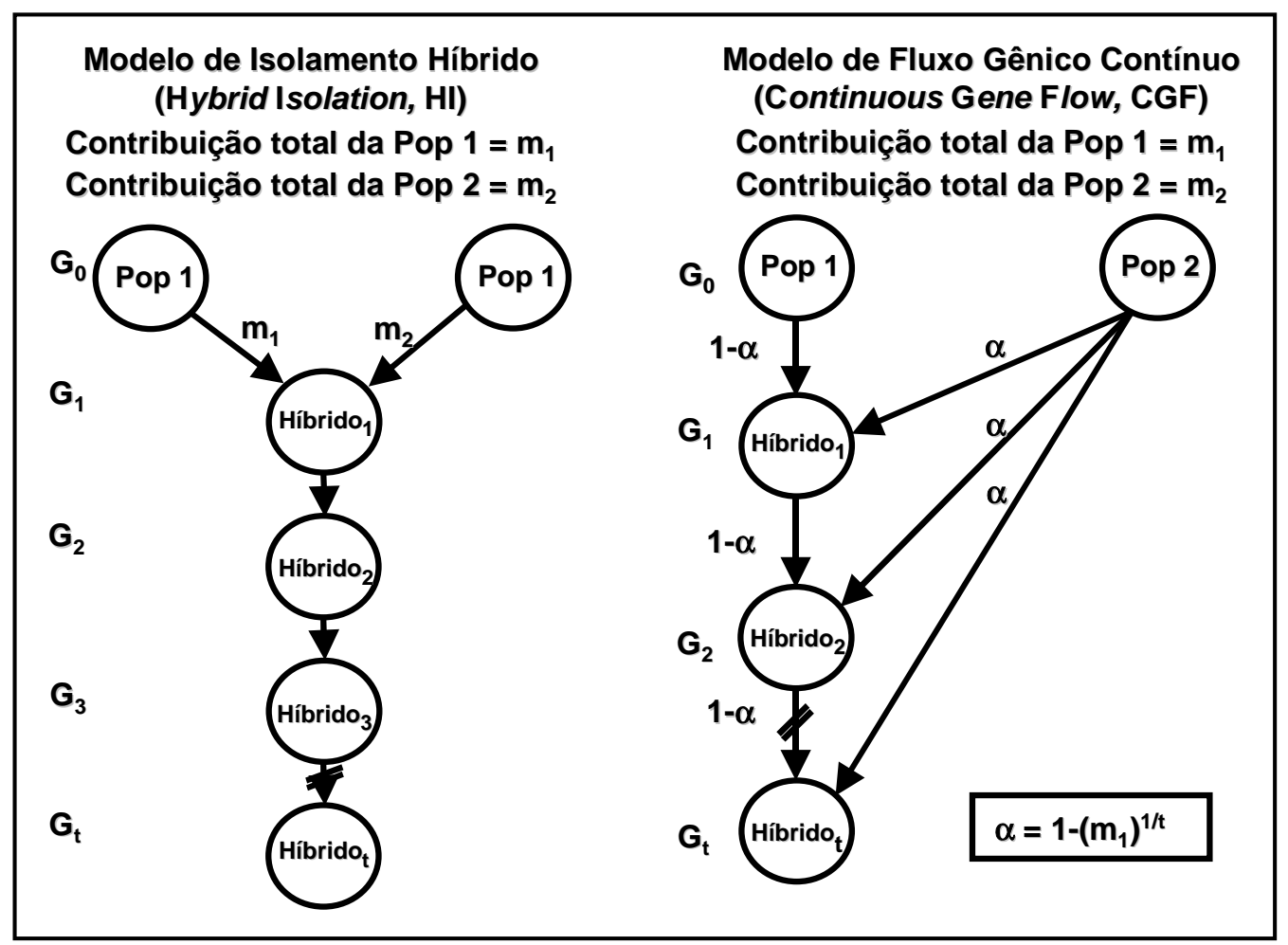

FIGURA 2. Esquema apresentando dois modelos extremos de mistura; isolamento híbrido (HI) e fluxo gênico continuo (CGF; modificado de Pfaff et al., 2001).

Os padrões de LD em populações Afro-americanas dos EUA (Jackson, MS e da Carolina do Sul) se assemelham aos padrões observados em populações simuladas para CGF, por dois motivos; 1) associação significante entre os loci FY e AT3-I/D, que estão separados por 22cM no cromossomo 1 e são considerados fisicamente ligados. A manutenção de ALD ao longo de segmentos cromossômicos relativamente grandes $(>10 \mathrm{cM})$ é característico de um padrão CGF de mistura, mas não de um padrão $\mathrm{HI}$; 2) Associações significantes entre muitos pares de loci não ligados também foram detectadas, como observado nos resultados de simulação CGF, mas não nas simulações de populações HI (Pfaff et al., 2001). 
Um alto nivel de LD entre os loci ligados (FY e AT3-I/D) e não ligados foi observado em populações Afro-americanas dos EUA (Parra et al., 1998 e 2001), o que sugere a presença de estrutura genética nas mesmas. No entanto, este LD não foi observado para os Gullah nem mesmo entre os loci ligados, o que sugere a ausência total de estrutura populacional inferida a partir destes loci (Parra et al., 2001).

Uma considerável estrutura genética foi observada na população de São Tomé (Golfo da Guiné), estimada a partir de oito PSAs autossômicos. O LD significante entre 33\% dos pares de loci não ligados pode ter sido acarretado pela contribuição gênica Portuguesa $(10,7 \% \pm 0,9 \%)$ nesta população. A mistura recente teve um importante papel nestes valores, como pode ser observado pela remoção de indivíduos com pais ou avós portugueses ou de Cabo-Verde da amostra, que reduziu os níveis de miscigenação $(6,5 \% \pm$ 0,8\%) e de LD significativos (11\% dos pares de loci não ligados; Tomás et al., 2002).

A ausência de estrutura genética, avaliada por AIMs em uma população mexicana de ancestralidade predominantemente Nativo-americana da cidade de Tlapa, é consistente com a homogeneidade étnica da mesma. A adição de indivíduos denominados Mestizos à amostra não produziu mudança considerável nas estimativas de mistura, mas representou um grande efeito na estrutura populacional (Bonilla et al., 2005).

Conforme exposto nos tópicos anteriores, dado os diferenciais de freqüência alélica $(\delta)$ superiores a $30 \%$ entre populações parentais, os AIMs são os marcadores ideais para estimativas eficazes de mistura étnica (Parra 
et al., 1998; Bonilla et al., 2005; Miljkovic-Gacic et al., 2005) e na detecção de estrutura populacional (Pfaff et al., 2001; Choudhry et al., 2006).

\section{COMUNIDADES ANALISADAS NESTE TRABALHO}

A comunidade rural de São Gonçalo (SG-BA) é considerada um remanescente de quilombo pelo seu grau de isolamento geográfico e cultural, e por apresentar predominância de ascendência africana em sua formação, como indicado pela análise de marcadores clássicos e STRs autossômicos e ligados ao cromossomo Y (Sousa, 2001). A comunidade Afro-derivada de Barra (BR-BA) apresenta baixa taxa de migração e alta freqüência de casamentos consangüíneos, características que mantém a estrutura de semi-isolado (Abé-Sandes, 2002).

A análise de marcadores bialélicos do cromossomo Y revela um menor grau de diversidade genética na comunidade de BR em comparação com SG (Abé-Sandes et al., 2004), provavelmente explicado pela presença de haplogrupos típicos de Europeus nesta última. Estes resultados divergentes são devidos, provavelmente, às diferentes histórias de mistura das duas comunidades, hipótese que pode ser investigada pela análise dos AIMs.

Por outro lado, parâmetros demográficos indicam na comunidade Afroderivada isolada de Valongo (VAL-SC) um grau de migração muito baixo e um dos mais altos coeficientes de endocruzamento já registrados. Dados históricos indicam a contribuição de quatro casais na formação desta comunidade, sendo sete indivíduos negros e um branco (Souza e Culpi, 
1992). Esta predominante contribuição Africana é corroborada por marcadores clássicos (Souza e Culpi, 2005).

No presente estudo, oito AIMs foram investigados nestas três comunidades remanescentes de quilombo com diferentes histórias demográficas, no intuito de estimar as contribuições de cada grupo parental e elucidar a dinâmica do processo de mistura que ocorreu em cada uma delas. 


\section{HIPÓTESE}

Os conjuntos de marcadores genéticos previamente estudados nas três comunidades remanescentes de quilombo, São Gonçalo, Barra e Valongo, são diferentes e não comparáveis.

Os oito AIMs selecionados para o presente estudo serão capazes de revelar as diferentes histórias de formação destas comunidades, pois apresentam grandes diferenciais de freqüência $(\delta)$ entre os grupos parentais. Por este motivo, representam uma informação mais incisiva para estimativas de mistura populacional do que a obtida a partir de STRs, apesar destes últimos apresentarem maior heterozigose e, portanto, serem mais informativos na diferenciação populacional.

Portanto, a hipótese do presente trabalho é que a dinâmica do processo de mistura variou em diferentes remanescentes de quilombos brasileiros. A partir dos dados demográficos e genéticos pode-se supor que a comunidade de SG apresente maior estruturação do que a comunidade de BR, decorrentes de sua história recente de mistura étnica. Estas duas comunidades, entretanto, apresentariam maior mistura do que a comunidade de VAL, devido ao maior isolamento desta última.

Adicionalmente, a história de formação destas comunidades sugere que a mistura étnica na formação das populações Afro-derivadas Brasileiras difere do processo de formação das populações Afro-derivadas da América do Norte (EUA), principalmente devido à contribuição ameríndia. 


\section{OBJETIVOS}

O objetivo geral é levantar as freqüências alélicas de oito AIMs (FY, RB, LPL, AT3, Sb19.3, APO, PV92 e CYP1A1*2C) em amostras de três comunidades remanescentes de quilombo, São Gonçalo (BA, $n=51$ ), Barra (BA, $n=47)$ e Valongo (SC, $n=25)$, e em amostras de duas populações urbanas, Jequié (BA, $n=47$ ) e Hemosc (SC, $n=25)$, das regiões Nordeste e Sul do Brasil.

As freqüências do alelo $C Y P 1 A 1 * 2 C$ foram determinadas em quatro tribos indigenas $(n=297)$ da Amazônia Brasileira, e comparadas com populações mundiais.

A partir destas será possível:

- Quantificar a mistura étnica nestas comunidades remanescentes e estabelecer comparações com outras populações Afro-derivadas;

- Demonstrar a diferença na dinâmica do processo de mistura étnica das comunidades remanescentes de quilombo, em conjunto com dados demográficos.

- Estimar os diferentes graus de mistura étnica nas populações urbanas de Jequié (região Nordeste) e de Florianópolis (região Sul). 


\section{MATERIAL E MÉTODOS}

\section{ESQUEMA DO TRABALHO}

Neste trabalho foram analisados oito AIMs; seis deles (FY, RB, LPL, AT3, Sb19.3 e APO) apresentam valores de $\delta>50 \%$ entre Africanos e Europeus ou Amerindios, enquanto que PV92 e CYP1A1*2C apresentam valores de $\delta>50 \%$ entre Ameríndios e Africanos ou Europeus.

A partir das freqüências alélicas foram verificados; a diferenciação gênica e genotípica das mesmas, a heterozigose, a aderência ao equilíbrio de Hardy-Weinberg, o desequilíbrio de ligação (LD) entre loci ligados ou nãoligados, a diversidade genética interpopulacional, a estrutura populacional, realizadas análises de componente principal e de estimativas de mistura étnica.

\section{COMUNIDADES REMANESCENTES DE QUILOMBO}

\section{Caracterização da População de Barra}

Barra é uma comunidade rural semi-isolada e oficialmente reconhecida como remanescente de quilombo (Fundação Cultural Palmares, 2007). Está localizada a $13^{\circ} 36^{\prime}$ de latitude Sul e $41^{\circ} 47^{\prime}$ de Longitude Oeste, no município de Rio de Contas (BA; Figura 3). Na comunidade de Barra vivem 179 pessoas, 78 homens e 101 mulheres (dados de 1998) compondo 59 famílias, dos quais 118 individuos foram amostrados (Abé-Sandes, 2002). 


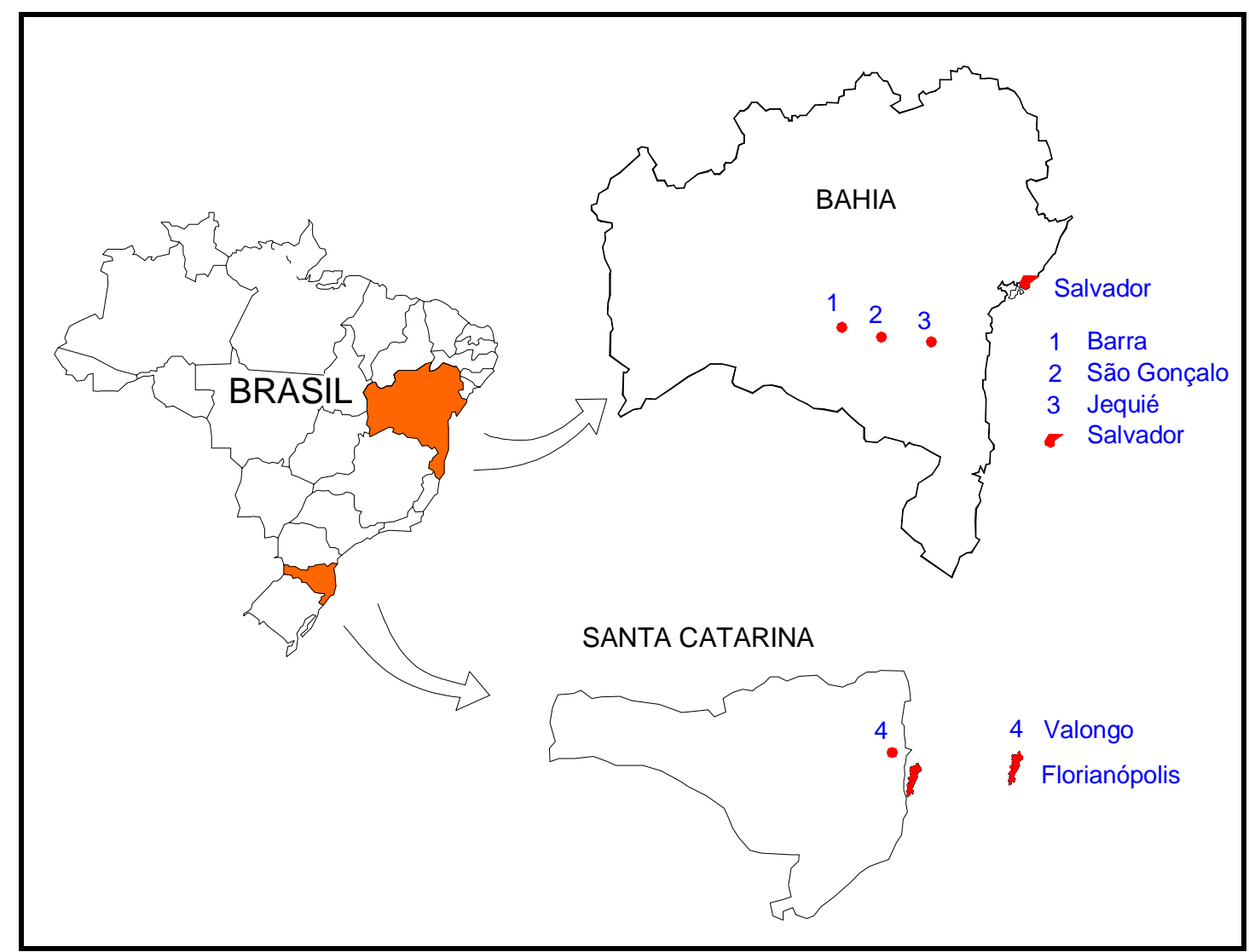

FIGURA 3. Localização das comunidades remanescentes de quilombo (Barra, São Gonçalo e Valongo) e das populações urbanas (Jequié e Florianópolis, ou Hemosc) analisadas. Crédito: Antonio Sérgio Bento Moreira.

A principal atividade desenvolvida na comunidade é a agricultura de subsistência, entremeada por migrações masculinas temporárias principalmente para São Paulo, onde buscam trabalho. Na época das chuvas, estes homens retornam às comunidades e retomam suas atividades na lavoura.

Fatos que explicam como e quando a comunidade de Barra se formou ainda permanecem obscuros. A tradição oral do grupo nos remete a um momento impreciso, relacionado à ação mineradora na região, e segundo Messeder e Martins (1991) esse povoado tem pelo menos 138 anos. Com relação à sua origem, os arraiados relatam que os primeiros habitantes 
instalaram-se ali clandestinamente, fugidos das minas próximas, o que permite considerá-la como um remanescente de quilombo.

\section{Caracterização da População de São Gonçalo}

A comunidade de São Gonçalo está localizada a 1345’46" de latitude Sul e 4102'28” de Longitude Oeste, a $13 \mathrm{Km}$ do perimetro urbano do município de Contendas do Sincorá, a $133 \mathrm{Km}$ da cidade de Jequié (BA; Figura 3). A comunidade é constituída por 194 indivíduos de cor negra, sendo 86 do sexo masculino e 108 do sexo feminino, os quais compõem 44 grupos familiares.

A tradição oral, passada pelo líder da comunidade, refere que a comunidade descende de remanescentes escravos, havendo poucos relatos de casamentos de membros desta vila com pessoas externas à comunidade. Atualmente, a comunidade é considerada oficialmente como remanescente de quilombo pela Fundação Cultural Palmares (2007).

A comunidade é pobre e a agricultura de subsistência é a principal atividade desenvolvida, tendo esta situação agravada devido aos longos períodos de seca. A comunidade possui um poço artesiano. No entanto, grande parte das pessoas se utiliza da água proveniente do rio próximo, fato que vem expondo tais indivíduos a muitos problemas de saúde, dentre os quais infecções gastrintestinais e esquistossomose em índices elevados. Descrição detalhada da comunidade encontra-se em Sousa (2001). 


\section{Caracterização da comunidade de Valongo}

A comunidade de Valongo ocupa um pequeno vale, de difícil acesso, distante cerca de $20 \mathrm{Km}$ do litoral, uma região chamada de Sertão do Valongo. Parte dela se encontra no município de Porto Belo e a outra parte em Tijucas, no Estado de Santa Catarina, a 27¹2'12" de Latitude Sul e 4844’30" de Longitude Oeste (Figura 03; Souza, 1992).

A comunidade isolada de Valongo foi fundada por volta de 1880 por sete escravos fugidos e alforriados, mais um homem branco, e em 1995 possuía uma população de 74 pessoas de origem predominantemente africana (Souza e Culpi, 2005). A descrição detalhada da comunidade encontra-se em Souza e Culpi (1992).

O coeficiente médio de endocruzamento é alto $(\mathrm{F}=0.081)$, devido principalmente à grande permanência de parentes na região e a segregação religiosa (eles são Adventistas do Sétimo Dia) e racial (as comunidades

vizinhas descendem de Europeus Católicos de origem alemã, italiana e portuguesa). O pequeno tamanho da população efetiva e baixa freqüência de migração efetiva (4\%) sugerem fortemente a possibilidade de deriva genética (Souza et al., 2005).

\section{POPULAÇÕES URBANAS}

\section{População de Jequié}

O município de Jequié está localizado a 1351'27" de Latitude Sul e 4005’01" de Longitude Oeste, no Sudoeste da Bahia, a $360 \mathrm{Km}$ de Salvador, 
nos limites entre a caatinga e a zona da mata. O último censo indicou uma população de 147.115 habitantes, sendo 71.800 homens e 75.315 mulheres (IBGE, 2000).

Entre 1860 e 1880, então um pequeno povoado denominado Boca do Sertão, Jequié crescia às margens do Rio das Contas, o qual era uma importante via de transportes por onde barcos de pequeno porte levavam produtos de subsistência a habitantes de suas margens. Tropeiros chegavam de cidades maiores carregando suas mercadorias em lombos de burros, trabalhando como mascates (Sousa, 2001).

No fim do século XIX, a cidade se desenvolveu a partir da movimentada feira que atraía comerciantes de várias regiões. Segundo relato oral, esta população tem na sua formação a mistura étnica de "indios, negros, italianos e árabes”.

\section{População do Estado de Santa Catarina (HEMOSC)}

A amostra constitui-se de material de 58 doadores de sangue do HEMOSC (Centro de Hematologia e Hemoterapia de Santa Catarina; http://www.HEMOSC.org.br/), de ambos os sexos, com faixa etária entre 26 e 62 anos, a grande maioria da capital do Estado, Florianópolis. Esses indivíduos são voluntários que consentiram que parte de seu sangue fosse também utilizada para fins de pesquisa. 


\section{TRIBOS INDÍGENAS DA AMAZÔNIA BRASILEIRA}

As amostras de sangue venoso foram coletadas no ano de 1976 durante a expedição "Alpha-Hélix" (Neel et al., 1980; Mestriner et al., 1980), destinada à Amazônia oriental brasileira e aprovada segundo processo FUNAI/BSB/4854/75 e autorizações 26/76, 27/76, 74/76 e 75/76. Descrição detalhada encontra-se em Simões (1980). A localização geográfica e o número das amostras selecionadas para o presente estudo estão apresentados na Figura 4.

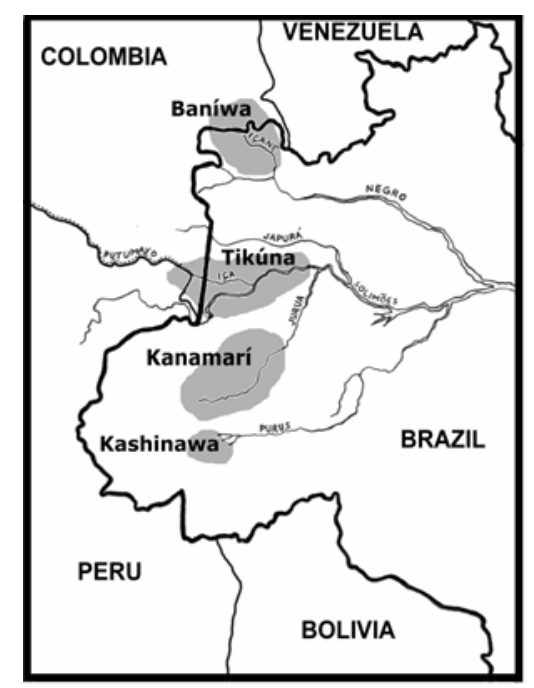

\begin{tabular}{lllll}
\hline \multicolumn{1}{c}{ Tribos } & \multicolumn{1}{c}{ Aldeias } & Latitude & Longitude & n \\
\hline \multirow{4}{*}{ Tikúna } & Umariaçu & $4^{\circ} 17^{\prime} \mathrm{S}$ & $69^{\circ} 55^{\prime} \mathrm{O}$ & 52 \\
& Feijoal & $4^{\circ} 15^{\prime} \mathrm{S}$ & $69^{\circ} 35^{\prime} \mathrm{O}$ & 52 \\
& Vendaval & $3^{\circ} 30^{\prime} \mathrm{S}$ & $69^{\circ} 27^{\prime} \mathrm{O}$ & 53 \\
& Belém & $3^{\circ} 55^{\prime} \mathrm{S}$ & $69^{\circ} 37^{\prime} \mathrm{O}$ & 50 \\
\hline \multirow{2}{*}{ Kashinawa } & Canabrava & $8^{\circ} 07^{\prime} \mathrm{S}$ & $70^{\circ} 19^{\prime} \mathrm{O}$ & 23 \\
& Paredão & $8^{\circ} 07^{\prime} \mathrm{S}$ & $70^{\circ} 19^{\prime} \mathrm{O}$ & 07 \\
\hline \multirow{2}{*}{ Baníwa } & Jandu Cachoeira & $1^{\circ} 33^{\prime} \mathrm{N}$ & $68^{\circ} 44^{\prime} \mathrm{O}$ & 52 \\
\hline Kanamarí & Três Unidos & $6^{\circ} 37^{\prime} \mathrm{S}$ & $69^{\circ} 32^{\prime} \mathrm{O}$ & 34 \\
\hline \multicolumn{5}{c}{ Total de indivíduos } \\
\hline
\end{tabular}

FIGURA 4. Localização geográfica das aldeias pertencentes às tribos Tikúna, Kashinawa, Baniwa e Kanamari e número de amostras analisadas.

O critério para a seleção dos individuos da amostra analisada foi o menor grau de parentesco possivel dentro da amostra total. A partir das fichas de coleta, que incluem o número de identificação, o nome do individuo, sexo, idade, notas sobre parentesco, mistura com brancos e o nome dos pais e/ou esposos, foi possivel excluir primeiramente os filhos e netos da amostra. Em uma segunda triagem foram escolhidos, de maneira aleatória, apenas um indivíduo dentre os que apresentavam irmãos ou o 
mesmo sobrenome, o que resultou em uma amostra de 323 indígenas (Mendes Jr., 2001).

\section{Tikúna}

Os Tikúna habitam o Estado do Amazonas, mas representantes também podem ser encontrados em território peruano e colombiano. $\mathrm{Na}$ época da coleta haviam cerca de 11.000 membros desta tribo em território brasileiro. No entanto, o censo de 1994 indicou 23.000 membros, também em território brasileiro. Embora apresentem contatos com não-indigenas, esta tribo ainda mantém a sua identidade étnica e casamentos com pessoas de fora são raros (Simões, 1980).

\section{Kashinawa}

Os Kashinawa habitam o extremo sudoeste do Estado do Amazonas e uma porção do Estado do Acre. Apresentavam cerca de 2.000 indivíduos habitando as margens do Rio Embira e seus tributários na época da coleta (Mestriner et al., 1980). Estimativas de 1994 apontaram 3.387 membros desta tribo em território brasileiro. O grau de aculturação desta tribo é bastante variado (Simões, 1980).

\section{Baniwa}

Os Baníwa habitam a região pertencente aos municípios de São Gabriel da Cachoeira e Japurá (AM), noroeste do Estado do Amazonas. Estimativas na época da coleta (1976) indicavam a existência de aproximadamente 1.500 
indígenas distribuídos em 16 aldeias, consideradas semi-aculturadas. Em censo realizado em 1995 foram apontados 3.189 individuos (Oliveira, 1999).

\section{Kanamari}

Os Kanamarí são encontrados na região das bacias dos Rios Juruá e Purus, sudoeste do Estado do Amazonas. O censo de 1994 indicava aproximadamente 1.300 indivíduos. Esta tribo apresenta uma longa história de contato com neobrasileiros e praticam agricultura de subsistência (Mohrenweiser et al., 1979).

\section{ASPECTOS ÉTICOS}

As amostras analisadas são oriundas de coletas prévias realizadas e detalhadas em outros projetos (Sousa, 2001; Abé-Sandes, 2002; Souza, 1992). As amostras do estado da BA foram fornecidas pela Profa. Sandra Mara Bispo Sousa, do Departamento de Ciências Biológicas (DCB) da Universidade Estadual do Sudoeste da Bahia (UESB), Campus de Jequié, e pela Profa. Kiyoko Abé Sandes, do Departamento de Ciências da Vida da Universidade do Estado da Bahia (UNEB), Campus de Salvador. As amostras do Estado de SC foram cedidas pela Profa. Iliada Rainha de Souza, do Departamento de Biologia Celular, Embriologia e Genética (BEG) da Universidade Federal de Santa Catarina (UFSC).

As coletas foram realizadas nas próprias localidades, por meio de visitas domiciliares ou em grupo, onde foi perguntado a cada indivíduo sobre a concordância na participação no estudo, dando a oportunidade de negar a sua participação sem qualquer prejuizo dos beneficios (exames médicos e 
tratamentos). Os voluntários assinaram um termo de consentimento e, no caso dos menores, o termo foi assinado pelo responsável. Os termos de consentimento, assim como um coletivo do líder da comunidade, encontramse em poder das Professoras supracitadas.

O uso destas amostras foi analisado e aprovado em seus aspectos éticos. As amostras de SG, BR e JQ pelo Comitê de Ética em Pesquisa (CEP) da UESB, Campus de Jequié, processo n058/2007. As amostras de VAL e HEMOSC pelo CEP da UFSC, de acordo com o adendo ao projeto no 74/2002. O estudo das populações indígenas da Amazônia Brasileira também foi aprovado pelo CEP do HC-FMRP/USP, processo HCRP no 4610/2001, e pela Comissão Nacional de Ética em Pesquisa (CONEP), segundo processo no 25000.097241.2001-83.

A coleta de informações demográficas e de material biológico das populações envolvidas seguiu rigorosamente os preceitos de conscientização e autorização dos participantes e das lideranças das comunidades, aquiescência voluntária e garantia de anonimato dos participantes.

Cada indivíduo foi identificado com um código, e somente o pesquisador saberá o código pertence a cada indivíduo. Além disso, os dados destas pesquisas serão apresentados em termos de populações e nunca em termos individuais. 


\section{COLETA E CONSERVAÇÃO DO MATERIAL}

\section{Amostras da Bahia}

Todo o procedimento de coleta foi realizado em 1999. Uma equipe multidisciplinar, liderada pelas Profas. Ana Angélica Leal Barbosa, Sandra Mara Bispo Sousa e Kiyoko Abé Sandes, todas na época da coleta pertencentes ao DCB/UESB, foi composta para a realização das visitas às comunidades. As visitas preliminares tiveram por objetivo a coleta de dados oficiais sobre as comunidades, sendo posteriormente seguidas pela informação às famílias sobre os objetivos da pesquisa e a aplicação de questionários para caracterização demográfica. Além disso, foram obtidas três medidas da pressão arterial de cada indivíduo e coletadas fezes, material este submetido a análises cujos resultados foram devolvidos aos membros da comunidade, sendo os resultados anormais encaminhados a atendimento médico especializado. As coletas foram realizadas nas próprias localidades, por meio de visitas domiciliares ou em grupo.

De cada indivíduo com idade superior a 3 anos foram coletados de $5 \mathrm{~mL}$ de sangue por punção venosa com tubo VacuTainer, sendo utilizado EDTA como anticoagulante. Os individuos foram devidamente identificados e os tubos de coleta mantidos e transportados em caixas de isopor até a cidade de Jequié, sendo transferidos para geladeira no período de 6-8 horas após a coleta.

Todas as amostras foram processadas em até $24 \mathrm{~h}$ após a coleta. A amostra total foi homogeneizada, da qual foram recolhidos de $300-500 \mu \mathrm{L}$ de 
sangue total em tubo de polipropileno do tipo eppendorf de 1,5 mL, devidamente etiquetados e mantidos em geladeira para posterior extração de DNA. Uma alíquota de $500 \mu \mathrm{L}$ de plasma separado das hemácias por centrifugação foi recolhida e estocada diretamente a $-20^{\circ} \mathrm{C}$ para análise de proteînas séricas. Os eritrócitos restantes foram glicerolizados em tampão glicerol $40 \%$ em Citrato tripotássio $0,1 \mathrm{M}, \quad \mathrm{KH}_{2} \mathrm{PO}_{4} \quad 0,0345 \mathrm{M}, \mathrm{K}_{2} \mathrm{HPO}_{4}$ 0,0344M e estocados a $-20^{\circ} \mathrm{C}$, para análise das proteinas eritrocitárias.

\section{Amostras de Santa Catarina (HEMOSC)}

Uma equipe multidisciplinar liderada pelas Profa. Iliada Rainha de Souza, da UFSC, foi composta para a realização das visitas às comunidades. De cada indivíduo foram coletados $5 \mathrm{~mL}$ de sangue por punção venosa com tubo VacuTainer, sendo utilizado EDTA como anticoagulante. As amostras de sangue transportadas para o Laboratório de Polimorfismos Genéticos da UFSC foram submetidas à centrifugação, sendo o sobrenadante (plasma) estocado em frascos $\mathrm{a}-20^{\circ} \mathrm{C}$.

Os buffy coats (leucócitos já separados por centrifugação, com um pouco de hemácias e plasma) foram congelados a $-20^{\circ} \mathrm{C}$ e, posteriormente, foi realizada a extração de DNA, utilizado no presente trabalho. Parte das hemácias foi glicerolizada (solução de glicerol a 40\%), segundo especificações de Mollison (1972) e também estocadas em frascos a $-20^{\circ} \mathrm{C}$.

\section{Amostras das tribos indigenas}

Durante a expedição "Alpha-Helix" em 1976, as amostras de sangue foram coletadas em tubos VacuTainer contendo 2,0 $\mathrm{mL}$ de anticoagulante 
ACD e foram refrigeradas cerca de 12 horas após a coleta. Cerca de três dias após a coleta este material foi processado para estocagem. As amostras foram então centrifugadas (1.500 rpm, durante 10 minutos) e o plasma retirado. As hemácias foram lavadas três vezes em solução salina isotônica, e o sedimento resultante após a última centrifugação foi ressuspenso em igual volume de solução de glicerol a 40\% em tampão de estocagem $(32,5 \mathrm{~g}$ de citrato de tripotássio $+6,0 \mathrm{~g}$ de fosfato dibásico de potássio $+4,7 \mathrm{~g}$ de fosfato monobásico de potássio + água destilada qsp. 1 litro). As amostras foram então mantidas a $-20^{\circ} \mathrm{C}$ até o presente.

\section{AIMs ANALISADOS}

Neste trabalho foram analisados oito AIMs, seis (FY, RB, LPL, AT3, Sb19.3 e APO) com valores de $\delta>50 \%$ entre Africanos e Europeus ou Amerindios (Parra et al.,, 1998) e dois (PV92 e CYP1A1*2C) $\operatorname{com} \delta>50 \%$ entre Amerindios e Africanos ou Europeus (Shriver et al., 2003; Luizon et al., 2007b; Tabela 3).

Para os AIMs analisados no presente estudo, será denominado de alelo *1 (ex., RB*1) o fragmento correspondente à banda de maior peso molecular observada no gel de poliacrilamida, devido à presença de uma inserção ou inserção Alu (para os loci AT3-I/D, Sb19.3, APO e PV92) ou à ausência de um sítio de restrição (para os loci FY, RB e LPL), seguindo a convenção estabelecida em Parra et al. (1998). O alelo CYP1A1*2C é considerado aqui como um AIM (Luizon et al., 2007b). No entanto, para simplificar seu uso durante o texto este alelo será mencionado como CYP1A1. 
TABELA 3: Localização citogenética, enzimas de restrição, seqüência dos primers e condições de PCR dos oito AIMs analisados.

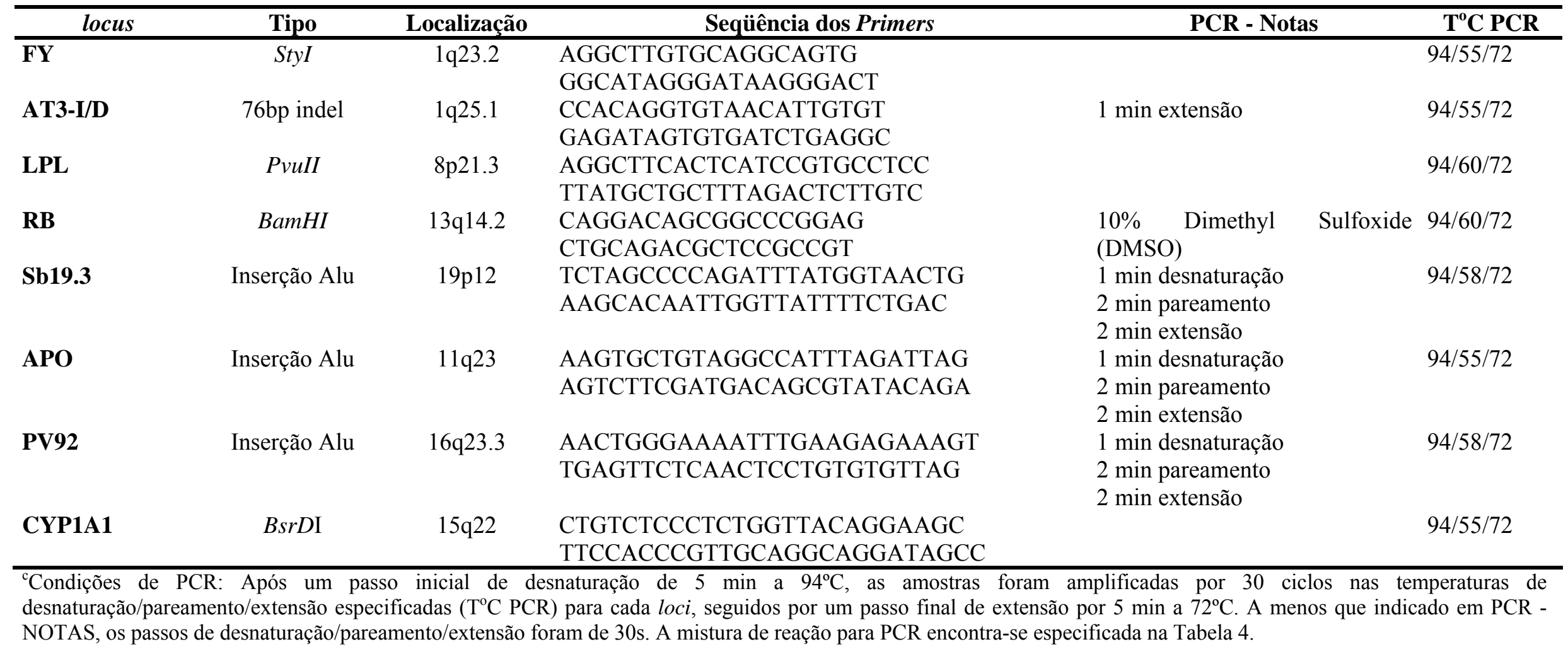


Os primers e enzimas de restrição, a localização citogenética e as condições de PCR dos AIMs analisados estão relacionados nas Tabelas 3 e 4.

TABELA 4: Condições de PCR para os AIMs analisados. Quantidade em $\mu 1$ suficiente para uma reação.

\begin{tabular}{lccccccc}
\hline AIMs & Água & $\begin{array}{c}\text { Tampão PCR } \\
\text { livre de cloreto }\end{array}$ & DMSO & $\begin{array}{c}\text { MgCl } \\
\mathbf{( 5 0} \mathbf{~ m M})\end{array}$ & $\begin{array}{c}\text { dNTP } \\
\mathbf{( 2 0 ~ m M )}\end{array}$ & $\begin{array}{c}\text { Primers } \\
\text { (solução } \\
\text { trabalho) }\end{array}$ & Taq pol \\
\hline FY & 13,75 & 2,5 & & 1,0 & 0,25 & 1,5 & 0,25 \\
B2300 & 10,75 & 2,5 & 2,5 & 0,75 & $0,25 \mu 1$ & 3,0 & 0,50 \\
LPL & 13 & 2,5 & & 1,0 & 0,25 & 3,0 & 0,25 \\
AT3 & 13 & 2,5 & & 1,0 & 0,25 & 3,0 & 0,25 \\
Sb19.3 & 13 & 2,5 & 1,0 & 0,25 & 3,0 & 0,25 \\
APO & 13 & 2,5 & 1,0 & 0,25 & 3,0 & 0,25 \\
PV92 & 13 & 2,5 & 1,0 & 0,25 & 3,0 & 0,25 \\
CYP1A1 & 13 & 2,5 & 1,0 & 0,25 & 3,0 & 0,25 \\
\hline
\end{tabular}

\section{ANÁLISE LABORATORIAL}

\section{Extração do DNA Genômico}

\section{Reagentes e Soluções:}

Detergente Nonidet (polyethoxyethanol).

\section{Triton $\mathbf{X}$}

Tween 20

Tampão de lise de eritrócitos (Tris/ $\mathrm{HCl} 0,01 \mathrm{M} \mathrm{pH} \mathrm{7,6;} \mathrm{sacarose}$ 0,32 M; $\mathrm{MgCl}$ 5,0 mM; e Triton X-100 1\%)

Tampão de lise de leucócitos (Tris/ $\mathrm{HCl} 0,01 \mathrm{M} \mathrm{pH} \mathrm{8,5;} \mathrm{KCl} 50$ mM; $\mathrm{MgCl}_{2}$ 2,5 mM; NP-40 0,45\%; Tween 20 - 0,45\%)

Proteinase $\mathbf{K}(10 \mathrm{mg} / \mathrm{mL})$

\section{Procedimento:}

A extração de DNA foi realizada a partir de uma adaptação ao método de Higuchi (1989). Aproximadamente $300 \mu \mathrm{L}$ de cada amostra foi colocada em um microtubo de polipropileno de 1,5 mL (tipo eppendorf), utilizando-se 
uma micropipeta e ponteiras estéreis. Em seguida, adiciona-se 1,0 mL de tampão de lise de eritrócitos a cada microtubo. Homogeneiza-se a mistura e centrifuga-se o conteúdo dos microtubos a 12.000 giros durante 2 minutos. Retira-se o sobrenadante com o auxilio de um sugador, e acrescenta-se, novamente, 1,0 $\mathrm{mL}$ de tampão de lise de eritrócitos ao precipitado avermelhado. Homogeneiza-se e centrifuga-se cada microtubo novamente. Repete-se estes procedimentos até que o precipitado se encontre de cor branca (de 3-4 repetições), indicando a presença de glóbulos brancos (leucócitos) e a ausência de hemácias.

Quando o precipitado adquire esta aparência branca, retira-se o sobrenadante, suspende-se o precipitado em $300 \mu \mathrm{L}$ de tampão de lise de leucócitos, e adiciona-se $5 \mu \mathrm{L}$ de proteinase $\mathrm{K}$ em cada microtubo.

Terminadas estas etapas da extração, as amostras devem ser colocadas em uma estufa a $65^{\circ} \mathrm{C}$ por um periodo de 1 hora, e em seguida, em uma estufa a $37^{\circ} \mathrm{C}$ por um periodo de aproximadamente 12 horas. Por fim, as amostras devem ser armazenadas em um refrigerador com temperatura aproximada de $-4^{\circ} \mathrm{C}$

\section{Reação em Cadeia da Polimerase (PCR)}

\section{Reagentes e Soluções:}

DNA polimerase (Taq): $1 \mathrm{U} / \mu \mathrm{L}$ de tampão de estocagem (BIOTOOLS B \& M Labs, AS).

Tampão de estocagem da DNA polimerase: $10 \mathrm{mM}$ de Tris/ $\mathrm{HCl}(\mathrm{pH}$ 8,0), $50 \mathrm{mM} \mathrm{KCl}, 1 \mathrm{mM}$ EDTA, 01\% Triton $\mathrm{x}-100$, 50\% de glicerol (BIOTOOLS - B \& M Labs, AS). 
dNTP solução estoque: quatro soluções separadas de $100 \mathrm{mM}$ de cada base (dATP, dCTP, dGTP, dTTP), pH 8,3 (BIOTOOLS - B \& M Labs, AS).

dNTP solução trabalho $(20 \mathrm{mM})$ : obtida diluindo-se com água a solução estoque $(100 \mathrm{mM})$ de cada dNTP para uma solução única de concentração $20 \mathrm{mM}(160 \mu \mathrm{L}$ de água de MiliQ autoclavada mais $10 \mu \mathrm{L}$ da solução estoque de cada dNTP).

Iniciadores (Primers) especificos - solução estoque (50 $\mu \mathrm{M}$ ): os primers liofilizados (Bio-Synthesis) A e B específicos para cada locus foram diluídos em água auto-clavada, e estocados separadamente.

Iniciadores (Primers) - solução trabalho (2,5 $\mu \mathbf{M}): 10 \mu \mathrm{L}$ do primer A, $10 \mu \mathrm{L}$ do primer B e $180 \mu \mathrm{L}$ de água auto-clavada.

Tampão PCR livre de $\mathbf{M g C l}_{2}$ : Tris/ $\mathrm{HCl} 75 \mathrm{mM} \mathrm{pH} \mathrm{9.0;} \mathrm{KCl} 50 \mathrm{mM}$; $\left(\mathrm{NH}_{4}\right)_{2 \mathrm{SO}_{4}} 20 \mathrm{mM}$. (BIOTOOLS - B \& M Labs, AS).

$\mathbf{M g C l}_{2}$ : Concentração de 50 mM (BIOTOOLS - B \& M Labs, AS).

\section{Procedimento:}

Os ensaios da PCR foram realizados em um volume total de $25 \mu \mathrm{L}$. Todos os reagentes (Água, Tampão, dNTP - solução trabalho, primers solução trabalho, $\mathrm{MgCl} 2$ e a Taq DNA polimerase), com exceção do DNA, foram misturados em quantidade específica para cada locus (Tabela 4) em um único tubo (mistura de reação) para garantir a homogeneidade das reações. As seqüências dos primers estão na Tabela 3.

Em cada microtubo de $0,5 \mathrm{~mL}$ foram pipetados $4 \mu \mathrm{L}$ do DNA genômico, previamente extraído. Para cada análise foi usado como controle negativo contendo água no lugar do DNA genômico. Em cada microtubo, sob a amostra, foram pipetados $20 \mu \mathrm{L}$ da mistura de reação e uma gota de óleo mineral foi adicionada para evitar a evaporação da mistura de reação durante o processo. O termociclador utilizado foi o MJ Research (Inc PTC100TM). A este passo seguiu-se o programa correspondente a cada locus 
(Tabela 3). Após o término da reação de PCR o produto da PCR foi guardado em geladeira $\left(4 \mathrm{C}^{\circ}\right)$ até sua utilização.

\section{Reação de Restrição}

Para a detecção dos SNPs analisados no presente estudo (FY, RB, LPL e CYP1A1) foi utilizada a técnica de PCR-RFLP. Esta consiste basicamente de um ensaio onde o produto da PCR é posteriormente submetido à ação de endonucleases de restrição. Os primers utilizados na PCR flanqueiam a região do gene que contém, ou não, o sítio de restrição específico da enzima utilizada na reação de restrição para cada locus (Tabela 3).

O individuo pode ser homozigoto para a presença do sítio de restrição da enzima (genótipo $* 2 /{ }^{*} 2$ ), heterozigoto (genótipo ${ }^{*} 1 /{ }^{*} 2$ ), ou homozigoto para a ausência do sítio de restrição (genótipo * $1 /{ }^{*} 1$ ).

A reação de restrição foi feita em microtubos tipo eppendorf de $500 \mu \mathrm{L}$ para cada amostra, ambas as séries contendo $5 \mu \mathrm{L}$ de DNA previamente amplificado. O controle de reação foi o DNA amplificado de um indivíduo ao qual foi submetido somente água e o tampão comercial específico da enzima. O controle de leitura é o DNA amplificado de um indivíduo de genótipo conhecido.

Em microtubos tipo eppendorf de 1,5 $\mathrm{mL}$ é preparada a mistura de Reação, onde o volume de cada componente utilizado deve ser multiplicado pelo número de amostras a serem utilizadas na reação. A mistura de Reação é constituída por $0,3 \mu \mathrm{L}(3 \mathrm{U})$ da enzima de restrição $(10 \mathrm{U} / \mu \mathrm{L}), 1,0 \mu \mathrm{L}$ do tampão de reação (específico para cada enzima) e 5,7 $\mu \mathrm{L}$ de água deionizada 
autoclavada. O tampão de reação deverá conter as condições de $\mathrm{pH}$ e salinidade ótimas para a atividade da enzima de restrição, sendo estas condições específicas para cada enzima. Neste trabalho foram utilizados tampões comerciais que atendiam a estas exigências.

Aplicou-se $7 \mu \mathrm{L}$ da mistura de Reação em cada eppendorf com o auxílio de uma micropipeta e ponteiras estéreis. Com o auxilio de pipetas Hamilton, homogeneiza-se $5 \mu \mathrm{L}$ de DNA previamente amplificado de cada indivíduo aos eppendorf que já contém a mistura de reação. Estes foram então levados a um banho Maria ou ao termociclador, à temperatura de atividade específica para a enzima de restrição utilizada (geralmente $37^{\circ} \mathrm{C}$ ), por um período de 2 horas.

Após este período os tubos são retirados do banho Maria e realiza-se um choque térmico para inativação da enzima com água e gelo e conservamse os tubos em geladeira, sendo os fragmentos resultantes da reação de Restrição submetidos à eletroforese para detecção da presença ou ausência do sítio de restrição investigado.

\section{Análise do Produto Amplificado}

Os produtos amplificados e oriundos das reações de restrição foram separados por eletroforese em géis de poliacrilamida (PAGE) nãodesnaturantes a 6\% de concentração, exceto para o AIM FY, para o qual foi utilizado PAGE a 10\% não-desnaturante.

\section{Reagentes e Soluções:}

TEMED: tetrametiletilenodiamina (Pharmacia Biotech). 
Solução de acrilamida/bis-acrilamida (29:1): 29 g de acrilamida; 1 g de bis-acrilamida diluídas em $100 \mathrm{~mL}$ de água deionizada.

Solução de EDTA pH 8,0: 186 g de EDTA; 11 de $\mathrm{H}_{2} \mathrm{O}$. Acertar o pH com pastilhas de hidróxido de sódio $(\mathrm{NaOH})$.

Solução saturada de Persulfato de potássio: $650 \mathrm{mg}$ de persulfato de potássio; $6,5 \mathrm{~mL}$ de $\mathrm{H}_{2} \mathrm{O}$.

Tampão TBE 10X (0,9M) pH 8,0: $108 \mathrm{~g}$ de Tris $(\mathrm{PM}=121,1) ; 53 \mathrm{~g}$ ácido bórico; $40 \mathrm{~mL}$ de solução de EDTA; $\mathrm{H}_{2} \mathrm{O}$ qsp $1 \mathrm{~L}$.

Tampão TBE cubas (1X): $100 \mathrm{~mL}$ do tampão TBE (10X); $900 \mathrm{~mL} \mathrm{H} \mathrm{H}_{2} \mathrm{O}$.

Tampão de amostra (Loadding buffer): $900 \mu \mathrm{L}$ de brofenol; $900 \mu \mathrm{L}$ xilenocianol; $900 \mu \mathrm{L}$ TBE; 4,5 mL Ficol 30\% diluído em água destilada; 1,8 mL EDTA 0,5 M pH 8,0; 3,6 g sacarose. Misturar tudo até a dissolução completa da sacarose.

Gel não desnaturante 6\%: 1,4 $\mathrm{mL}$ de glicerol, $12,4 \mathrm{~mL}$ de $\mathrm{H}_{2} \mathrm{O} ; 4 \mathrm{~mL}$ solução de bis-acrilamida; 2 mL TBE (10x); $15 \mu \mathrm{L}$ TEMED; $300 \mu \mathrm{L}$ Solução de persulfato de potássio.

\section{Procedimento:}

Os géis não-desnaturantes $6 \%$ foram feitos como na receita acima determinada. Os catalizadores da reação de polimerização do gel, TEMED e persulfato de potássio foram adicionados à mistura do gel imediatamente antes de vertê-la em um cassete previamente montado, composto de duas placas de vidro de $12 \mathrm{~cm}$ de altura por 16,5 cm de largura, separadas por espaçadores de teflon e presas com grampos. Logo após, um pente de teflon foi colocado na borda superior, formando poços no gel, onde posteriormente foram aplicadas as amostras de DNA amplificado por PCR ou oriundos das reações de restrição. Aguardou-se a polimerização por cerca de 30 minutos.

Após a polimerização do gel o pente foi retirado e os poços foram lavados com água. O gel polimerizado foi montado em cuba de eletroforese vertical contendo tampão TBE cubas (1x), em ambos os pólos (porção superior e inferior). Esta cuba foi conectada a uma fonte de voltagem, 
Amershan Pharmacia Biotech (EPS 1001) e ajustada à voltagem constante de 200V, necessária para uma boa separação dos fragmentos amplificados.

Uma pré-corrida de pelo menos 15 minutos foi realizada, onde as cubas com os géis foram ligados às fontes e submetidos à voltagem. A fonte foi desligada e as amostras foram aplicadas nos poços. A eletroforese foi realizada por 1 hora, exceto para o AIM FY, para o qual a eletroforese teve a duração de 1 h30 minutos.

Aproximadamente $7 \mu \mathrm{L}$ de amostra de DNA amplificado oriundos da PCR ou Reação de restrição, juntamente com $4 \mu \mathrm{L}$ de Tampão amostra, foram aplicados nos géis. Para os AIMs que são SNPs (FY, RB e LPL) uma eletroforese prévia era realizada, no intuito de confirmar a amplificação positiva do fragmento de interesse, antes de submetê-lo à ação da enzima de restrição adequada (Tabela 3).

Após a aplicação das amostras as fontes foram novamente ligadas e a eletroforese prosseguiu da maneira descrita acima. Com o término da corrida eletroforética, o gel foi retirado cuidadosamente das placas de vidro e submetido aos procedimentos de coloração e secagem.

\section{Coloração com Nitrato de Prata e Secagem do Gel}

\section{Reagentes e soluções:}

Solução de nitrato de prata: $10 \mathrm{~g}$ nitrato de prata; $100 \mathrm{~mL}$ de $\mathrm{H}_{2} \mathrm{O}$. Dissolver a prata em uma parte da água e depois completar com o restante, manter a solução ao abrigo da luz (volume final 100 $\mathrm{mL})$.

Solução fixadora: $160 \mathrm{~mL}$ etanol (PA) e $7 \mathrm{~mL}$ de ácido acético glacial (PA); $833 \mathrm{~mL}$ de $\mathrm{H}_{2} \mathrm{O}$ (volume final $1 \mathrm{~L}$ ). 
Solução reveladora: $22,5 \mathrm{~g}$ de $\mathrm{NaOH} ; 1 \mathrm{~L}$ de $\mathrm{H}_{2} \mathrm{O}$. Dissolver em um agitador o hidróxido de sódio em uma parte da água e depois completar com o restante (volume final $1 \mathrm{~L}$ ). Na hora da coloração adicionar $1 \mathrm{~mL}$ de formaldeído para cada $100 \mathrm{~mL}$ da solução.

\section{Procedimento:}

A coloração do gel foi feita de acordo com protocolo adaptado de Sanguinetti et al. (1994):

Fixação: Após a retirada das placas de vidro e dos espaçadores o gel foi colocado em um recipiente de vidro contendo $100 \mathrm{~mL}$ de solução fixadora.

Impregnação com Nitrato de prata: adicionou-se 2,0 mL de solução de nitrato de prata, e agitou-se por 5 minutos. A solução foi então descartada e o gel lavado em água quente por cerca de 10 segundos, agitando levemente e, ao final, descartando a água.

Revelação: A solução reveladora foi despejada cuidadosamente no recipiente contendo o gel, que foi submetido à agitação por alguns minutos até que as bandas aparecessem nitidamente. A solução foi pré-aquecida em estufa a $65^{\circ} \mathrm{C}$, para facilitar a reação de coloração.

Bloqueio da reação: Após ter sido revelado, a solução reveladora foi descartada e a reação bloqueada com a lavagem direta do gel em $100 \mathrm{~mL}$ de solução fixadora.

Secagem do gel: Após a leitura, todos os géis passaram por um simples processo de secagem para que pudessem ser armazenados para análises e confirmações posteriores. Duas folhas de papel celofane foram molhadas; uma placa de vidro, com a área maior que a do gel, foi coberta com uma das folhas; o gel foi colocado sobre a placa com o celofane sem deixar bolhas; o gel foi então bem molhado e coberto com a outra folha de celofane, também com cuidado de não deixar bolhas; este gel foi deixado secando à temperatura ambiente por dois ou três dias até a secagem completa, sendo então devidamente identificado e arquivado. 


\section{ANÁLISE ESTATÍSTICA}

\section{Freqüências Gênicas em Populações Ancestrais}

A partir de freqüências alélicas de populações parentais disponíveis na literatura foi possivel realizar o cálculo da heterozigose e as análises de componente principal.

A média européia ponderada foi obtida a partir das freqüências na Inglaterra, Irlanda, Alemanha (Parra et al., 1998), Portugal (Tomás et al., 2002) e Espanha (dbSNP/NCBI). As freqüências alélicas de República Centro Africana, Nigéria (Benin e Ibadan) (Parra et al., 1998), e Serra Leoa (Mende e Temne) (Parra et al., 2001), foram tomadas para o cálculo da média ponderada Africana; e a média ponderada das freqüências alélicas dos Maias (México) e de indigenas do Sudoeste dos Estados Unidos (representados por uma amostra envolvendo os Pima, Pueblo e Cheyenne; dbSNP/NCBI) foi calculada para os indigenas da América do Norte. As freqüências destes AIMs em indígenas da Amazônia Brasileira foram obtidas em Luizon et al. (2007a).

As estimativas de mistura obtidas com o software ADMIX também podem ser calculadas a partir de freqüências alélicas. Entretanto, nesse caso as freqüências parentais européias foram representadas por Portugueses e as e africanas pela freqüência observada na cidade de Santana, cidade da Ilha de São Tomé (Tomás et al., 2002), tal como realizado por Parra et al. (2003). Esta Ilha serviu como entreposto durante o tráfico negreiro pelo 
Atlântico e, por isso, possui uma população teve origem em várias regiões Africanas (Tomás et al., 2002).

No entanto, o cálculo do $F_{S T}$ e as análises do software Structure exigem freqüências genotípicas, que não estão disponíveis na literatura. Esta informação genotipica referente aos AIMs aqui analisados, exceto o CYP1A1, para indivíduos da Nigéria (Africana) e da Espanha e Alemanha foi gentilmente cedida pelo Dr. Mark David Shriver, Professor do Departamento de Antropologia da Universidade da Pennsylvania (Shriver, informação pessoal). Duas amostras aleatórias de 55 indivíduos para cada um daqueles grupos étnicos foram selecionadas com o uso da função aleatório no programa Excel®. Estes genótipos Africanos e Europeus foram admitidos como parentais nas comparações par a par dos valores de $F_{S T}$ e também nas análises do software Structure.

\section{Aderência ao equilibrio de Hardy-Weinberg}

Segundo o teorema de Hardy-Weinberg, as freqüências genotípicas esperadas no equilíbrio podem ser estimadas a partir da expansão do seguinte binômio:

$\left(x_{i}+x_{j}\right)^{2}=x_{i}^{2}+2 x_{i} x_{j}+2 x_{j}^{2}$

Em que:

$\mathrm{x}_{\mathrm{i}}^{2}$ é a freqüência esperada dos homozigotos do alelo $\mathrm{i}$;

$2 \mathrm{x}_{\mathrm{i}} \mathrm{x}_{\mathrm{j}}$ é a freqüência esperada do heterozigoto $\mathrm{ij}$;

$2 \mathrm{x}_{\mathrm{j}}^{2}$ é a freqüência esperada dos homozigotos para o alelo $\mathrm{j}$. 
A aderência das freqüências genotípicas observadas às proporções teóricas de Hardy-Weinberg foi verificada com o emprego do programa GENEPOP (Raymond \& Rousset, 1995a) versão 3.4, disponivel em http://wbiomed.curtin.edu.au/genepop. Foram realizados três testes baseados na hipótese nula de união aleatória dos gametas: teste exato de probabilidade, teste para detecção da deficiência e para detecção do excesso de heterozigotos.

No teste exato de probabilidade, o valor de $\mathrm{P}$ corresponde à soma de probabilidades de todas as tabelas com probabilidade menor ou igual ao observado.

O segundo e o terceiro são testes mais sensíveis do que o de probabilidade e utilizam uma hipótese alternativa $(\mathrm{H} 1)$ de excesso ou de deficiência de heterozigotos, respectivamente.

\section{Desequilíbrio de Ligação entre Loci}

A análise de associações par-a-par entre loci foi realizada utilizado-se o programa GENEPOP 3.4 (Raymond \& Rousset, 1995a). A hipótese nula é de que a distribuição genotípica em um locus é independente da distribuição em outro locus. Esta análise foi aplicada para verificar desvios do esperado pela regra de multiplicação entre pares de loci localizados em diferentes cromossomos. A palavra "ligação" neste caso não está relacionada com associação física entre alelos de loci de um mesmo cromossomo. 


\section{Diferenciação genética das populações}

Os testes exatos para diferenciação populacional foram realizados com o uso do programa GENEPOP 3.4 (Raymond \& Rousset, 1995a). Este utiliza tabelas de contingência $\mathrm{RxC}$ geradas automaticamente para cada locus, em que $\mathrm{R}$ é o número de populações e C é o número de alelos no locus.

Este procedimento compara cada locus em pares de populações, para determinar se existem diferenças nas freqüências alélicas observadas, onde a hipótese nula testada é a de que a distribuição alélica é idêntica entre as populações (Raymond \& Rousset, 1995b).

\section{Diversidade gênica}

A diversidade gênica média $\left(\bar{H}_{S}\right)$ com o respectivo erro padrão foi calculada para cada comunidade utilizando o programa DISPAN (Ota, 1993), conforme a equação 8.6 apresentada em Nei (1987):

$$
H=\sum_{j=i}^{r} h_{j} / r
$$

Em que r é o número de loci utilizados e $h_{j}$, de acordo com a equação 8.1 de Nei (1987), é a heterozigose esperada para cada locus na j-ésima população, estimada por:

$$
h=1-\sum_{i=1}^{m} x_{i}^{2}
$$

Em que m é o número de alelos. 
Esta medida de heterozigose média é equivalente à proporção média de heterozigotos por locus em uma população com padrão de acasalamento aleatório e, também, é igual à proporção de loci heterozigotos em um indivíduo escolhido aleatoriamente. O desvio padrão desta estimativa é descrito pela seguinte equação adaptada (Nei, 1987):

$$
\left.H=\left[\sum_{j=1}^{r} h_{j}-H\right)^{2} /(r-1) r\right]^{1 / 2}
$$

As estatísticas F foram obtidas como descrito por Weir (1984), usando o pacote Genetic Data Analysis Package GDA (Lewis \& Zaykin, 1997). São definidos 3 parâmetros:

FIS: Coeficiente de endogamia dentro de uma população (déficit de heterozigotos dentro de uma população);

$F_{I T}$ : Coeficiente de endogamia total, dado pela probabilidade de dois alelos tomados ao acaso de todo o conjunto populacional sejam idênticos por descendência (déficit de heterozigotos global);

$F_{S T}$ : Coeficiente de endogamia em um par de populações, dado pela probabilidade de dois alelos tomados ao acaso em duas populações serem idênticos por descendência (déficit de heterozigotos entre populações).

Estes três parâmetros estão relacionados da seguinte maneira:

$F i s=(F i t-F s t) /(1-F s t)$

Para testar se os valores de $F_{S T}$ diferiam significativamente de zero, foi realizado o procedimento de bootstrap com 1000 replicações. Se os intervalos de confiança de $95 \%$ e $99 \%$ assim obtidos não incluíam o zero, a estimativa 
foi considerada significativamente diferente de zero com $\alpha=5 \%$ ou $1 \%$, respectivamente.

\section{Inferência de Estrutura Populacional (Structure)}

O programa Structure (http://pritch.bsd.uchicago.edu/structure.html) utiliza um método de agrupamento, baseado no modelo desenvolvido por Pritchard et al. (2000), para a inferência de estrutura populacional utilizando dados genotípicos de marcadores não ligados.

A opção Use Pop Info Selection FLAG foi habilitada no intuito de determinar de forma mais precisa os clusters que representam os indivíduos sabidamente pertencentes a populações consideradas parentais: Africana (55 Nigerianos) e Européia (55 Espanhóis e Alemães) e Ameríndios da Amazônia Brasileira (55 individuos aleatoriamente selecionados dentre os 309 genotipados por Luizon et al., 2007a). Na opção Ancestry Model foi selecionado Use Population Information. As análises foram realizadas com $\mathrm{K}=$ 3 como parâmetro predefinido para o número de populações assumidas como parentais, com 30.000 interações para o período burn-in e 100.000 interações adicionais para obter as estimativas dos parâmetros.

\section{Análises de Componente Principal}

O programa MVSP (Multivariate Statistical Package for Windows, version 3.1, acessado em http://www.kovcomp.com/mvsp/) foi utilizado para a obtenção de Análises de Componente Principal relacionando as populações remanescentes de quilombo e as urbanas analisadas com populações africanas, européias, afro-americanas e euro-americanas (Parra 
et al., 1998) e também com populações Amerindias dos EUA (dbSNP) e da Amazônia Brasileira (Luizon et al., 2007a).

Devido ao número diferente de freqüências alélicas disponíveis na literatura para comparação, foram realizadas duas análises: (1) com seis AIMs (FY, RB, LPL, AT3, Sb19.3 e APO) e (2) adicionando-se o locus PV92 aos seis primeiros AIMs.

\section{Estimativas de mistura étnica}

As estimativas das proporções étnicas foram obtidas segundo o método de identidade gênica (Chakraborty, 1985) a partir do programa ADMIX 2 e 3.

A estimativa foi primeiro realizada admitindo-se um modelo tri-híbrido de mistura, no qual as freqüências de Portugueses foram utilizadas como parental européia, da cidade de Santana (Ilha de São Tomé) como parental africana (Tomás et al., 2002) e a freqüência média de sete aldeias da Amazônia Brasileira como parental ameríndia (Luizon et al., 2007a), utilizando o programa ADMIX 3. Nos casos onde houve inconsistência com alguma das populações consideradas como parentais, a mesma foi retirada e a estimativa foi refeita somente com as duas outras populações parentais, utilizando o programa ADMIX 2.

O método de identidade gênica foi escolhido para permitir a comparação com as estimativas de mistura obtidas a partir de marcadores clássicos, STRs autossômicos e ligados ao cromossomo Y nas mesmas amostras de São Gonçalo e Jequié (Sousa, 2001). 


\section{RESULTADOS}

\section{FREQÜÊNCIAS ALÉLICAS E HETEROZIGOSE}

O presente trabalho apresenta resultados gerados a partir da freqüência alélica de oito AIMs (FY, RB, LPL, AT3, Sb19.3, APO, PV92 e CYP1A1) em três comunidades remanescentes de quilombo, duas populações urbanas e em quatro tribos indígenas da Amazônia Brasileira. Para estas últimas, as freqüências dos primeiros sete marcadores são aquelas já anteriormente publicadas (Luizon et al., 2007a).

Em todas estas populações foram observados os dois alelos previamente identificados para os AIMs analisados (Tabela 5 e Figura 5), com exceção do alelo $C Y P 1 A 1^{*} 2 C$, ausente na comunidade de Valongo. As freqüências deste alelo nas tribos indígenas da Amazônia Brasileira foram superiores a 80\%.

TABELA 5. Freqüências alélicas dos oito AIMs e diversidade genética ( $\left.H_{s}\right)$ nas comunidades remanescentes de quilombo, populações urbanas e amerindias analisadas. As freqüências se referem ao alelo CYP1A1*2C e aos alelos * 1 dos demais loci.

\begin{tabular}{lccccccccc}
\hline & FY & RB & LPL & AT3 & Sb19.3 & APO & PV92 & CYP1A1 & $\begin{array}{c}\boldsymbol{H}_{S} \pm \\
\text { Desvio padrão }\end{array}$ \\
\hline S. Gonçalo & $43 / 96$ & $82 / 100$ & $80 / 102$ & $58 / 102$ & $45 / 100$ & $70 / 100$ & $15 / 102$ & $18 / 102$ & $0,388 \pm 0,036$ \\
Barra & $21 / 94$ & $82 / 94$ & $82 / 94$ & $85 / 94$ & $38 / 94$ & $40 / 92$ & $30 / 94$ & $3 / 94$ & $0,308 \pm 0,056$ \\
Valongo & $11 / 40$ & $38 / 48$ & $28 / 36$ & $35 / 50$ & $33 / 50$ & $49 / 50$ & $27 / 50$ & $0 / 50$ & $0,317 \pm 0,067$ \\
Jequié & $44 / 94$ & $53 / 94$ & $64 / 94$ & $41 / 94$ & $49 / 94$ & $73 / 94$ & $31 / 94$ & $9 / 90$ & $0,427 \pm 0,039$ \\
HEMOSC & $33 / 36$ & $14 / 48$ & $30 / 50$ & $12 / 48$ & $38 / 46$ & $45 / 48$ & $14 / 50$ & $4 / 46$ & $0,303 \pm 0,051$ \\
Tikúna & $289 / 290$ & $28 / 398$ & $193 / 370$ & $19 / 392$ & $292 / 396$ & $391 / 392$ & $368 / 386$ & $344 / 374$ & $0,170 \pm 0,063$ \\
Umariaçú & $42 / 84$ & $2 / 102$ & $55 / 96$ & $4 / 102$ & $82 / 102$ & $97 / 98$ & $95 / 98$ & $92 / 98$ & $0,140 \pm 0,061$ \\
Feijoal & $62 / 62$ & $15 / 104$ & $63 / 98$ & $9 / 96$ & $72 / 100$ & $102 / 102$ & $99 / 102$ & $94 / 98$ & $0,178 \pm 0,064$ \\
Vendaval & $70 / 70$ & $2 / 98$ & $35 / 92$ & $1 / 100$ & $61 / 100$ & $98 / 98$ & $85 / 92$ & $74 / 90$ & $0,182 \pm 0,073$ \\
Belém & $73 / 74$ & $9 / 94$ & $40 / 84$ & $5 / 94$ & $77 / 94$ & $94 / 94$ & $89 / 94$ & $84 / 88$ & $0,162 \pm 0,056$ \\
Baníwa & $92 / 92$ & $14 / 92$ & $45 / 92$ & $3 / 92$ & $63 / 90$ & $91 / 92$ & $78 / 92$ & $78 / 88$ & $0,218 \pm 0,065$ \\
Kashináwa & $50 / 50$ & $4 / 60$ & $9 / 44$ & $3 / 60$ & $50 / 56$ & $60 / 60$ & $50 / 60$ & $40 / 50$ & $0,170 \pm 0,048$ \\
Kanamarí & $62 / 62$ & $19 / 66$ & $36 / 60$ & $3 / 66$ & $27 / 66$ & $66 / 66$ & $53 / 58$ & $61 / 66$ & $0,223 \pm 0,074$ \\
\hline
\end{tabular}



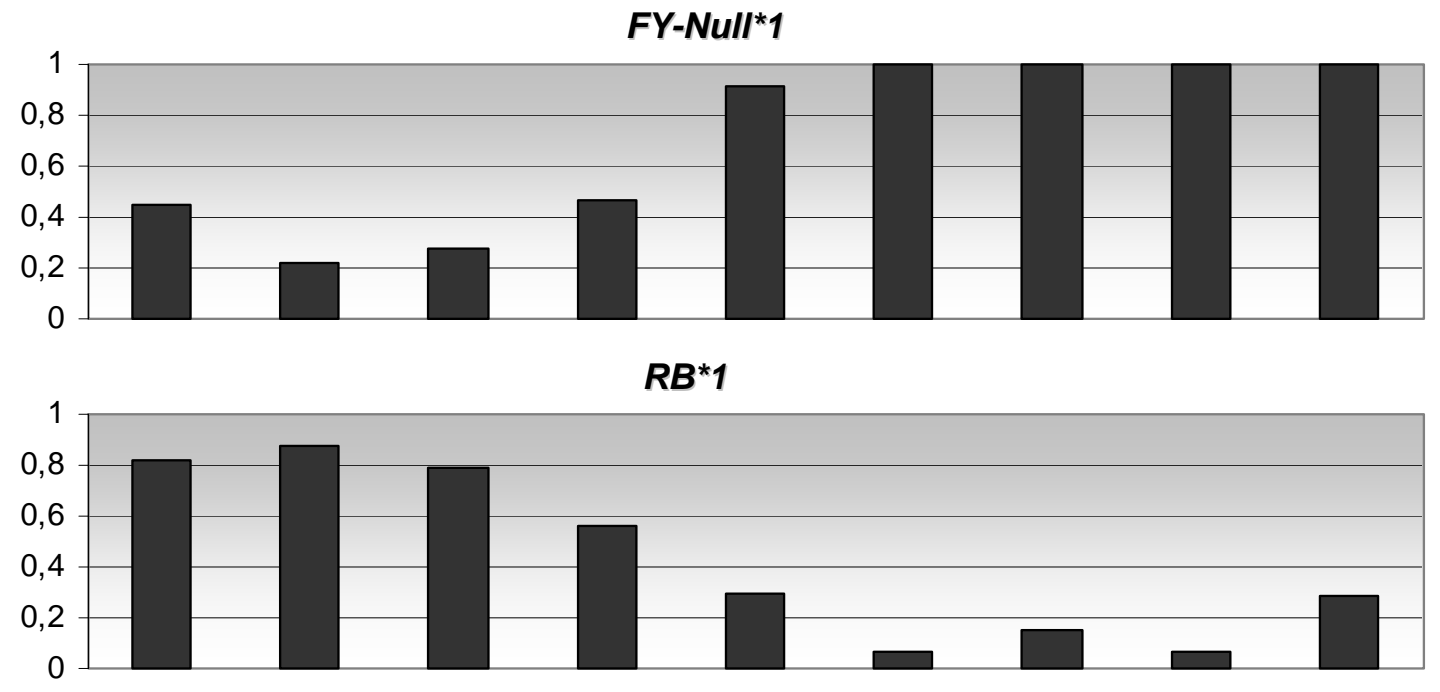

$L P L{ }^{*} 1$

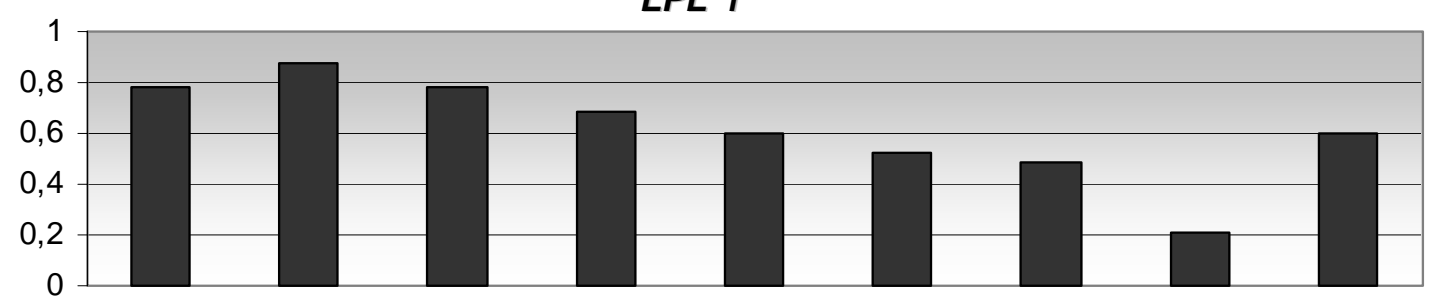

AT3*1

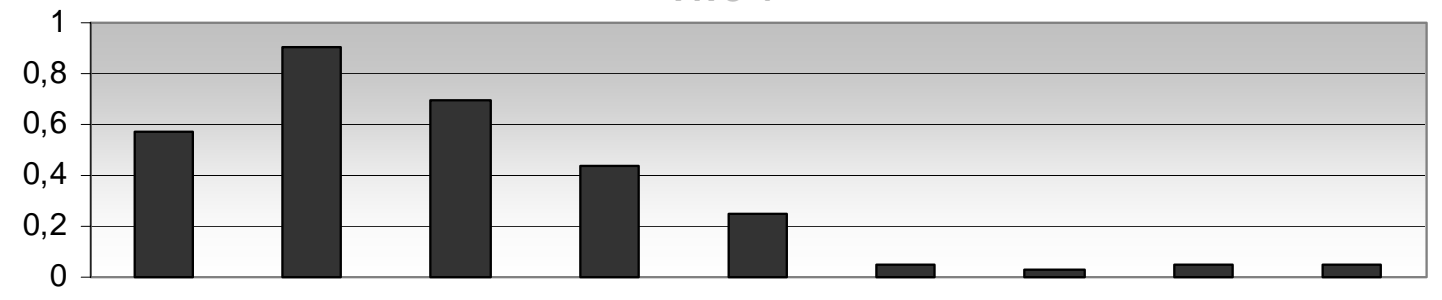

Sb19.3*1

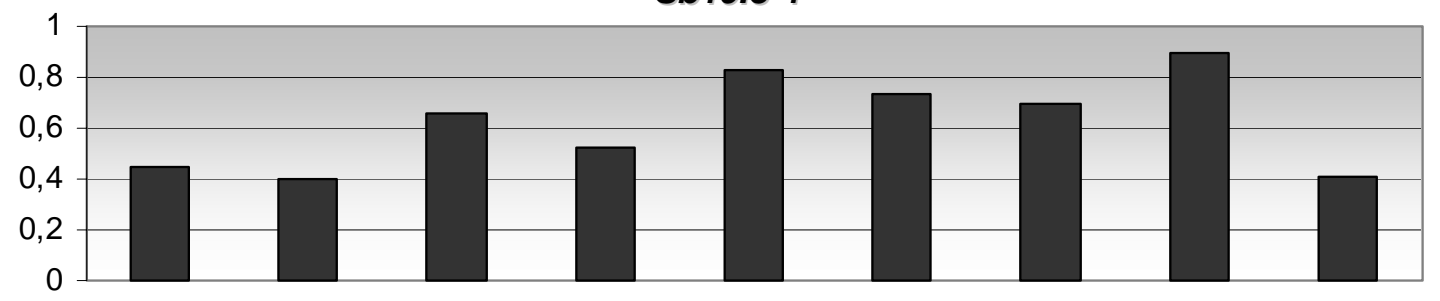

$A P O^{* 1}$

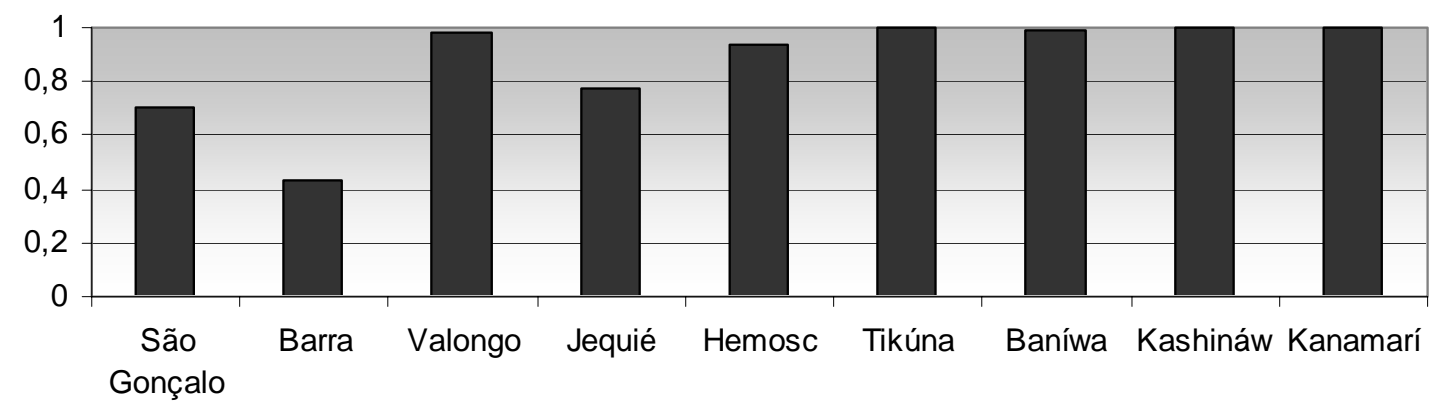



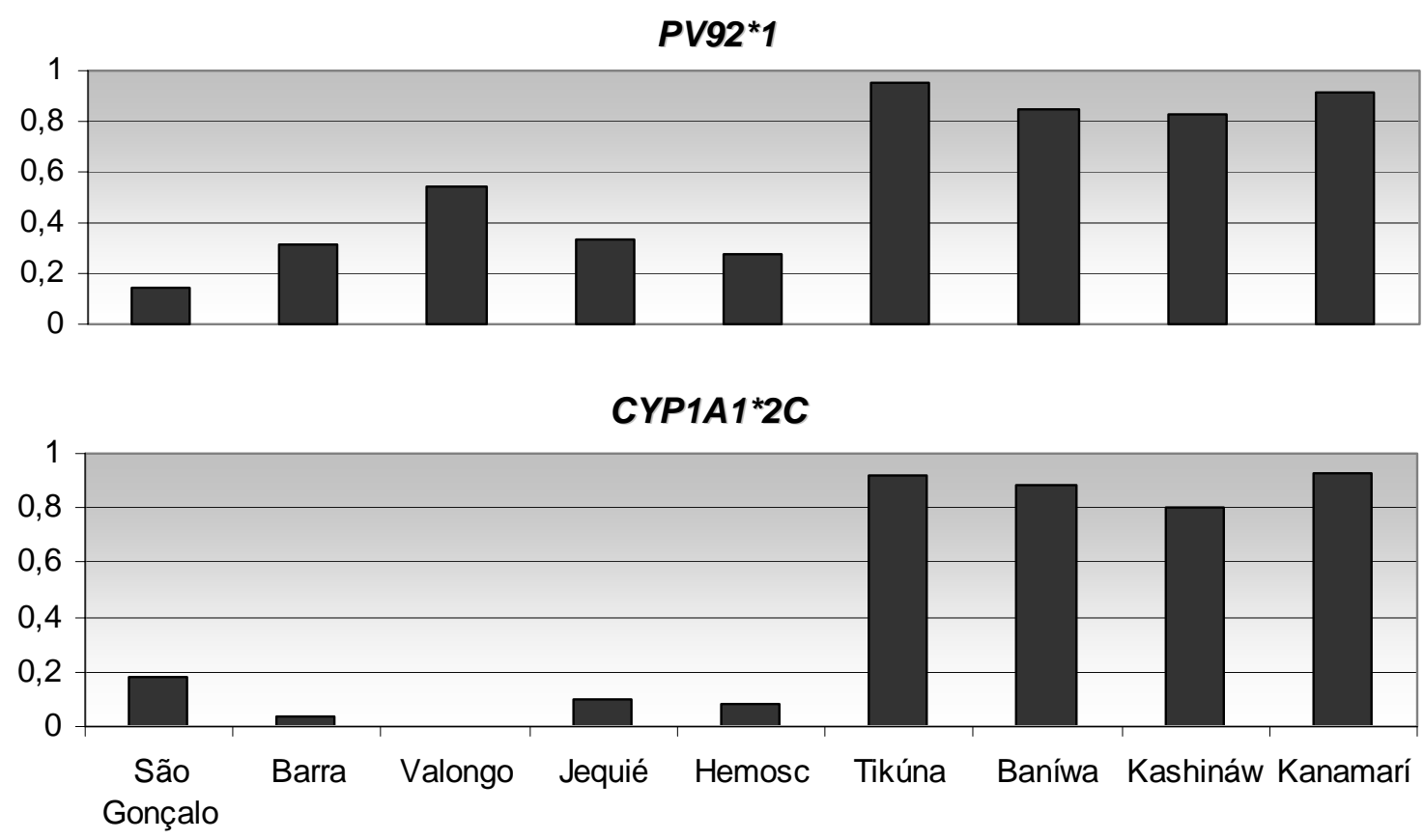

FIGURA 5. Comparação das freqüências dos AIMs entre as comunidades remanescentes de quilombo de São Gonçalo, Barra e Valongo, as populações urbanas de Jequié e HEMOSC, e as tribos da Amazônia Brasileira, Tikúna, Baniwa, Kashináwa e Kanamari.

A comparação das freqüências alélicas e genotípicas entre as três comunidades remanescentes de quilombo e as duas amostras urbanas par a par, pelo teste exato de Fisher, revela diferenças altamente significativas $(\mathrm{p}<0,01)$ quando considerados todos os loci, exceto entre São Gonçalo e Jequié para as freqüências genotípicas (Tabela 6).

Dentre as comparações envolvendo as populações ameríndias, destaques para a diferenciação entre Vendaval e Feijoal e Belém dentre as aldeias da tribo Tikúna, com relação às freqüências alélicas, e a não diferenciação da tribo Baniwa das demais aldeias analisadas (Tabela 6). 
TABELA 6. Diferenciação das frequencias gênicas e genotípicas entre os pares de populações analisadas. Os valores significativos $(p<0,05)$ após a correção de Bonferroni ( $a_{\text {Bonf. }}<0,007$ ) estão destacados em negrito.

\begin{tabular}{lcc}
\hline Populações & Gênica & Genotípica \\
\hline Umariąú x Feijoal & 0,0382 & 0,1044 \\
Umariąú x Vendaval & 0,0023 & 0,0039 \\
Umariąú x Belém & 0,5727 & 0,6086 \\
Umariąú x BAN & 0,0024 & 0,0012 \\
Umariąú x KASH & $<\mathbf{1 0}^{-4}$ & $\mathbf{0 , 0 0 0 1}$ \\
Umariąú x KAN & $<\mathbf{1 0}^{-4}$ & $<\mathbf{1 0}^{-4}$ \\
Umariaçú x SG & $<\mathbf{1 0}^{-4}$ & $<\mathbf{1 0}^{-4}$ \\
Umariaçú x JQ & $<\mathbf{1 0}^{-4}$ & $<\mathbf{1 0}^{-4}$ \\
Umariaçú x BR & $<\mathbf{1 0}^{-4}$ & $<\mathbf{1 0}^{-4}$ \\
Umariaçú x VAL & $<\mathbf{1 0}^{-4}$ & $<\mathbf{1 0}^{-4}$ \\
Umariaçú x HEM & $<\mathbf{1 0}^{-4}$ & $<\mathbf{1 0}^{-4}$ \\
Feijoal x Vendaval & $<\mathbf{1 0}^{-4}$ & $<\mathbf{1 0}^{-4}$ \\
Feijoal x Belém & 0,2730 & 0,3212 \\
Feijoal x BAN & 0,0123 & 0,0128 \\
Feijoal x KASH & $<\mathbf{1 0}^{-4}$ & $<\mathbf{1 0}^{-4}$ \\
Feijoal x KAN & $\mathbf{0 , 0 0 0 7}$ & $\mathbf{0 , 0 0 0 6}$ \\
Feijoal x SG & $<\mathbf{1 0}^{-4}$ & $<\mathbf{1 0}^{-4}$ \\
Feijoal x JQ & $<\mathbf{1 0}^{-4}$ & $<\mathbf{1 0}^{-4}$ \\
Feijoal x BR & $<\mathbf{1 0}^{-4}$ & $<\mathbf{1 0}^{-4}$ \\
Feijoal x VAL & $<\mathbf{1 0}^{-4}$ & $<\mathbf{1 0}^{-4}$ \\
Feijoal x HEM & $<\mathbf{1 0}^{-4}$ & $<\mathbf{1 0}^{-4}$ \\
Vendaval x Belém & $\mathbf{0 , 0 0 0 4}$ & 0,0018 \\
Vendaval x BAN & 0,0085 & 0,0081 \\
Vendaval x KASH & $\mathbf{0 , 0 0 0 9}$ & 0,0009 \\
Vendaval x KAN & $<\mathbf{1 0}^{-4}$ & $<\mathbf{1 0}^{-4}$ \\
Vendaval x SG & $<\mathbf{1 0}^{-4}$ & $<\mathbf{1 0}^{-4}$ \\
Vendaval x JQ & $<\mathbf{1 0}^{-4}$ & $<\mathbf{1 0}^{-4}$ \\
Vendaval x BR & $<\mathbf{1 0}^{-4}$ & $<\mathbf{1 0}^{-4}$ \\
Vendaval x VAL & $<\mathbf{1 0}^{-4}$ & $<\mathbf{1 0}^{-4}$ \\
Vendaval x HEM & $<\mathbf{1 0}^{-4}$ & $<\mathbf{1 0}^{-4}$ \\
Belém x BAN & 0,2014 & 0,2385 \\
Belém x KASH & 0,0047 & 0,0087 \\
Belém x KAN & $<\mathbf{1 0}^{-4}$ & $<\mathbf{1 0}^{-4}$ \\
\hline & &
\end{tabular}

\begin{tabular}{lcc}
\hline Populações & Gênica & Genotípica \\
\hline Belém x SG & $<\mathbf{1 0}^{-4}$ & $<\mathbf{1 0}^{-4}$ \\
Belém x JQ & $<\mathbf{1 0}^{-4}$ & $<\mathbf{1 0}^{-4}$ \\
Belém x BR & $<\mathbf{1 0}^{-4}$ & $<\mathbf{1 0}^{-4}$ \\
Belém x VAL & $<\mathbf{1 0}^{-4}$ & $<\mathbf{1 0}^{-4}$ \\
Belém x HEM & $<\mathbf{1 0}^{-4}$ & $<\mathbf{1 0}^{-4}$ \\
BAN x KASH & 0,0076 & 0,0056 \\
BAN x KAN & 0,0102 & 0,0125 \\
BAN x SG & $<\mathbf{1 0}^{-4}$ & $<\mathbf{1 0}^{-4}$ \\
BAN x JQ & $<\mathbf{1 0}^{-4}$ & $<\mathbf{1 0}^{-4}$ \\
BAN x BR & $<\mathbf{1 0}^{-4}$ & $<\mathbf{1 0}^{-4}$ \\
BAN x VAL & $<\mathbf{1 0}^{-4}$ & $<\mathbf{1 0}^{-4}$ \\
BAN x HEM & $<\mathbf{1 0}^{-4}$ & $<\mathbf{1 0}^{-4}$ \\
KASH x KAN & $<\mathbf{1 0}^{-4}$ & $<\mathbf{1 0}^{-4}$ \\
KASH x SG & $<\mathbf{1 0}^{-4}$ & $<\mathbf{1 0}^{-4}$ \\
KASH x JQ & $<\mathbf{1 0}^{-4}$ & $<\mathbf{1 0}^{-4}$ \\
KASH x BR & $<\mathbf{1 0}^{-4}$ & $<\mathbf{1 0}^{-4}$ \\
KASH x VAL & $<\mathbf{1 0}^{-4}$ & $<\mathbf{1 0}^{-4}$ \\
KASH x HEM & $<\mathbf{1 0}^{-4}$ & $<\mathbf{1 0}^{-4}$ \\
KAN x SG & $<\mathbf{1 0}^{-4}$ & $<\mathbf{1 0}^{-4}$ \\
KAN x JQ & $<\mathbf{1 0}^{-4}$ & $<\mathbf{1 0}^{-4}$ \\
KAN x BR & $<\mathbf{1 0}^{-4}$ & $<\mathbf{1 0}^{-4}$ \\
KAN x VAL & $<\mathbf{1 0}^{-4}$ & $<\mathbf{1 0}^{-4}$ \\
KAN x HEM & $<\mathbf{1 0}^{-4}$ & $<\mathbf{1 0}^{-4}$ \\
SG x JQ & $<\mathbf{0 0 0 2}^{-4}$ & 0,0010 \\
SG x BR & $<\mathbf{1 0}^{-4}$ & $<\mathbf{1 0}^{-4}$ \\
SG x VAL & $<\mathbf{1 0}^{-4}$ & $<\mathbf{1 0}^{-4}$ \\
SG x HEM & $<\mathbf{1 0}^{-4}$ & $<\mathbf{1 0}^{-4}$ \\
JQ x BR & $<\mathbf{1 0}^{-4}$ & $<\mathbf{1 0}^{-4}$ \\
JQ x VAL & $<\mathbf{1 0}^{-4}$ & $<\mathbf{1 0}^{-4}$ \\
JQ x HEM & $<\mathbf{1 0}^{-4}$ & $<\mathbf{1 0}^{-4}$ \\
BR x VAL & $<\mathbf{1 0}^{-4}$ & $<\mathbf{1 0}^{-4}$ \\
BR x HEM & \\
VAL x HEM & & \\
\hline & &
\end{tabular}

Os marcadores PV92 e CYP1A1 não apresentam freqüências alélicas disponiveis para muitas populações, razão pela qual não foram considerados 
como base para a estimativa da diversidade genética $\left(H_{S}\right)$ em diferentes populações mundiais (Tabela 7). Dentre as comunidades remanescentes de quilombo do presente trabalho, os valores de heterozigose $\left(H_{S}\right)$ observados em BR $(0,308)$ e VAL $(0,317)$ são concordantes com o valor observado para os Afro-americanos dos EUA, exceto os Gullah (Pfaff et al., 2001). Por outro lado, os valores observados em JQ e SG (Tabela 5) são superiores a todos os valores apresentados na Tabela 7 , provavelmente explicados pela maior mistura étnica nestas comunidades (Sousa, 2001).

TABELA 7. Diversidade genética $\left(H_{S}\right)$ obtidas a partir dos AIMs FY, RB, LPL, AT3, Sb19.3 e APO entre diferentes populações mundiais.

\begin{tabular}{|c|c|c|c|}
\hline Populações & $\mathbf{n}$ & $\begin{array}{c}H s \pm \text { desvio } \\
\text { padrão }\end{array}$ & Refs. \\
\hline Europa & 407 & $0,295 \pm 0,090$ & (1) \\
\hline Inglaterra & 44 & $0,291 \pm 0,101$ & (2) \\
\hline Irlanda & 86 & $0,282 \pm 0,095$ & (2) \\
\hline Alemanha & 30 & $0,340 \pm 0,095$ & (2) \\
\hline Portugal & 168 & $0,297 \pm 0,086$ & (3) \\
\hline Espanha & 79 & $0,299 \pm 0,093$ & (4) \\
\hline África & 474 & $0,186 \pm 0,085$ & (1) \\
\hline Repúb. Centro Africana & 49 & $0,189 \pm 0,083$ & (3) \\
\hline Nigéria-1 & 46 & $0,189 \pm 0,086$ & (3) \\
\hline Nigéria-2 & 100 & $0,171 \pm 0,090$ & (3) \\
\hline Serra Leoa (Mende) & 181 & $0,192 \pm 0,083$ & (5) \\
\hline Serra Leoa (Temne) & 98 & $0,189 \pm 0,090$ & (5) \\
\hline Indígenas da Am. do Norte & 184 & $0,285 \pm 0,090$ & (1) \\
\hline Maias & 96 & $0,293 \pm 0,088$ & (4) \\
\hline Pima, Pueblo e Cheyenne & 88 & $0,277 \pm 0,095$ & (4) \\
\hline Afro-Americanos & 1020 & $0,327 \pm 0,051$ & $\left(1^{*}\right)$ \\
\hline Euro-Americanos & 125 & $0,302 \pm 0,092$ & $(1 *)$ \\
\hline Gullah (isolado) & 83 & $0,210 \pm 0,074$ & (5) \\
\hline $\begin{array}{l}\text { Referências: (1) Valores o } \\
\text { ponderadas das frequiências } \\
\text { Materiais e Métodos (pag. } 53 \\
\text { Parra et al., 1998, (3) Tomás } \\
\text { (http://www.ncbi.nlm.nih.gov/ }\end{array}$ & btidos & Parra et al., 19 & $\begin{array}{l}\text { médias } \\
\text { as em } \\
\text { as } \\
\text { P8. (2) } \\
\text { P/NCBI } \\
\text { 2001. }\end{array}$ \\
\hline
\end{tabular}

\section{EQUILÍBRIO DE HARDY-WEINBERG}

As freqüências genotípicas dos oito loci foram comparadas aos valores esperados pelo equilibrio de Hardy-Weinberg pelo teste exato (Tabela 8). 
TABELA 8. Probabilidade de desvio casual segundo teste exato (Guo e Thompson, 1992) para a verificação do equilibrio de Hardy-Weinberg. Os valores significativos antes da correção de Bonferroni estão destacados em itálico e sublinhado e os valores significativos após a correção ( $\alpha_{\text {Bonf. }}<$ 0,0005) estão destacados em negrito

\begin{tabular}{|c|c|c|c|c|c|c|c|c|c|}
\hline & FY & RB & LPL & AT3 & Sb19.3 & APO & PV92 & CYP1A1 & $\begin{array}{l}\text { Multi- } \\
\text { locus }\end{array}$ \\
\hline São Gonçalo & 0,2402 & 0,6422 & 0,2085 & 0,1595 & $\underline{0,0432}$ & $\underline{0,0048}$ & $\underline{0,0061}$ & & 0,0017 \\
\hline Barra & & & & & $\underline{0,0019}$ & $<10^{-4}$ & 0,7442 & & 0,0003 \\
\hline Valongo & & 0,5394 & 0,5289 & & 0,6626 & & 0,4340 & & 0,9579 \\
\hline Jequié & 0,5637 & 0,0003 & 0,7442 & 0,0003 & $\underline{0,0030}$ & 0,2002 & & 0,3576 & $<10^{-4}$ \\
\hline HEMOSC & & & & 0,0004 & & & & & 0,4845 \\
\hline Tikúna & & $\underline{0,0009}$ & 0,883 & 0,367 & 0,365 & & & $\underline{0,002}$ & 0,0030 \\
\hline Umariaçú & & & 0,7728 & & 0,3731 & & & & 0,9982 \\
\hline Feijoal & & $\underline{0,0056}$ & & & & & & & 0,5842 \\
\hline Vendaval & & & 0,7643 & & & & & $\underline{0,0184}$ & 0,5776 \\
\hline Belém & & 0,3441 & 0,7631 & 0,1058 & 0,6257 & & & 0,0686 & 0,3361 \\
\hline Baníwa & & 0,5699 & 0,7677 & & 0,1672 & & & & 0,9498 \\
\hline Kashináwa & & & & & & & 0,1547 & 0,5418 & 0,9594 \\
\hline Kanamarí & & 0,2226 & 0,2643 & & 0,4700 & & 0,1707 & & 0,5537 \\
\hline $\begin{array}{c}\text { Multi- } \\
\text { populacional }\end{array}$ & 0,9474 & 0,0714 & 0,9954 & 0,0115 & 0,0255 & $<10^{-4}$ & 0,7116 & 0,7834 & 0,000 \\
\hline
\end{tabular}

O locus CYP1A1 mostrou desvio significativo $(\mathrm{P}<0,05)$ na aldeia Vendaval e na tribo Tikúna (considerando as quatro aldeias conjuntamente). O teste sensivel à deficiência de heterozigotos indica que deficiência significativa $(\mathrm{P}<0,05)$ de heterozigotos deste locus nestas amostras.

Desvios significativos foram também observados nas comunidades de SG e BR, bem como nas amostras urbanas de Jequié e HEMOSC (Tabela 8). O teste sensível à deficiência de heterozigotos indicou deficiência significativa de heterozigotos nestas amostras.

O teste exato não foi aplicado aos loci APO e CYP1A1 em VAL, e FY e APO nos amerindios, pois estes se mostraram monomorfos. 
Dado o grande número de testes independentes (72), torna-se necessário realizar a correção de Bonferroni (Hartl \& Clark, 2007). Por este procedimento, o limite $\alpha$ de $5 \%$ foi recalculado pelo número de testes $(0,05 / 72)$, de onde derivou-se o valor de $\alpha_{\text {Bonf. }}=0,0007$.

\section{DESEQUILÍBRIO DE LIGAÇÃO}

Associações significativas entre loci não ligados sugerem a presença de estrutura genética, razão pela qual o padrão de associações par-a-par entre os AIMs não ligados foi analisado. Os locus FY e AT3, considerados ligados, embora distantes 22cM (Parra et al., 1998), também foram incluídos na análise, pois a associação entre os mesmos é indicativa de ALD (Admixture Linkage Disequilibrium), isto é, desequilíbrio de ligação gerado pela mistura recente (Pfaff et al., 2001).

Em cada uma das populações, os oito AIMs considerados par a par permitiram 28 comparações. Dentre as comunidades remanescentes de quilombo foram observadas associações entre os loci FY/AT3 (P=0,043), FY/Sb19.3 (P=0,009) e FY/CYP1A1 (P=0,040) em SG; entre os loci FY/AT3 $(\mathrm{P}=0,036), \mathrm{FY} / \mathrm{APO}(\mathrm{P}=0,000), \mathrm{AT} 3 / \mathrm{APO}(\mathrm{P}=0,014), \mathrm{Sb} 19.3 / \mathrm{PV} 92(\mathrm{P}=0,040)$, RB/CYP1A1 $(\mathrm{P}=0,013)$ e LPL/CYP1A1 $(\mathrm{P}=0,013)$ em $\mathrm{BR}$, e entre os loci RB/PV92 (P=0,031) em VAL.

$\mathrm{Na}$ amostra urbana de JQ foram observadas associações entre os loci FY/AT3 $(\mathrm{P}=0,022)$ e APO/PV92 $(\mathrm{P}=0,002)$, e na amostra do HEMOSC entre os loci LPL/Sb19.3 (P=0,040). 
Pelo nivel de significância aqui considerado $(\alpha=0,05)$ seriam esperadas de uma a duas associações significativas. No entanto, após realizada a correção de Bonferroni (alfa=0,05/28 comparações) o novo valor de significância admitido é $\alpha_{\text {bonf }}=0,0018$, e somente a associação entre os loci FY e APO $(p=0,000)$ em BR foi considerada significativa.

\section{DIVERSIDADE INTERPOPULACIONAL (ESTATISTICAS F)}

\section{Coeficiente de Endogamia $\left(F_{I S}\right)$}

O coeficiente de endogamia $\left(F_{I S}\right)$ foi altamente significativo $(\mathrm{p}<0,01)$ para SG e VAL, e significativo ao nivel de 5\% para JQ (Tabela 9).

TABELA 9. Valores de $F_{I S}$ e seus intervalos de confiança (IC) para as populações analisadas. Valores significativos em negrito, pois seus IC não incluem o valor zero.

\begin{tabular}{lccc}
\hline \multicolumn{1}{c}{ Populações } & $\mathbf{F}_{\text {IS }}$ & IC $=\mathbf{9 5 \%}$ & IC $=\mathbf{9 9 \%}$ \\
\hline $\begin{array}{c}\text { Três Remanescentes } \\
\text { São Gonçalo }\end{array}$ & $\mathbf{0 , 2 3 7}$ & 0,134 a 0,344 & 0,046 a 0,373 \\
Barra & 0,196 & $-0,092$ a 0,472 & $-0,102$ a 0,536 \\
Valongo & $\mathbf{- 0 , 1 5 2}$ & $-0,211$ a $-0,089$ & $-0,226$ a $-0,063$ \\
Amostras urbanas & & & \\
Jequié & $* \mathbf{0 , 2 2 8}$ & $* 0,033$ a 0,418 & $-0,026$ a 0,467 \\
HEMOSC & 0,103 & $-0,078$ a 0,366 & $-0,117$ a 0,470 \\
\hline Africanos & $-0,036$ & $-0,102$ a 0,032 & $-0,118$ a 0,051 \\
Europeus & $-0,035$ & $-0,098$ a 0,043 & $-0,102$ a 0,076 \\
Ameríndios & $\mathbf{0 , 1 4 2}$ & 0,057 a 0,207 & 0,020 a 0,226 \\
\hline
\end{tabular}

\section{Diversidade inter-populacional $\left(F_{S T}\right.$ e $\left.G_{S T}\right)$}

Todos os valores de $F_{S T}$ (Tabela 10) foram significativos e indicam diferenças entre as três comunidades remanescentes de quilombo, quando estas são individualmente comparadas às populações urbanas e na 
comparação entre as duas populações urbanas. Isto demonstra a grande heterogeneidade existente entre estas populações.

TABELA 10. Valores de $F_{S T}$ e intervalos de confiança (IC) para diferentes conjuntos e pares de populações. Valores significativos em negrito, pois seus IC não incluem o valor zero.

\begin{tabular}{lccc}
\hline \multicolumn{1}{c}{ Pares ou conjuntos } & $\boldsymbol{F}_{\boldsymbol{S T}}$ & IC $=\mathbf{9 5 \%}$ & IC $=\mathbf{9 9 \%}$ \\
\hline Três Remanescentes & $\mathbf{0 , 1 0 3}$ & 0,043 a 0,162 & 0,031 a 0,179 \\
São Gonçalo / Valongo & $\mathbf{0 , 0 9 4}$ & 0,102 a 0,337 & 0,019 a 0,208 \\
Valongo / Barra & $\mathbf{0 , 1 4 7}$ & 0,030 a 0,301 & 0,015 a 0,346 \\
São Gonçalo / Barra & $\mathbf{0 , 0 8 5}$ & 0,024 a 0,145 & 0,012 a 0,172 \\
Remanescentes vs. Urbanas & & & \\
São Gonçalo / Jequié & $\mathbf{* 0 , 0 3 0}$ & $* 0,002$ a 0,067 & $-0,001$ a 0,079 \\
Barra / Jequié & $\mathbf{0 , 1 4 7}$ & 0,050 a 0,251 & 0,035 a 0,293 \\
São Gonçalo / HEMOSC & $\mathbf{0 , 2 1 6}$ & 0,114 a 0,311 & 0,081 a 0,334 \\
Barra / HEMOSC & $\mathbf{0 , 4 0 8}$ & 0,239 a 0,540 & 0,183 a 0,578 \\
Valongo / HEMOSC & $\mathbf{0 , 2 7 4}$ & 0,115 a 0,409 & 0,058 a 0,454 \\
Duas amostras urbanas - Jequié / & $\mathbf{0 , 1 0 8}$ & 0,026 a 0,189 & 0,010 a 0,221 \\
HEMOSC & $\mathbf{0 , 1 3 9}$ & 0,084 a 0,183 & 0,078 a 0,201 \\
\hline Todas as populações & & &
\end{tabular}

Todas as comparações entre as populações aqui analisadas e as populações parentais (Africanos, Europeus e Amerindios) mostraram diferenças significativas, exceto Barra vs. Africanos e HEMOSC vs. Europeus (Tabela 11). 
TABELA 11. Valores de $F_{S T}$ e intervalos de confiança (IC) entre as populações analisadas e populações mundiais. Valores significativos em negrito, pois seus IC não incluem o valor zero.

\begin{tabular}{lccc}
\hline Pares ou conjuntos & $\boldsymbol{F}_{\boldsymbol{S T}}$ & IC $=\mathbf{9 5 \%}$ & IC $=\mathbf{9 9 \%}$ \\
\hline Africanos / São Gonçalo & $\mathbf{0 , 1 5 0}$ & 0,035 a 0,288 & 0,020 a 0,329 \\
Africanos / Jequié & $\mathbf{0 , 2 4 1}$ & 0,128 a 0,353 & 0,0950 a 0,383 \\
Africanos / Barra & 0,043 & $-0,001$ a 0,114 & $-0,006$ a 0,144 \\
Africanos / Valongo & $\mathbf{0 , 2 6 1}$ & 0,098 a 0,395 & 0,057 a 0,434 \\
Africanos / HEMOSC & $\mathbf{0 , 5 3 8}$ & 0,324 a 0,743 & 0,259 a 0,806 \\
Europeus / São Gonçalo & $\mathbf{0 , 2 7 3}$ & 0,140 a 0,399 & 0,107 a 0,443 \\
Europeus / Jequié & $\mathbf{0 , 1 7 3}$ & 0,044 a 0,334 & 0,040 a 0,371 \\
Europeus / Barra & $\mathbf{0 , 4 6 0}$ & 0,286 a 0,608 & 0,252 a 0,643 \\
Europeus / Valongo & $\mathbf{0 , 3 3 8}$ & 0,170 a 0,550 & 0,149 a 0,606 \\
Europeus / HEMOSC & 0,004 & $-0,0080$ a 0,024 & $-0,012$ a 0,035 \\
Ameríndios / São Gonçalo & $\mathbf{0 , 4 4 7}$ & 0,239 a 0,630 & 0,157 a 0,663 \\
Ameríndios / Jequié & $\mathbf{0 , 2 9 7}$ & 0,126 a 0,466 & 0,080 a 0,504 \\
Ameríndios / Barra & $\mathbf{0 , 5 7 6}$ & 0,379 a 0,733 & 0,285 a 0,759 \\
Ameríndios / Valongo & $\mathbf{0 , 4 4 9}$ & 0,204 a 0,660 & 0,081 a 0,721 \\
Ameríndios / HEMOSC & $\mathbf{0 , 2 2 9}$ & 0,032 a 0,496 & 0,021 a 0,574 \\
\hline Todas as populações & $\mathbf{0 , 3 2 4}$ & 0,226 a 0,440 & 0,196 a 0,462 \\
\hline
\end{tabular}

\section{ESTRUTURA POPULACIONAL}

Para as análises com o software Structure foram utilizados os genótipos de 55 indivíduos da Nigéria como parentais Africanos, 55 Espanhóis e Alemães como parentais Europeus (Shriver, comunicação pessoal), e 55 indivíduos aleatoriamente selecionados de quatro tribos indígenas da Amazônia Brasileira como parentais amerindios (Luizon et al., 2007a). A opção FLAG foi habilitada no intuito de determinar de forma mais precisa os clusters que representam os indivíduos reconhecidamente pertencentes a populações consideradas parentais. 
As análises foram realizadas com $\mathrm{K}=3$ como parâmetro predefinido para o número de populações, com 30.000 interações para o período burn-in e 100.000 interações adicionais para obter as estimativas dos parâmetros.

A comunidade de Barra e a população urbana de Florianópolis (HEMOSC) apresentam grande contribuição africana e européia, respectivamente. Por outro lado, as comunidades de Valongo e São Gonçalo apresentam estrutura populacional, isto é, sub-populações de indivíduos geneticamente similares (Figura 6).

Os diagramas triangulares reforçam a maior a similaridade de Barra com os Africanos (Figura 7A) e a heterogeneidade dos indivíduos da comunidade de São Gonçalo e da população urbana de Jequié (Figura 7B).

É importante notar que estas análises não foram realizadas com o locus CYP1A1, pois o mesmo não apresenta dados disponíveis para as mesmas populações reconhecidas como parentais utilizadas nesta análise. Assim como lembrar também que o alelo $C Y P 1 A 1 * 2 C$ apresenta grandes diferencias de freqüência alélica entre populações amerindias e africanas e européias (Luizon et al., 2007b). 


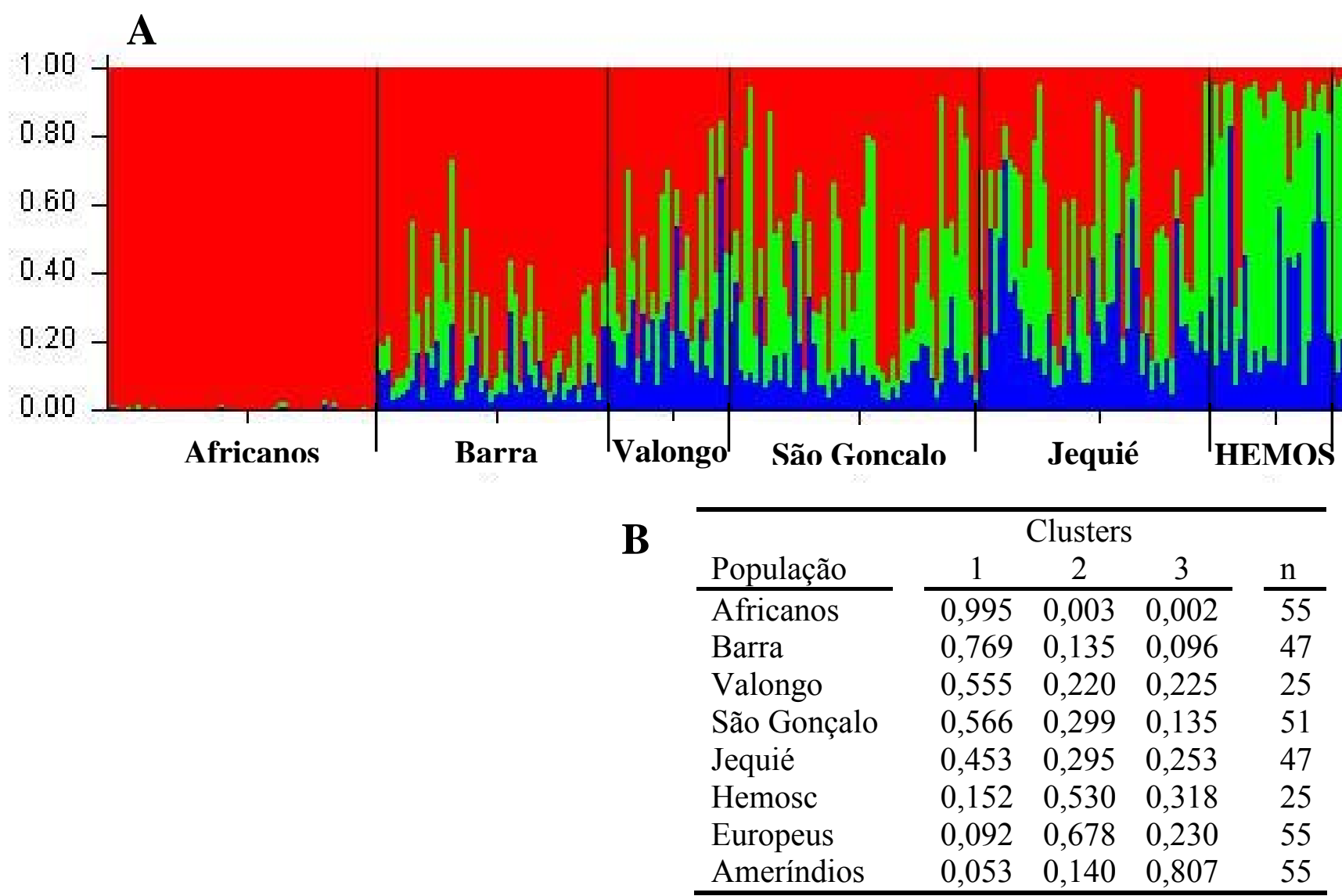

FIGURA 6. (A) Estrutura populacional nas comunidades remanescentes de quilombo e nas populações urbanas, em comparação com populações parentais Africanas, Européias e Amerindios da Amazônia Brasileira, obtido a partir de sete AIMs (com exceção do CYP1A1). Foram admitidas $k=3$ populações, 30.000 interações para o periodo burn-in e 100.000 interações para as estimativas dos parâmetros. (B) Proporção de associação de cada população a cada um dos três clusters. 

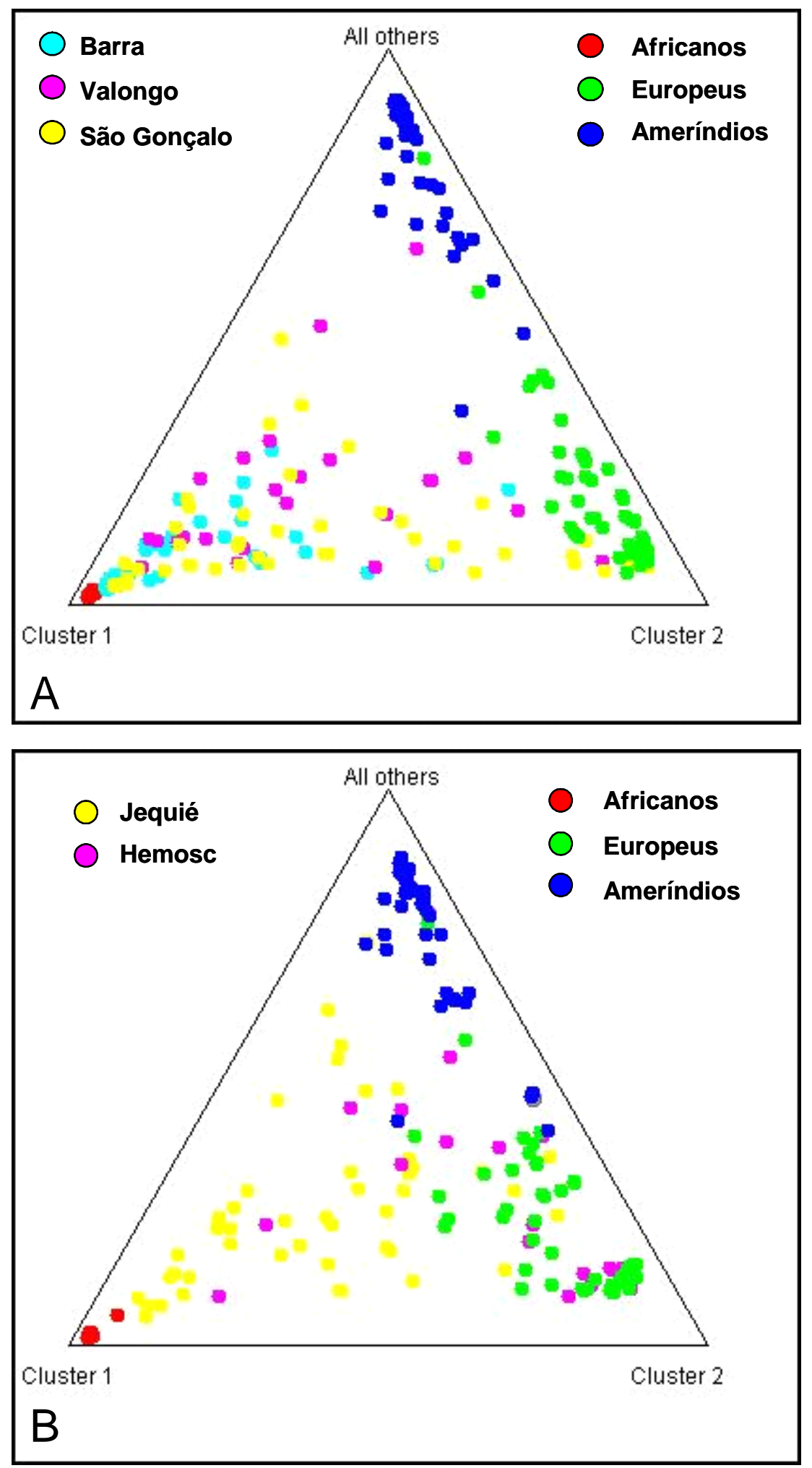

FIGURA 7. Agrupamento dos individuos (circulos) das comunidades de (A) Barra, Valongo e São Gonçalo e de (B) Jequié e do HEMOSC, de acordo a contribuição dos grupos étnicos parentais: africano, europeu e amerindio. 


\section{ANÁLISE DE COMPONENTE PRINCIPAL}

O objetivo das análises de componente principal foi verificar o agrupamento, com base nas freqüências alélicas, das comunidades remanescentes de quilombo e populações urbanas aqui analisadas com populações africanas, européias, ameríndias, afro-americanas e euroamericanas. Para tanto, foram utilizadas as freqüências da literatura citadas no Material e Métodos (página 53). As análises obtidas a partir de seis AIMs (FY, RB, LPL, AT3, Sb19.3 e APO) encontram-se na Figura 8 e nas Tabelas 12 e 13.

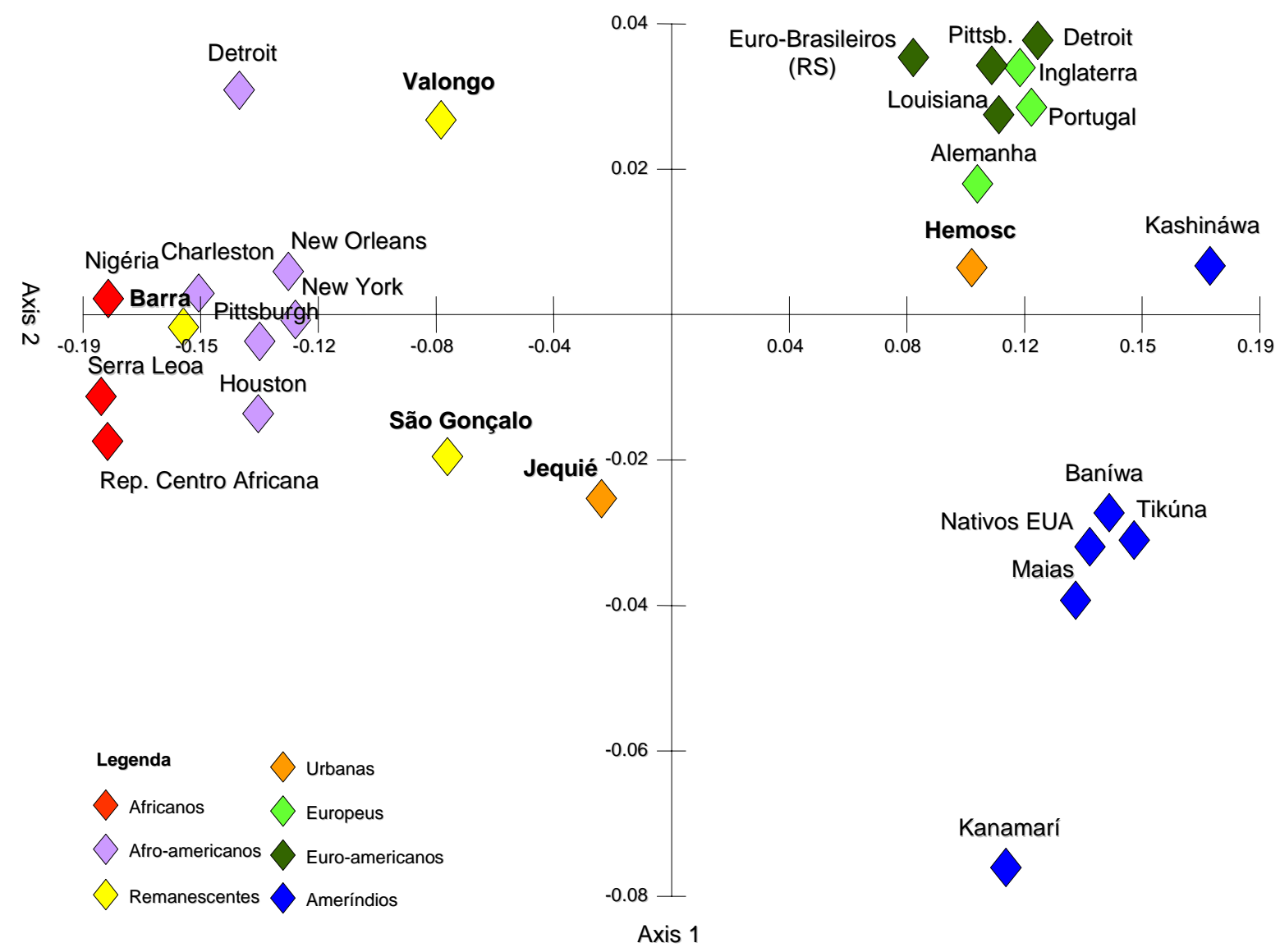

FIGURA 8. Componentes principais obtidos a partir de seis AIMs (FY, RB, LPL, AT3, Sb19.3 e APO) que relacionam as freqüências alélicas das populações analisadas com populações mundiais. Populações africanas e européias (Parra et al., 2001; Tomás et al., 2002), afro- e euro-americanas (Parra et al., 1998), euro-brasileiros (Zembrzuski et al., 2006), e populações indigenas da América do Norte (dbSNP, PSU-ANTH) e da Amazônia Brasileira (Luizon et al., 2007a). 
Tabela 12. Caracteristicas dos componentes principais baseados nas freqüências alélicas de seis AIMs (FY, RB, LPL, AT3, Sb19.3 e APO).

\begin{tabular}{cccc}
\hline Componente & Eigenvalue & $\begin{array}{c}\text { Proporção } \\
\text { explicada (\%) }\end{array}$ & $\begin{array}{c}\text { Proporção cumulativa } \\
\text { explicada (\%) }\end{array}$ \\
\hline Axis 1 & 0,469 & 92,605 & 92,605 \\
Axis 2 & 0,021 & 4,052 & 96,657 \\
\hline
\end{tabular}

Tabela 13. Pesos (loadings) das variáveis na resolução dos componentes principais na análise baseada em seis AIMs (FY, RB, LPL, AT3, Sb19.3 e APO).

\begin{tabular}{lcc}
\hline & Axis 1 & Axis 2 \\
\hline FY & 0,602 & 0,06 \\
RB & $-0,444$ & 0,184 \\
LPL & $-0,316$ & $-0,179$ \\
AT3 & $-0,435$ & 0,486 \\
Sb19.3 & 0,224 & 0,832 \\
APO & 0,318 & 0,044 \\
\hline
\end{tabular}

A população de BR está agrupada com as populações africanas e afroamericanas. As comunidades remanescentes de quilombo de VAL e SG encontram-se próximas a este agrupamento, mas mais distantes que os Afro-americanos dos EUA das populações Africanas. A população urbana do HEM, por outro lado, encontra-se próxima ao agrupamento das populações européias, euro-americanas e euro-brasileiros (Figura 8).

As freqüências do locus PV92 não estão disponiveis para todas as populações acima. No entanto, devido à importância deste AIM na separação entre ameríndios e europeus, uma análise separada foi realizada incluindo este marcador (Figura 9 e Tabelas 14 e 15). O alelo CYP1A1*2C não foi incluso nesta análise, pois suas freqüências não estão disponíveis para as populações comparadas. 


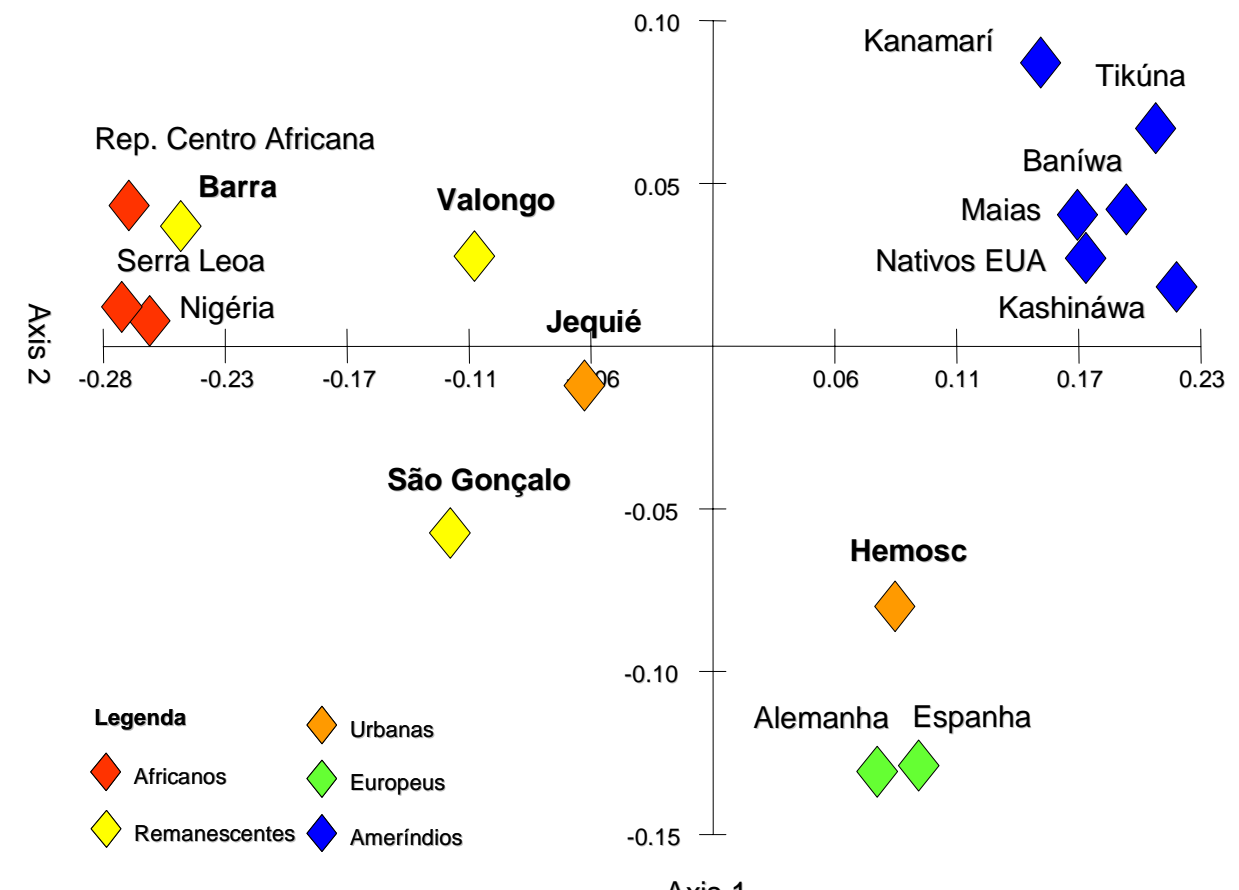

Axis 1

FIGURA 9. Componentes principais obtidos a partir da adição do locus PV92 aos seis AIMs da Figura 8, que relacionam as freqüências alélicas das populações analisadas com populações mundiais. Populações africanas e européias (Parra et al., 2001; Tomás et al., 2002), afro- e euro-americanas (Parra et al., 1998), euro-brasileiros (Zembrzuski et al., 2006), e populações indigenas da América do Norte (dbSNP, PSU-ANTH) e da Amazônia Brasileira (Luizon et al., 2007a).

Tabela 14. Caracteristicas dos componentes principais baseados nas freqüências alélicas de sete AIMs (FY, RB, LPL, AT3, Sb19.3, APO e PV92).

\begin{tabular}{cccc}
\hline Componente & Eigenvalue & $\begin{array}{c}\text { Proporção } \\
\text { explicada }(\%)\end{array}$ & $\begin{array}{c}\text { Proporção cumulativa } \\
\text { explicada (\%) }\end{array}$ \\
\hline Axis 1 & 0,560 & 85,43 & 85,43 \\
Axis 2 & 0,064 & 9,7 & 95,13 \\
\hline
\end{tabular}

Tabela 15. Pesos (loadings) das variáveis na resolução dos componentes principais na análise baseada em sete AIMs (FY, RB, LPL, AT3, Sb19.3, APO e PV92).

\begin{tabular}{lrr}
\hline & Axis 1 & Axis 2 \\
\hline FY & 0,552 & $-0,286$ \\
RB & $-0,442$ & $-0,017$ \\
LPL & $-0,29$ & 0,09 \\
AT3 & $-0,454$ & $-0,02$ \\
Sb19.3 & 0,186 & $-0,391$ \\
APO & 0,298 & $-0,051$ \\
PV92 & 0,293 & 0,869 \\
\hline
\end{tabular}


As populações amerindias e européias encontram-se separadas (Figura 8) dado o alto diferencial de freqüência do AIM PV92 entre estes dois grupos étnicos (Shriver et al., 2003). Isto se reflete no peso $(0,869)$ deste locus na resolução do segundo componente principal (Tabela 15). A comunidade de BR encontra-se novamente agrupada com as populações africanas e a população urbana do HEM com as populações européias.

O locus FY apresenta o peso mais importante na resolução do primeiro componente principal (Tabelas 13 e 15) em ambas as análises. Nas duas análises é importante notar também que que os dois componentes principais explicaram mais do que 95\% da variância total (Tabelas 12 e 14).

\section{ESTIMATIVAS DE MISTURA ÉTNICA}

A Tabela 16 apresenta a contribuição dos componentes Africano, Europeu e Amerindio para as populações estudadas.

TABELA 16. Contribuição dos componentes africano, europeu e amerindio obtidos a partir dos oito AIMs para as comunidades remanescentes de quilombo e populações urbanas analisadas.

\begin{tabular}{lccccccc}
\hline \multirow{2}{*}{ Componentes } & \multicolumn{3}{c}{ Remanescentes de Quilombo } & & \multicolumn{2}{c}{ Populações Urbanas } \\
\cline { 2 - 4 } & São Gonçalo & Barra & Valongo & & Jequié & HEMOSC \\
\hline Africano & $0,681 \pm 0,007$ & $0,954 \pm 0,009$ & $0,681 \pm 0,004$ & & $0,520 \pm 0,003$ & $0,072 \pm 0,007$ \\
Europeu & $0,216 \pm 0,016$ & & $0,319 \pm 0,004$ & & $0,306 \pm 0,008$ & $0,833 \pm 0,017$ \\
Ameríndio & $0,103 \pm 0,011$ & $0,046 \pm 0,009$ & & & $0,174 \pm 0,005$ & $0,095 \pm 0,012$ \\
\hline
\end{tabular}

O modelo tri-híbrido foi inconsistente na determinação das estimativas de mistura nas comunidades de BR e VAL, apresentando inconsistência com o componente amerindio. Portanto, este foi retirado da análise e foi admitido 
um modelo de mistura a partir de duas populações parentais para estas comunidades.

A população do HEM apresentou preponderante contribuição européia, concordante com estimativas de contribuição para populações da região Sul do Brasil (Parra et al., 2003). As contribuições dos componentes europeu em BR e africano no HEM não foram considerados porque o desvio padrão é maior do que as estimativas nos dois casos (Tabela 11). 


\section{DISCUSSÃO}

\section{FREQÜÊNCIAS ALÉLICAS E HETEROZIGOSE}

Dos oito AIMs aqui analisados, que apresentam altos diferenciais de

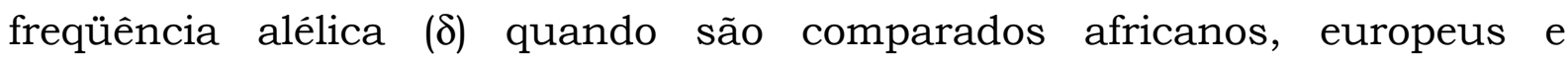
amerindios seis deles (FY, RB, LPL, AT3, Sb19.3, APO) apresentam freqüências semelhantes em ameríndios e populações européias, mas muito diferentes daquelas encontradas em populações africanas (Parra et al.,, 1998). Os outros dois (PV92 e o alelo CYP1A1*2C) apresentam alta freqüência entre amerindios, mas baixa nos outros dois grupos populacionais (Shriver et al., 2003; Tabela 17). O alelo CYP1A1*2C é aqui definido como AIM, pois até agora havia sido estudado em apenas sete tribos indígenas Sul-americanas (Tabela 17).

No presente trabalho a freqüência deste marcador foi determinada em um grande número (297) de Amerindios de quatro tribos indígenas da Amazônia Brasileira caracterizadas por uma baixa mistura (2 a 3\%) com populações não-índígenas (Mohrenweiser et al., 1979, Neel et al., 1980). Além dos baixos valores de mistura, o estudo destas tribos é também relevante dada a posição geográfica central ocupada pelas mesmas no continente Sul-americano.

A média ponderada das freqüências aqui descritas $(90,9 \%)$ é maior do que a das demais tribos $(73,2 \%)$ relatadas na literatura (Tabela 17). As primeiras são provavelmente mais representativas, pois as tribos apresentam baixa mistura de acordo com marcadores clássicos (Mohrenweiser et al., 
1979, Neel et al., 1980), do DNAmt, para o qual nenhum haplogrupo não indígena foi observado (Mendes-Junior, 2005), e a partir da análise de AIMs (Luizon et al., 2007a).

Tabela 17. Freqüências $(\%)$ do alelo CYP1A1*2C em populações mundiais.

\begin{tabular}{|c|c|c|c|}
\hline População & $2 n$ & $* 2 C$ & Referências \\
\hline África ${ }^{a}$ & 228 & 1,3 & Dandara et al., 2002 \\
\hline Europa & 924 & $2,8-5,8$ & Cascorbi et al., 1996, Esteller et al., 1997 \\
\hline Itália & 242 & 6 & Landi et al., 2005 \\
\hline \multicolumn{4}{|l|}{ Ásia } \\
\hline China & 2454 & 24,8 & Boyapati et al., 2005 \\
\hline Sibéria & 102 & 35 & Duzhak et al., 2000 \\
\hline \multicolumn{4}{|l|}{ América } \\
\hline Aché & 134 & 100 & Gaspar et al., 2002a \\
\hline Baníwa & 98 & 89,8 & present study \\
\hline Gavião & 60 & 59 & Kvitko et al., 2000 \\
\hline Guarani & 102 & 90,2 & Gaspar et al., 2002a \\
\hline Kanamarí & 68 & 92,6 & presente estudo \\
\hline Kashinawa & 50 & 80 & presente estudo \\
\hline Mapuche & 168 & 77 & Muñoz et al., 1998 \\
\hline Suruí & 48 & 54 & Kvitko et al., 2000 \\
\hline Tikúna (4 aldeias) & 378 & 92,1 & presente estudo \\
\hline Umariaçú & 100 & 94 & presente estudo \\
\hline Feijoal & 98 & 95,9 & presente estudo \\
\hline Vendaval & 90 & 82,2 & presente estudo \\
\hline Belém & 90 & 95,6 & presente estudo \\
\hline Xavante & 42 & 97 & Kvitko et al., 2000 \\
\hline Wai Wai & 52 & 81 & Kvitko et al., 2000 \\
\hline Zoró & 60 & 76 & Kvitko et al., 2000 \\
\hline \multicolumn{4}{|l|}{ Afro-brasileiros } \\
\hline Porto Alegre & 274 & 15,7 & Gaspar et al., 2002b \\
\hline Rio de Janeiro & 128 & 11,7 & Gaspar et al., 2002b \\
\hline Salvador & 60 & 15 & Gaspar et al., 2002b \\
\hline São Paulo & 180 & 8,3 & presente estudo \\
\hline Valongo & 104 & 0 & presente estudo \\
\hline \multicolumn{4}{|l|}{ Euro-brasileiros } \\
\hline Porto Alegre & 172 & 11,6 & Gaspar et al., 2002b \\
\hline
\end{tabular}


Diante de tais resultados aqui observados e comparados àqueles de populações mundiais (Tabela 17) conclui-se que este marcador pode ser considerado um AIM, isto é, capaz de distinguir os Amerindios dos outros grupos (Luizon et al., 2007b).

Estes dois marcadores, capazes de diferenciar os indigenas dos grupos restantes, são particularmente importantes para o estudo da composição tri-híbrida da população brasileira que, como nos informam os dados históricos, foi constituída pela união de contingentes de colonizadores europeus (principalmente portugueses), escravos africanos por eles trazidos e indigenas autóctones (Ribeiro 1995).

Estas comunidades indigenas pequenas e isoladas são particularmente sensiveis ao efeito da deriva genética (Salzano, 2002). Embora os efeitos da deriva genética e/ou efeito do fundador sejam facilmente observáveis pela análise de distribuição de freqüências do alelo $C Y P 1 A 1 * 2 C$ (que variou de $54 \%$ em Surui até 100\% em Aché; Tabela 17), ainda assim observa-se elevada freqüência média ponderada $(78,3 \%)$ nos Amerindios Sulamericanos, e elevado diferencial de freqüências em relação a europeus, africanos e asiáticos.

Como previamente mostrado para outros polimorfismos dos genes do citocromo P450 analisados nos Mapuche, estas diferenças podem ser interpretadas como uma conseqüência de deriva genética causada por um efeito do fundador no povoamento dos Sul-amerindios, ou seleção natural causada por fatores da dieta ou ambientais (Muñoz et al., 1998). 
Em princípio, um remanescente de quilombo deve ter grande proporção de seus genes derivados de estoques africanos. Conseqüentemente, seriam esperadas freqüências alélicas mais próximas daquelas encontradas em populações do continente africano. De fato, a comunidade remanescente de quilombo de Valongo demonstrou ausência de contribuição ameríndia e a africana foi estimada em $97,33 \% \pm 10,41$ por marcadores clássicos (Souza e Culpi, 2005). A baixa freqüência $(1,3 \%)$ do alelo $C Y P 1 A 1 * 2 C$ em populações africanas (Dandara et al., 2002) explicaria a sua ausência em VAL e sua baixa freqüência em BR $(2,7 \%)$. Por outro lado, as altas freqüências em SG $(20,3 \%)$ e JQ $(10,2 \%)$ poderiam ser explicadas por uma participação mais intensa de ameríndios na formação destas populações, como indicado por marcadores clássicos, STRs autossômicos e ligados ao cromossomo Y (Sousa, 2001).

A freqüência do alelo $C Y P 1 A 1 * 2 C(8,3 \%)$ em uma amostra de indivíduos não aparentados nascidos no Estado de São Paulo (dados não publicados) é menor do que as observadas em outras populações urbanas brasileiras (Gaspar et al., 2002). Por outro lado, é maior do que a freqüência africana e européia, e concordante com a contribuição ameríndia estimada (7\%) para a mesma a partir de STRs autossômicos (Ferreira et al., 2006).

Considerando-se as três comunidades remanescentes de quilombo (SG, BR, VAL), as duas populações urbanas (JQ e HEMOSC), e as sete aldeias ameríndias (considerando as quatro aldeias Tikúna independentemente) par a par, foi possível realizar um total de 66 comparações das freqüências alélicas e das genotípicas pelo teste exato de Fisher (Tabela 6, Resultados, 
pág.63). Destas, 63 comparações resultaram em desvios significativos no caso das freqüências gênicas e 62 no caso das freqüências genotípicas $(\mathrm{P}<$ 0,05). Entretanto, 55 no primeiro caso e 52 no segundo exibiram $\mathrm{P}<0,0007$, limite recalculado após a correção de Bonferroni $(0,05 / 66)$, e foram os únicos considerados desvios realmente significativos.

Considerando a já citada ausência de mistura étnica nas amostras Amerindias aqui analisadas, as diferenças entre as tribos indigenas devem ser decorrentes da deriva genética. Por outro lado, as diferenças entre as comunidades não indígenas, tendo em vista a conhecida história recente de sua formação, seriam mais plausivelmente atribuídas ao fluxo gênico.

Quanto menor a população e quanto menos imigrantes receber, maior é a tendência desta população à homozigose de seus locos em decorrência basicamente de dois processos: a imigração - ou fluxo gênico - e o endocruzamento que, embora de natureza diferente, produzem o mesmo resultado, isto é, diminuem o número esperado de heterozigotos.

Os aldeias amerindias apresentaram os menores valores de $H_{S}$ dentre as populações analisadas (Tabela 6). Estes poderiam ser decorrentes do pequeno tamanho populacional aliado ao isolamento característico de certas tribos, características que indicam que a deriva genética seja um fator preponderante dentre os indigenas da Amazônia (Tarazona-Santos et al., 2001).

Os menores valores de diversidade genética $(H s)$ observados em BR e $\operatorname{VAL}(0,308 \pm 0,056$ e 0,317 $\pm 0,067$, respectivamente) dentre as populações remanescentes de quilombo analisadas são, portanto, concordantes com o 
isolamento geográfico e cultural destas comunidades (Abé-Sandes, 2002; Souza et al., 1992).

A menor diversidade haplotípica do cromossomo $\mathrm{Y}$ observada em BR $(0,394 \pm 0,119)$ na comparação com populações Afro-derivadas de Salvador, Ribeirão Preto e São Gonçalo também foi explicada pelo isolamento desta comunidade, e conseqüente perda de variabilidade por deriva genética (AbéSandes et al., 2004). A análise de marcadores clássicos em VAL também exibe baixo valor de $H_{S}(0,242 \pm 0,063$; Souza e Culpi, 2005), tais como os observados nas populações isoladas Afro-derivadas de Cametá $(0,192 \pm$ 0,049) e Paredão (0,262 \pm 0,061; Bortolini et al., 1992).

A única comunidade afro-derivada Norte-americana que se assemelha a um remanescente é representada pelos Gullah, localizada na Carolina do Sul (EUA; Parra et al., 2001), que também apresentam baixa diversidade $(0,210$ $\pm 0,074)$, a menor dentre as populações afro-derivadas norte-americanas investigadas por Parra et al., (2001). Este baixo valor de $H_{S}$ está de acordo com a baixa contribuição européia, e com evidências históricas, culturais e antropológicas que indicam o maior isolamento dos Gullah (Parra et al., 2001).

No mesmo sentido, o alto valor de diversidade observado para SG $(0,388$ \pm 0,036; Tabela 7) pode ser explicado pela mistura com populações não africanas, tal como sugerido pela análise de haplogrupos do cromossomo Y nesta mesma população (Abé-Sandes et al., 2004); baixa freqüência do haplogrupo E-M2, característico de populações africanas do Sub-Saara (Flores et al., 2001) e pela alta freqüência do haplogrupo P-92R7, 
freqüentemente observado em Italianos (44\%; Previderè et al.,, 2000), Portugueses (52\%) e Espanhóis (54\%), mas não detectado no Sub-Saara Africano (Flores et al., 2001).

Altos valores de $H_{S}(0,384$ a 0,500$)$ foram observados também em populações remanescentes de quilombo do Vale do Ribeira, Estado de São Paulo, analisadas por quatro inserções Alu (Cotrim et al., 2004). Estes altos indices foram explicados não somente pela mistura com outros grupos étnicos não africanos, mas também pela origem Africana diversa dos escravos trazidos para o Brasil (Cotrim et al., 2004).

A alta diversidade observada em JQ $(0,427)$ foi superior a todos os valores observados nas populações analisadas (Tabela 6) e nas populações mundiais (Tabela 8), para os oito AIMs. Este alto valor de $H_{S}$ também pode ser explicado pela mistura étnica, pois sua população também é considerada tri-híbrida, de acordo com dados de sua história demográfica (Sousa, 2001). Nesta mesma população, a diversidade estimada a partir de marcadores clássicos $(0,270)$, STRs autossômicos $(0,767)$ e STRs ligados ao cromossomo Y $(0,587)$ foi equivalente ao observado para populações africanas (Sousa, 2001). Por sua vez, a $H_{S}$ observada no HEM $(0,303)$ é semelhante aos valores observados em populações européias e euro-americanas (Tabela 8).

\section{EQUILÍBRIO DE HARDY-WEINBERG}

Considerando-se as aldeias da tribo Tikúna isoladamente e as demais populações, foi possivel realizar um total de 72 comparações entre as freqüências genotípicas observadas e esperadas (Tabela 8, Resultados, pág. 
65), das quais 13 resultaram em desvios significativos $(P<0,05)$. Destes, quatro (BR/APO, JQ/RB e AT3 e HEM/AT3; Tabela 8) exibiram P < 0,0007, limite recalculado após a correção de Bonferroni $(0,05 / 72)$, e foram os únicos considerados desvios realmente significativos.

Devido ao isolamento e pequeno tamanho populacional da comunidade remanescente de quilombo de $\mathrm{BR}$, o único desvio observado (locus APO) poderia ser explicado por casamentos não-aleatórios. A migração também poderia explicar este desvio, visto que migrações temporárias masculinas, às vezes definitivas, em busca de trabalho são características nesta comunidade (Abé-Sandes, 2002).

Os desvios observados nas amostras urbanas de JQ e HEM, por outro lado, poderiam ser explicados por fluxo gênico, como indicado pela história demográfica destas populações. Desvios também foram evidenciados pela análise de marcadores clássicos (loci HP, Haptoglobina) e STRs autossômicos (loci vWF2 e vWA) em JQ (Sousa, 2001).

Os outros nove casos em que o desvio foi significativo apenas sem a correção de Bonferroni devem ser, por força do teste, considerados como variação casual.

Entretanto, a correção de Bonferroni é considerada uma medida conservadora, ou seja, modifica o limite de $\alpha$ para valores muito baixos, o que aumentaria a possibilidade de erros do tipo $\beta$, isto é, aumentaria a probabilidade de se aceitar o desvio como sendo casual quando deveria ser considerado significativo. 
Sendo assim, apesar provavelmente serem casuais, esses desvios ‘intermediários’ exigem alguma discussão adicional.

Os indigenas exibiram apenas dois desvios o que aparentemente é muito menor do que o número de desvios encontrados dentre as amostras populacionais urbanas (JQ e HEMOSC) e dos remanescentes de quilombo (SG, BR e VAL). Chama a atenção o fato de que, entre altamente significativos e moderadamente significativos, observam-se três desvios em SG e três outros em JQ.

Tais populações apresentam uma história demográfica de clara miscigenação recente (Sousa, 2001), enquanto que os ameríndios aqui estudados foram selecionados de amostras praticamente sem contato com populações não indigenas (Neel et al., 1980).

\section{DESEQUILÍBRIO DE LIGAÇÃO ENTRE LOCI}

O fluxo gênico entre populações geneticamente distintas gera desequilíbrio de ligação (admixture linkage disequilibrium, ALD) entre os loci (ligados e não ligados) que possuem freqüências alélicas diferentes (Hartl \& Clark, 2007). Associações entre loci não ligados sugerem a presença de estrutura genética.

Considerando-se as aldeias agrupadas em suas respectivas tribos, foi possivel testar a associação em um total de 28 pares de loci (Resultados, pág. 66), das quais 13 resultaram em desvios significativos $(P<0,05)$. Destes, apenas um exibiu $\mathrm{P}<0,0018$, limite recalculado após a correção de Bonferroni, e foi o único considerado realmente significativo. 
Esta única associação significativa foi observada entre os loci FY e APO $(p=0,000)$ em BR, e sugere a presença de estrutura genética nesta comunidade.

Como salientado previamente, sendo a correção de Bonferroni considerada uma medida conservadora, discutiremos aqui as possiveis explicações para as associações significativas antes de admitida esta correção.

O desequilíbrio de ligação entre os loci FY e AT3, separados por 22cM no cromossomo 1 e considerados físicamente ligados, assim como entre os outros AIMs não ligados, é característico de ALD. A presença de ALD entre estes loci em BR poderia ser explicada por um evento de mistura na fundação desta população, similar ao modelo de isolamento híbrido descrito por Pfaff et al. (2001). Por outro lado, a manutenção das associações significativas em SG e JQ poderia ser explicada por eventos adicionais de fluxo gênico, em um modelo semelhante ao de fluxo gênico contínuo (Pfaff et al., 2001). A possibilidade de ocorrência destes modelos é reforçada pela história demográfica e por estimativas de mistura nestas populações (Sousa, 2001; Abé-Sandes, 2002; Abé-Sandes et al., 2004).

\section{ESTATÍSTICA F E DIVERSIDADE INTER-POPULACIONAL}

\section{Coeficiente de endogamia $\left(F_{I S}\right)$}

O coeficiente de endogamia (Fis) significativo para VAL (Tabela 9) era esperado dado o seu isolamento geográfico e cultural em relação às 
comunidades vizinhas, como também pelo alto coeficiente de endogamia $(F=0,081)$ calculado a partir de dados demográficos (Souza e Culpi, 2005).

Apesar de possuir uma formação tri-híbrida, a comunidade de SG é caracterizada como um remanescente de quilombo pelo seu grau de isolamento geográfico e cultural, com baixo tamanho efetivo e populacional (Abé-Sandes, 2002). Semelhantemente a VAL, SG também apresenta um coeficiente de endogamia significativo $(\mathrm{p}<0,01$; Tabela 9) que também poderia ser acarretado por seu isolamento e, conseqüentemente, pela endogamia.

A população urbana de JQ também apresentou $F_{I S}$ significativo. Entretanto, apresenta história demográfica de mistura étnica característica de uma população exogâmica. Marcadores clássicos, STRs autossômicos e YSTRs (Sousa, 2001) e os AIMs analisados neste estudo indicam que esta população é tri-híbrida (Tabela 16 e, portanto, tal parâmetro seria provavelmente decorrente da sub-estrutura populacional e não de endogamia.

O valor significativo de $F_{I S}$ (Tabela 9) no caso dos Ameríndios seria mais provavelmente influenciado pelo pequeno tamanho amostral e conseqüente endogamia destas populações, principalmente quando se considera a comprovada e já citada ausência de mistura com populações não indígenas (Neel et al., 1980). 


\section{Diversidade inter-populacional (Fst)}

A maioria das populações são constituídas por subpopulações, dentro das quais ocorre geralmente a reprodução. Tal agrupamento é denominado estrutura populacional ou subdivisão populacional (Hartl \& Clark, 2007).

A diferenciação entre as três comunidades remanescentes e as duas urbanas medida pelos valores do parâmetro $F_{S T}$ são concordantes com as estimativas de diferenciação gênica e genotípica significativas encontradas pelas comparações par a par entre todas estas populações (Tabela 6).

O cálculo do $F_{S T}$ exige freqüências genotípicas, que não estão disponiveis na literatura. Para tanto, os genótipos de indivíduos Africanos (Nigerianos) e Europeus (Espanhóis e Alemães) nos foram gentilmente cedidos pelo Dr. Mark David Shriver, Professor do Departamento de Antropologia da Universidade da Pennsylvania (Shriver, comunicação pessoal). Duas amostras aleatórias de 55 indivíduos para cada um daqueles grupos étnicos foram selecionadas com o uso do programa Excel (Material e Métodos, pág. 54). Estas mesmas amostras aleatórias foram utilizadas na análise destas duas populações parentais com o software Structure.

Comparadas às populações parentais (15 comparações; Tabela 11), as três comunidades de remanescentes de quilombo e as duas urbanas apresentaram valores de $F_{S T}$ significativamente diferentes, exceto na comparação de Africanos vs. Barra e Europeus vs. HEMOSC. A comunidade de Barra e a população urbana do HEMOSC compartilham uma grande proporção de alelos característicos de Africanos e Europeus, respectivamente. 


\section{ESTRUTURA POPULACIONAL}

O software Structure utiliza um método de agrupamento, baseado no modelo desenvolvido por Pritchard et al. (2000), para a inferência de estrutura populacional utilizando dados genotípicos de marcadores não ligados. Por estrutura populacional entende-se a presença de subpopulações de indivíduos geneticamente similares que diferem entre as mesmas.

O diagrama (Figura 6A) representa cada indivíduo das populações analisadas como uma barra. Esta barra tem três partes correspondentes às proporções africana, européia e amerindia representadas pelas cores vermelha, verde e azul, respectivamente.

Três clusters (Figura 6B) foram designados a partir das freqüências genotípicas das populações analisadas na Figura 6A. Pode-se observar que grande proporção $(0,995)$ da amostra de africanos está representada no cluster 1 , assim como a amostra de europeus $(0,678)$ está representada no cluster 2 e a amostra amerindia $(0,807)$ no cluster 3 . Entretanto, é importante salientar que todos estes clusters, principalmente os de número 2 e 3, possuem contribuição dos outros dois grupos reconhecidos como parentais. No cluster 2 pode-se observar uma proporção $(0,140)$ que refere-se ao componente amerindio e no cluster 3 uma proporção $(0,230)$ que refere-se ao componente europeu.

Os clusters 2 e 3 têm informação 'sobreposta', isto é, cada um deles apresenta componentes característicos do outro o que se caracteriza, no gráfico (Figura 6A) por barras isoladas azuis que "invadem" a área verde e 
por barras verdes que "invadem" a área azul, nas regiões correspondentes às populações européia e ameríndia, respectivamente. Um maior número de AIMs informativos na separação destes dois clusters é necessária para que as proporções dos três clusters determinadas para cada população (Figura 6B) possa ser interpretada como contribuição dos componentes parentais para as mesmas.

A comunidade de BR e a população de HEM apresentam uma maior homogeneidade em comparação com as demais populações, o que está de acordo com as estimativas de mistura (Tabela 16).

A comunidade de SG e a população urbana de JQ apresentam níveis de estrutura populacional elevados, isto é, sub-populações de indivíduos geneticamente similares, como salientado pelas barras (Figura 6A) e círculos (Figuras 7A e B), que representam seus indivíduos.

\section{ANÁLISES DE COMPONENTE PRINCIPAL}

Os componentes principais são procedimentos utilizados na simplificação de dados multivariados com uma perda mínima de informação (Cavalli-Sforza et al., 1994). As populações do presente trabalho foram submetidas a esta análise em conjunto com populações mundiais com o intuito de verificar eventual agrupamento por similaridade das freqüências dos alelos examinados. O maior número de populações disponiveis na literatura é obtido considerando-se apenas seis (FY, RB, LPL, AT3, Sb19.3 e APO) dos loci aqui descritos. A análise de componente principal de tais dados está reproduzida na Figura 8. 
Os loci CYP1A1 e PV92 diferenciam amerindios dos outros dois grupos, africanos e europeus, mas apenas deste último encontram-se na literatura relatos de sua freqüência em número significativo de populações. A Figura 9 reproduz a análise componente principal acrescentando-se o locus PV92, mas diminuindo-se o número de amostras populacionais.

Em ambas as análises de componente principal (Figuras 8 e 9) as três comunidades remanescentes de quilombo tendem a agrupar-se próximas às populações africanas e afro-americanas, em posição intermediária entre estas e as amostras urbanas brasileiras. Seguindo o mesmo sentido, as amostras européias se agrupam em posição mais distante. As amostras ameríndias se agrupam isoladamente em ambas as situações.

Este posicionamento reflete as diferentes contribuições européia e ameríndia (Tabela 16) obtidas a partir dos oito AIMs analisados, inclusive a população urbana do Estado de SC (HEM) posicionou-se muito próxima às amostras européias e euro-derivadas, como seria esperado por sua a preponderante contribuição do componente europeu $(0,833 \pm 0,017)$ nesta amostra.

A contribuição européia estimada a partir dos AIMs em populações Afro-derivadas dos EUA variou de 3,5\% nos Gullah (Parra et al., 2001) a 22,5\% em New Orleans (Parra et al., 1998). A contribuição amerindia na formação destas comunidades foi negligenciada. Entretanto, estas populações Afro-derivadas se agruparam na análise de componente principal (Figura 8) muito próximas às amostras africanas e muito distantes das amerindias, confirmando tal 'ausência'. 


\section{ESTIMATIVAS DE MISTURA ÉTNICA}

Os resultados mostraram que SG e JQ são amostras tri-híbridas, o que está de acordo com estimativas prévias obtidas a partir de marcadores clássicos, STRs autosômicos e ligados ao cromossomo Y (Sousa, 2001) para estas mesmas amostras (Tabela 18).

TABELA 18. Comparação das contribuições africana, européia e amerindias obtidas a partir dos oito AIMs com marcadores previamente analisados nas comunidades de São Gonçalo e Valongo e na população urbana de Jequié.

\begin{tabular}{ccccccc}
\hline Componentes & \multicolumn{2}{c}{ Remanescentes de Quilombo } & & \multicolumn{2}{c}{ Populações Urbanas } \\
\cline { 2 - 3 } & São Gonçalo & Barra & Valongo & & Jequié & HEMOSC \\
\hline Africano & $0,681 \pm 0,007$ & $0,954 \pm 0,009$ & $0,681 \pm 0,004$ & & $0,520 \pm 0,003$ & $0,072 \pm 0,007$ \\
$(1)$ & $0,540 \pm 0,016$ & & & $0,344 \pm 0,153$ & \\
$(2)$ & & $0,977 \pm 0,104$ & & \\
Europeu & $0,216 \pm 0,016$ & $0,319 \pm 0,004$ & $0,306 \pm 0,008$ & $0,833 \pm 0,017$ \\
$(1)$ & $0,317 \pm 0,296$ & & & $0,510 \pm 2,86$ & \\
$(2)$ & & & & $0,174 \pm 0,005$ & $0,095 \pm 0,012$ \\
Ameríndio & $0,103 \pm 0,011$ & $0,046 \pm 0,009$ & & $0,145 \pm 0,202$ & \\
$(1)$ & $0,144 \pm 0,209$ & & & & \\
$(2)$ & & $0,026 \pm 0,104$ & & \\
\end{tabular}

(1) Marcadores clássicos, STRs autossômicos e Y-STRs (Sousa 2001). (2) Marcadores clássicos (Souza e Culpi 2005).

Com exceção de VAL, a partir dos dados baseados em AIMS, a contribuição africana foi estimada em valores maiores do que aqueles obtidos a partir dos marcadores clássicos (Souza e Culpi, 2005; Tabela 18).

A preponderante contribuição européia na população urbana do HEM está de acordo com outras estimativas obtidas para populações da região Sul do Brasil a partir dos AIMs (Parra et al., 2003). A contribuição africana na amostra do HEMOSC $(7,2 \%)$ é similar à estimativa observada em uma 
amostra Euro-derivada formada por individuos controles saudáveis do RS (6,5\%; Zembrzuski et al., 2006), também obtida pelo método de identidade gênica (Chakraborty, 1985).

Em VAL as estimativas de mistura não foram consistentes com o modelo tri-híbrido, sugerindo ausência do componente ameríndio, o que refletiria a história demográfica desta comunidade, segundo a qual ela teria sido fundada por sete escravos fugidos e alforriados e um homem branco (Souza e Culpi, 1992; Souza e Culpi, 2005).

Ressalte-se que a estimativa do componente africano obtida a partir dos AIMs foi menor do que a obtida a partir dos marcadores clássicos (Tabela 18). Isto poderia ser considerado como evidência da maior eficiência destes marcadores na quantificação do componente africano, uma vez que o aumento das estimativas não foi generalizado e, portanto, provavelmente não viciado. Esta idéia é reforçada pelo fato de que, em comparação com $B R$, o outro remanescente, este está localizado em área geográfica em que a população envolvente tem grande componente europeu e seria de se esperar uma pressão imigratória deste componente para dentro do isolado. $\mathrm{O}$ componente europeu, portanto, seria decorrente não apenas daquele europeu fundador inicial juntamente com sete outros individuos negros de que nos conta a História (Souza e Culpi, 1992). Conclui-se que os AIMs seriam mais eficientes para o cálculo da proporção relativa dos diferentes componentes formadores destas populações, pois conduziriam a estimativas mais realistas. 


\section{CONCLUSÕES}

O presente trabalho é o primeiro relato de freqüências de AIMs em comunidades remanescentes de quilombo Brasileiras.

As freqüências alélicas aqui observadas e comparadas com populações mundiais atestam que o alelo $C Y P 1 A 1 * 2 C$ é um excelente AIM para distinguir Ameríndios de europeus e africanos.

Dos 11 casos de desvios do Equilibrio de Hardy-Weinberg em um total de 96 testes, apenas quatro permaneceram significativos após a correção de Bonferroni. Portanto, não houve número excessivo de desequilíbrios. Apesar disso, todos os casos de desequilibrio foram caracterizados pelo déficit de heterozigotos que, por sua vez, poderia ser ocasionado por consangüinidade ou heterogeneidade populacional (efeito de Wahlund).

A diferenciação gênica e genotípica apenas confirmou dados históricos de formação das populações aqui examinadas. As aldeias e tribos mostraram homogeneidade, enquanto que os três quilombos com histórias de formação muito diferentes entre si, bem como as duas comunidades urbanas muito distantes geográfica e demograficamente mostram grande diferenciação.

O grau relativo de isolamento dos amerindios em relação às outras comunidades aqui examinadas justifica os menores valores de heterozigose observados entre eles. 
Em 28 comparações para a par entre loci, 13 foram significativas, das quais apenas uma permaneceu assim, após a correção de Bonferroni. Se a mistura recente leva a desequilíbrios de ligação e, sabendo da história de formação recente destas populações, seria esperado um número significativo de desequilibrios. Entretanto, este achado indica que ou a mistura não foi tão intensa ou este teste não tem poder suficiente para ser aplicado às condições aqui encontradas.

Os valores de $F_{S T}$ confirmaram os resultados do teste exato que indicou diferenciação gênica e genotípica.

Nas análises de componente principal os AIMs agruparam todas as amostras estudadas de acordo com o que seria esperado pelos dados histórico-demográficos. Chama a atenção, contudo, que em ambas as análises (excluindo ou incluindo o loco PV92) o loco FY foi a variável que maior peso ('loading') demonstrou sobre o primeiro componente principal. Com relação ao segundo componente principal, na primeira análise a variável de maior peso foi o loco $\mathrm{Sb19.3,} \mathrm{porém} \mathrm{na} \mathrm{segunda} \mathrm{análise} \mathrm{o} \mathrm{loco}$ PV92 demonstrou o maior peso.

Este método demonstrou-se particularmente adequado, pois, em ambas as análises, os dois componentes principais explicaram mais do que $95 \%$ da variância total.

A partir das estimativas de mistura étnica aqui observadas conclui-se que os AIMs seriam mais eficientes para o cálculo da proporção relativa dos diferentes componentes formadores destas populações, pois conduziriam a estimativas mais realistas. 
Dentre as comunidades remanescentes de quilombo, Barra apresenta baixa heterozigose e não apresentou diferenciação $\left(F_{S T}\right)$ com a população africana. Concluímos que esta comunidade foi preponderantemente formada por indivíduos de origem africana (95,4\% de componente africano).

A comunidade de Valongo apresentou um dos maiores coeficientes de endogamia relatados na literatura. Esta população apresentou baixa heterozigose e uma alta contribuição européia em comparação com estimativas anteriormente obtidas por marcadores clássicos.

A comunidade de São Gonçalo apresentou $F_{I S}$ significativo, alta heterozigose e estimativas tri-híbridas de mistura. 


\section{REFERÊNCIAS}

ABÉ-SANDES, K. Diversidade genética de afro-brasileiros: DNA mitocondrial e cromossomo Y. 104 p. Tese de Doutorado, Faculdade de Medicina de Ribeirão Preto, Universidade de São Paulo, Ribeirão Preto, 2002.

ABÉ-SANDES, K; SILVA JR., W.A.; ZAGO. M.A. Heterogeneity of the Y Chromosome in AfroBrazilian Populations. Human Biology. 76(1):77-86, 2004.

ALVES-SILVA J.; DA SILVA SANTOS, M.; GUIMARAES, P.E.; FERREIRA, A.C.; BANDELT, H.J.; PENA, S.D.; PRADO, V.F. The ancestry of Brazilian mtDNA lineages. Am J Hum Genet. 67(2):444-61, 2000.

ARPINI-SAMPAIO, Z.; COSTA, M. C.; MELO, A. A.; CARVALHO, M. F.; DEUS, M. S.; SIMÕES AL. Genetic polymorphisms and ethnic admixture in African-derived black communities of northeastern Brazil. Hum Biol. 71: 69-85, 1999.

BEDOYA, G.; MONTOYA, P.; GARCIA, J.; SOTO, I.; BOURGEOIS, S.; CARVAJAL, L.; LABUDA, D., ALVAREZ, V.; OSPINA, J.; HEDRICK, P.W.; RUIZ-LINARES, A. Admixture dynamics in Hispanics: a shift in the nuclear genetic ancestry of a South American population isolate. Proc Natl Acad Sci USA. 103(19):7234-9, 2006.

BONILlA, C.; GUTIERREZ, G.; PARRA, E. J.; KLINE, C.; SHRIVER, M. D. Admixture analysis of a rural population of the state of Guerrero, Mexico. Am J Phys Anthropol 128:861-869, 2005.

BONILLA, C.; PARRA, E.J.; DIOS, S.; MARSHALL, J.A.; HAMMAN, R.F.; FERREL, R.E.; HOGGART, C.L.; McKEIGUE, P.M.; SHRIVER, M.D. Admixture in the Hispanics of the San Luis Valley, Colorado, and its implications for complex trait gene mapping. Ann Hum Genet. 68: 139-153, 2004.

BORTOLINI, M. C.; SILVA JR, W. A.; CASTRO DE GUERRA, D.; REMONATTO, G.; MIRANDOLA, R.; HUTZ, M. H.; WEIMER, T. A.; SILVA, M. C. B. O.; ZAGO, M. A.; SALZANO, F. M. African-derived South American populations: A history of symmetrical and asymmetrical matings according to sex revealed by bi- and uni-parental genetic markers. Am J Hum Biol, 11: 551-563, 1999.

BORTOLINI, M. C.; SILVA JR, W.A.; WEIMER, T. A.; ZAGO, M. A.; CASTRO DE GUERRA, D.; SCHNEIDER, M. P.; LAYRISSE, Z.; CASTELLANO, H. M.; SALZANO, F. M. Protein and hipervariable tandem repeat diversity in eight african-derived South American populations: inferred relationship do not coincide. Hum Biol, 70: 443-461, 1998

BORTOLINI, M. C.; WEIMER, T. A.; SALZANO, F. M.; CALLEGARI-JACQUES; SCHNEIDER, H.; LAYRISSE, Z.; BONATTO, S. L. Evolutionary relationships between Black South American and African Populations. Hum Biol, 67: 547-559, 1995.

BORTOLINI, M. C; WEIMER, T. A.; FRANCO, M. H. L. P.; SALZANO, F. M.; LAYRISSE, Z.; SCHNEIDER, H.; SCHNEIDER, M. P. C.; HARADA, M. L. Genetic studies in three South American Blacks populations. Gene Geogr, 6: 1-16, 1992. 
BOYAPATI, S.M; SHU, X. O.; GAO, Y. T.; CAI, Q.; JIN, F.; ZHENG, W.; Polymorphisms in CYP1A1 and breast carcinoma risk in a population-based case-control study of Chinese women. Cancer. 2005 Jun 1;103(11):2228-35, 2005.

CALMON, P. História do Brasil - Volume II. Editora José Olímpio, Rio de Janeiro-RJ, 1959.

CARVALHO-SILVA, D.R.; SANTOS, F.R.; ROCHA, J.; PENA, S.D. The phylogeography of Brazilian Y-chromosome lineages. Am J Hum Genet 68:281-286, 2001.

CASCORBI, I.; BROCKMOLLER, J.; ROOTS, I. A C4887A polymorphism in exon 7 of human CYP1A1: population frequency, mutation linkages, and impact on lung cancer susceptibility. Cancer Res 56(21):4965-9, 1996.

CAVALLI-SFORZA, L. L.; MENOZZI, P.; PIAZZA, A. History and geography of human genes. Princeton: Princeton University Press, 1994.

CHAKRABORTY, R.; WEISS, K. M. Admixture as a tool for finding linked genes and detecting that difference from allelic association between loci. Proc Natl Acad Sci USA, 85:91199123, 1988.

CHAKRABORTY, R. Gene identity in racial hybrids and estimation of admixture rates. In Ahuja YR, Neel JV, editors. Genetic diferentiation in human and others animal populations. Indian Anthropological Association. 1985. p, 171-180.

CHOUDHRY, S.; COYLE, N. E.; TANG, H.; SALARI, K.; LIND, D.; CLARK, S. L.; TSAI, H. J.; NAQ, VI, M.; PHONG, A.; UNG, N.; MATALLANA, H.; AVILA, P. C.; CASAL, J.; TORRES, A.; NAZARIO, S.; CASTRO, R.; BATTLE, N. C.; PEREZ-STABLE, E. J.; KWOK, P. Y.; SHEPPARD, D.; SHRIVER, M. D.; RODRIGUEZ-CINTRON, W.; RISCH, N.; ZIV, E.; BURCHARD, E. G. Genetics of Asthma in Latino Americans GALA Study. Population stratification confounds genetic association studies among Latinos. Hum Genet 118:652-664, 2006.

COLLINS-SCHRAMM, H. E.; CHIMA, B.; MORII, T.; WAH, K.; FIGUEROA, Y.; CRISWELL, L. A.; HANSON, R. L.; KNOWLER, W. C.; SILVA, G.; BELMONT, J. W.; SELDIN, M. F. Mexican American ancestryinformative markers: Examination of population structure and marker characteristics in European Americans, Mexican Americans, Amerindians and Asians. Hum Genet 114:263-271, 2004.

COLLINS-SCHRAMM, H. E.; PHILLIPS, C. M.; OPERARIO, D. J.; LEE, J. S.; WEBER, J. L.; HANSON, R. L.; KNOWLER, W. C.; COOPER, R.; LI, H.; SELDIN, M. F. Ethnic-difference markers for use in mapping by admixture linage disequilibrium. Am J Hum Genet, 70:737-750, 2002.

COTRIM, N. H.; AURICCHIO, M. T.; VICENTE, J. P.; OTTO, P. A.; MINGRONI-NETTO, R.C. Polymorphic Alu insertions in six Brazilian African-derived populations. Am J Hum Biol. May-Jun;16(3):264-77, 2004.

CURTIN, P.D. The Atlantic Slave Trade: A Census. University of Winsconsin Press, Madison, 1969.

DANDARA, C.; SAYI, J.; MASIMIREMBWA, C.M.; MAGIMBA, A.; KAAYA, S.; DE SOMMERS, K.; SNYMAN, JR.; HASLER J.A. Genetic polymorphism of cytochrome P450 1A1 (Cyp1A1) and glutathione transferases (M1, T1 and P1) among Africans. Clin Chem Lab Med 40(9):952-7, 2002.

DUZHAK, T.; MITROFANOV, D.; OSTASHEVSKII, V.; GUTKINA, N; CHASOVNIKOVA, O.; POSUKH, O.; OSIPOVA, L.; LYAKHOVICH, V. V. Genetic polymorphisms of CYP2D6, CYP1A1, GSTM1 and p53 genes in a unique Siberian population of Tundra Nentsi. Pharmacogenetics 10(6):531-537, 2000. 
FERREIRA, L. B.; MENDES-JUNIOR, C. T.; WIEZEL, C. E.; LUIZON, M. R.; SIMOES, A. L. Genomic ancestry of a sample population from the state of Sao Paulo, Brazil. Am J Hum Biol. 18(5):702-5, 2006.

FLORES, C.; MACA-MEYER, N.; PEREZ, J. A.; HERNANDEZ, M.; CABRERA, V. M. Ychromosome differentiation in Northwest Africa. Hum Biol. Aug;73(4):513-24, 2001.

FUNDAÇÃO CULTURAL PALMARES (http://www.palmares.gov.br). Acesso em fevereiro de 2002.

GASPAR P.; KVITKO, K.; PARADÓPOLIS, L. G.; HUTZ, M. H.; WEIMER, T. A. High frequency of CYP1A1*2C allele in Brazilian populations. Hum Biol. 74(2): 235-242, 2002.

GOUDET, J. FSTAT (vers. 1.2): a computer program to calculate F-statistics. J Hered, 86:485-486, 1995.

GOULART M. A escravidão africana no Brasil: Das origens à extinção do tráfico. Editora Alfa-Omega, São Paulo-SP, 1975.

GUERREIRO, J. F.; RIBEIRO-DOS-SANTOS, A. K. C.; SANTOS, E. J. M.; VALLINOTO, A. C. R.; CAYRES-VALlINOTO, I. M. V.; AGUIAR, G. F. S.; SANTOS, S. E. B. Geneticaldemographic data from two Amazonian populations composed of descendants of african slaves: Pacoval and Curiau. Genet Mol Biol, 22: 163-167, 1999.

GUO, S. W.; THOMPSON, E. A. Performing the exact test of Hardy-Weinberg proportion for multiple alleles. Biometrics, 48(2):361-372, 1992.

HARTL, D.L.; CLARK, A.G. Principles of population genetics. 4th ed. Sinauer Associates, Inc. Publishers. Sunderland, Massachusetts, 2007.

HIGUCHI, R. Simple and rapid preparation of samples for PCR. In: ERLICH, H. A. (Ed.). PCR technology: principles an applications for DNA amplification. New York, NY: Stockton Press, 1989. p. 31-38.

HOGGART, C. J.; PARRA, E. J.; SHRIVER, M. D.; BONILLA, C.; KITTLES, R. A.; CLAYTON, D. G.; MCKEIGUE, P. M. Control of confounding of genetic associations in stratified populations. Am J Hum Genet. 72(6):1492-1504, 2003.

IBGE - CENSO 2000. SITE DO INSTITUTO BRASILEIRO DE GEOGRAFIA E ESTATÍSTICA. Disponivel na Internet via WWW. URL: www.ibge.gov.br/. Acesso em maio de 2007.

KVITKO, K.; NUNES, J.C.; WEIMER, T.A.; SALZANO, F.M.; HUTZ, M.H. Cytochrome P4501A1 polymorphisms in South American Indians. Hum Biol 72(6):1039-43, 2000.

LANDI, M.T.; BERGEN, A.W.; BACCARELLI, A.; PATTERSON, D.G. JR, GRASSMAN, J.; TERMINASSIAN, M.; MOCARELLI, P.; CAPORASO, N.; MASTEN, S.A.; PESATORI, A.C.; PITTMAN, G.S.; BELL, D.A. CYP1A1 and CYP1B1 genotypes, haplotypes, and TCDDinduced gene expression in subjects from Seveso, Italy. Toxicology 207(2):191-202, 2005.

LEBOUTE, A. P. M.; CARVALHO, M. W. P.; SIMÕES, A. L. Absence of the $\Delta$ ccr5 mutation in indigenous populations of the Brazilian Amazon. Hum Genet, 105:442-443, 1999.

LEWIS, P. O.; ZAYKIN, D. Genetic data analysis: software for the analysis of discrete genetic data. Version 1.0. 1997

LIU, Y.; SAHA, N.; LOW, P. S.; TAY, J. S. Linkage disequilibrium between two loci (5' untranslated exon 1 and intron 5-DdeI) of the antithrombin III gene in three ethnic groups in Singapore. Hum Hered, 45:192-198, 1995. 
LUIZON, M. R.; MENDES-JUNIOR, C. T.; DE OLIVEIRA, S. F.; SIMOES, A. L. Ancestry informative markers in ameridians from Brazilian Amazon. Am J Hum Biol, 2007a (aceito para publicação)

LUIZON, M. R.; SOUZA, I. R. De; SIMOES, A. L. CYP1A1*2C as an Ancestry Informative Marker (AIM) to detect Amerindian contribution in Brazilian populations. 2007b (no prelo).

MARRERO, A.R.; DAS NEVES, LEITE F.P.; DE ALMEIDA, CARVALHO, B; PERES, L.M.; KOMMERS, T.C., DA CRUZ, I.M.; SALZANO, F.M.; RUIZ-LINARES, A.; DA SILVA Junior, WA.; BORTOLINI, M.C.; Heterogeneity of the genome ancestry of individuals classified as White in the state of Rio Grande do Sul, Brazil. Am J Hum Biol, 17(4):496-506, 2005.

MARTINEZ-MARIGNAC, V. L.; VALLADARES, A.; CAMERON, E.; CHAN, A.; PERERA, A.; GLOBUS-GOLDBERG, R.; WACHER, N.; KUMATE, J.; MCKEIGUE, P.; O'DONNELL, D.; SHRIVER, M. D.; CRUZ, M.; PARRA, E. J. Admixture in Mexico City: implications for admixture mapping of type 2 diabetes genetic risk factors. Hum Genet. Feb;120(6):80719, 2007.

MATTOSO, K. M. Q. Ser escravo no Brasil. São Paulo: Brasiliense, 1982.

MENDES-JUNIOR, CD. T. Dna mitocondrial na Amazônia brasileira: estrutura genética regional e inferências continentais. Tese de Doutorado, Faculdade de Medicina de Ribeirão Preto, Universidade de São Paulo, Ribeirão Preto, 2005

MENDES Jr., C. T. Freqüências alélicas de polimorfismos de DNA do tipo STR em indigenas da Amazônia brasileira. 2001. 160 p. Dissertação de Mestrado - Faculdade de Medicina de Ribeirão Preto, Universidade de São Paulo, Ribeirão Preto.

MESSEDER M.L.L.; MARTINS M.A.M. Arraiais de Rio de Contas: Uma comunidade de Cor. Caderno CRH Supl 36-49, 1991.

MESTRINER, M. A.; SIMÕES, A. L.; SALZANO, F. M. New studies on the esterase D polymorphism in South American Indians. Am J Phys Anthropol, 52(1):95-101, 1980.

MILJKOVIC-GACIC, I.; FERRELL, R. E.; PATRICK, A. L.; KAMMERER, C. M.; BUNKER, C. H. Estimates of African, European and Native American ancestry in Afro-Caribbean men on the island of Tobago. Hum Hered 60:129-133, 2005.

MOHRENWEISER, H.; NEEL, J. V.; MESTRINER, M. A.; SALZANO, F. M.; MIGLIAZZA, E.; SIMÕES, A. L.; YOSHIHARA, C. M. Electrophoretic variants in three Amerindian tribes: the Baniwa, Kanamari, and Central Pano of western Brazil. Am J Phys Anthropol, 50(2):237-46, 1979.

MOLLISON, P. L.. Blood transfusion in clinical medicine. 5.ed. Oxford: Blackwell, 1972.

MOURA, C. Dicionário da Escravidão Negra no Brasil/Clóvis Moura; assessora de pesquisa Soraya Silva Moura. São Paulo: Ed Universidade de São Paulo, 2004.

MUÑOZ, S.; VOLLRATH, V.; VALLEJOS, M. P.; MIQUEL, J. F.; COVARRUBIAS. C.; RADDATZ, A.; CHIANALE, J. Genetic polymorphisms of CYP2D6, CYP1A1 and CYP2E1 in the South-Amerindian population of Chile. Pharmacogenetics 8(4):343-51, 1998

NEEL, J. V.; GERSHOWITZ, H.; MOHRENWEISER, H. W.; AMOS, B.; KOSTYU, D. D.; SALZANO, F. M.; MESTRINER, M. A.; LAWRENCE, D.; SIMOES, A. L.; SMOUSE, P. E.; OLIVER, W. J.; SPIELMAN, R. S.; NEEL Jr., J. V. Genetic studies on the Ticuna, an enigmatic tribe of Central Amazonas. Ann Hum Genet, 44(Pt 1):37-54, 1980. 
NEI, M. Molecular evolutionary genetics. New York: Columbia University Press, 512p, 1987.

OLIVEIRA, S. F. Inserções Alu em populações indígenas da Amazônia Brasileira. 135 p. Tese de Doutorado - Faculdade de Medicina de Ribeirão Preto, Universidade de São Paulo, Ribeirão Preto, 1999.

OTA, T. DISPAN: genetic distance and phylogenetic analysis. Institute of Molecular Evolutionary Genetics, The University of Pennsylvania State University, University Park, PA, USA, 1993.

PARRA, E. J.; KITTLES, R. A.; ARGYROPOULOS, G.; PFAFF, C. L.; HIESTER, K.; BONILlA, C.; SYLVESTER, N.; PARRISH-GAUSE, D.; GARVEY, W. T.; JIN, L.; McKEIGUE, P. M.; KAMBOH, M. I.; FERRELL, R. E.; POLLITZER, W. S.; SHRIVER, M. D. Ancestral proportions and admixture dynamics in geographically defined African Americans living in South Carolina. Am J Phys Anthrop, 114:18-29, 2001.

PARRA, E. J.; MARCINI, A.; AKEY, J.; MARTINSON, J.; BATZER, M. A.; COOPER, R.; FORRESTER, T.; ALLISON, D. B.; DEKA, R.; FERRELL, R. E.; SHRIVER, M. D. Estimating African American admixture proportions by use of population-specific alleles. Am J Hum Genet, 63:1839-1851, 1998.

PARRA, F. C.; AMADO, R. C.; LAMBERTUCCI, J. R.; ROCHA, J.; ANTUNES, C. M.; PENA, S. D. Color and genomic ancestry in Brazilians. Proc Natl Acad Sci U S A, 100(1):177-82, Jan 2003.

PEDROSA, M. P. A presença africana em Alagoas: contribuições da genética e da biologia molecular ao perfil das comunidades de Muquém e Quilombo. 1998. Tese de Doutorado. Universidade Federal do Pará, PA.

PFAFF, C. L.; PARRA, E. J.; BONILLA, C.; HIESTER, K.; McKEIGUE, P. M.; KAMBOH, M. I.; HUTCHINSON, R. G.; FERRELL, R. E.; BOERWINKLE, E.; SHRIVER, M. D. Population structure in admixed populations: effect of admixture dynamics on the pattern of linkage disequilibrium. Am J Hum Genet, 68:198-207, 2001.

PRITCHARD J. K.; STEPHENS M., DONNELLY P. Inference of population structure using multilocus genotype data. Genetics. 155(2):945-59. 2000.

RAYMOND, M.; ROUSSET, F. GENEPOP (version 1.2): population genetics software for exact tests and ecumenicism. J Hered, 86:248-249, 1995.

RAYMOND, M.; ROUSSET, F. An exact test for population differenciation. Evolution, 49: 1280-1283, 1995b.

RIBEIRO, D. O povo brasileriro: a formação e o sentido do Brasil. Companhia das Letras, São Paulo, 1995.

RIBEIRO-DOS-SANTOS, A. K. C.; PEREIRA, J. M.; LOBATO, M. R. F.; CARVALHO, B. M.; GUERREIRO, J. F.; SANTOS, S. E. B. Dissimilarities in the process of formation of Curiaú a semi-isolated afro-brazilian population of the Amazon region. Am J Hum Biol, 14: 440-447, 2002.

RIBEIRO-DOS-SANTOS, A.K.; CARVALHO, B.M.; FEIO-DOS-SANTOS, A.C.; DOS SANTOS, S.E. Nucleotide variability of HV-I in Afro-descendents populations of the Brazilian Amazon Region. Forensic Sci Int. 167(1):77-80, 2007.

RICARDO, C. R. (Ed.). Povos Indigenas no Brasil, 1996-2000. São Paulo: Instituto Socioambiental, 2000. 
SAITOU, N.; NEI, M. The neighbor-joining method: a new method for reconstructing phylogenetic trees. Mol Biol Evol, 4(4):406-425, 1987.

SALARI, K.; CHOUDHR, Y. S.; TANG, H.; NAQVI, M.; LIND, D.; AVILA, P. C.; COYLE, N. E.; UNG, N.; NAZARIO, S.; CASAL, J.; TORRES-PALACIOS, A.; CLARK, S.; PHONG, A.; GOMEZ, I.; MATALlANA, H.; PEREZ-STABLE, E. J.; SHRIVER, M. D.; KWOK, P. Y.; SHEPPARD, D.; RODRIGUEZ-CINTRON, W.; RISCH, N. J.; BURCHARD, E. G,; ZIV, E. Genetic admixture and asthma-related phenotypes in Mexican American and Puerto Rican asthmatics. Genet Epidemiol. 29(1):76-86, 2005.

SALZANO, F. M. Em busca das raízes. Ciência Hoje, 5: 48-53, 1986.

SALZANO, F. M. Molecular variability in Amerindians: widespread but uneven information. An Acad Bras Cienc, 74(2):223-63, Jun 2002.

SANGUINETTI, C. J.; DIAS NETO, E.; SIMPSON, A. J. Rapid silver staining and recovery of PCR products separated on polyacrylamide gels. Biotechniques, 17:914-21, 1994.

SCHMITT, A.; TURATTI, M.C.M; CARVALHO, M.C.P. DE. A atualização do conceito de quilombo: identidade e território nas definições teóricas. Ambiente e Sociedade, Ano V, no.10, 1o Semestre de 2002.

SCHNEIDER, H.; GUERREIRO, J. F.; SANTOS, S. E. B.; WEIMER, T. A.; SCHNEIDER, M. P. C.; SALZANO, F. M. Isolate Breakdown in Amazonia - The blacks of the Trombetas river. Rev Brasil Genet, 10: 565-574, 1987.

SELDIN, M. F.; TIAN, C.; SHIGETA, R.; SCHERBARTH, H. R.; SILVA, G.; BELMONT, J. W.; KITTLES, R.; GAMRON, S.; AllEVI, A.; PALATNIK, S. A.; ALVAREllOS, A.; PAIRA, S.; CAPRARUlO, C.; GUILlERÓN, N. C.; CATOGGIO, L. J.; PRIGIONE, C.; BERBOTTO, G. A.; GARCIA, M. A.; PERANDONES, C. E.; PONS-ESTEL, B. A.; ALARCON-RIQUELME, M. E. Argentine population genetic structure: large variance in Amerindian contribution. Am J Phys Anthropol. 132(3):455-62, 2007.

SHRIVER, M. D.; PARRA, E. J.; DIOS, S.; BONILLA, C.; NORTON, H.; JOVEL, C.; PFAFF, C. L.; JONES, C.; MASSAC, A.; CAMERON, N.; BARON, A.; JACKSON, T.; ARGYROPOUlOS, G.; JIN, L.; HOGGART, C. J.; McKEIGUE, P. M.; KITTLES, R. A. Skin pigmentation, biogeographical ancestry and admixture mapping. Hum Genet, 112(4):387-99, 2003.

SHRIVER, M. D.; SMITH, M. W.; JIN, L.; MARCINI, A.; AKEY, J. M.; DEKA, R.; FERRELL, R. E. Ethnic-affiliation estimation by use of population-specific DNA markers. Am J Hum Genet, 60:957-964, 1997.

SILVA JR, W. A.; BORTOLINI, M. C.; MEYER, D.; SALZANO, F. M.; ELION, J.; KRISHNAMOORTHY, R.; SCHNEIDER, M. P. C.; CASTRO DE GUERRA, D.; LAYRISSE, Z.; CASTELlANO, H. M.; WEIMER, T. A.; ZAGO, M. A. Genetic diversity of two African and sixteen South American populations determined on the basis of six hipervariable loci. Am J Phisic Anthropol, 109: 425-437, 1999.

SIMÕES, A. L. O polimorfismo da esterase D em indigenas sul-americanos. 1980. 115 p. Tese de Doutorado - Faculdade de Medicina de Ribeirão Preto, Universidade de São Paulo, Ribeirão Preto.

SMITH, M. W.; LAUTERNBERGER, J. A.; DOO-SHINE, H.; CHREETIEN, J.; SHRESTHA, S.; GILBERT, D. A.; O'BRIEN, S. J. Markers for mapping by admixture linkage disequilibrium in African-American and Hispanic populations. Am J Hum Genet, 69:1080-1094, 2001. 
SOUZA, I.R. de. Estudos demográficos genéticos em uma comunidade negróide solada, Valongo, SC. Dissertação de Mestrado, Universidade Federal do Paraná, Curitiba, 209 pp, 1993.

SOUZA, I.R. de; CULPI, L. Valongo, an isolated Brazilian Black community. I. Structure of the population. Brazil J Genet 15:439-447, 1992.

SOUZA, I.R. de; CULPI, L. Valongo, genetic studies on an isolated Afro-Brazilian community. Genetics and Molecular Biology 28 (3) 402-406, 2005.

SOUZA, S. M. B. Estrutura genética de uma comunidade Afro-brasileira, São Gonçalo (BA). 2001. 109 p. Dissertação de Mestrado - Faculdade de Medicina de Ribeirão Preto, Universidade de São Paulo, Ribeirão Preto.

TARAZONA-SANTOS, E., CARVALHO-SILVA, D. R., PETTENER, D.; LUISELLI, D.; DE STEFANO, G. F.; LABARGA, C. M.; RICKARDS, O.; TYLER-SMITH, C.; PENA, S. D., SANTOS, F. R. Genetic differentiation in South Amerindians is related to environmental and cultural diversity: evidence from the $\mathrm{Y}$ chromosome. Am $\mathbf{J}$ Hum Genet. Jun;68(6):1485-96, 2001.

TOMÁS, G.; SECO, L.; SEIXAS, S.; FAUSTINO, P.; LAVINHA, J.; ROCHA, J. The peopling of São Tomé (Gulf of Guinea): origins of slave settlers and admixture with the Portuguese. Hum Biol, 74(3):397-411, Jun 2002.

VIANNA, F.L. O negro na Bahia. Editora Nova Fronteira, Rio de Janeiro-RJ, 1988.

WEBER, J. L.; DAVID, D.; HEIL, J.; FAN, Y.; ZHAO, C.; MARTH, G. Human diallelic insertion/deletion polymorphisms. Am J Hum Genet 2002; 71:854-862, 2002.

WEIR, B. S.; COCKERHAM, C. C. Estimating F-statistics for the analysis of population structure. Evolution, 38(6):1358-1370, 1984.

ZEMBRZUSKI, V.M.; CALLEGARI-JACQUES, S.M.; HUTZ, M.H. Application of an African Ancestry Index as a genomic control approach in a Brazilian population. Ann Hum Genet. 70(Pt 6):822-8, 2006.

\section{Banco de Dados em Meio Eletrônico}

dbSNP/NCBI. In: NATIONAL CENTER FOR BIOTECHNOLOGY INFORMATION INFORMATION. Disponivel em: <http://www.ncbi.nlm.nih.gov/SNP/>. Acesso em: 24 mai. 2003. 


\section{ANEXO}

\section{MANUSCRITO ENVIADO PARA PUBLICAÇÃO}

\section{Title page}

\section{CYP1A1*2C as an Ancestry Informative Marker (AIM) to detect Amerindian} contribution in Brazilian populations

Marcelo Rizzatti Luizon ${ }^{1}$, Ilíada Rainha de Souza ${ }^{2}$ and Aguinaldo Luiz Simões ${ }^{1}$

${ }^{1}$ (Institute where the work was conducted) Departamento de Genética, Faculdade de Medicina de Ribeirão Preto, Universidade de São Paulo, Ribeirão Preto, São Paulo, Brasil.

${ }^{2}$ Departamento de Biologia Celular, Embriologia e Genética, Universidade Federal de Santa Catarina, Florianópolis, Santa Catarina, Brasil.

Short title $\quad C Y P 1 A 1 * 2 C$ and Amerindian contribution in Brazilians

\section{A. L. Simões (Corresponding author)}

Departamento de Genética

Faculdade de Medicina de Ribeirão Preto, Universidade de São Paulo

Av. Bandeirantes 3900, Ribeirão Preto

State of São Paulo, Brasil, CEP 14049-900

E-mail: alsimoes@fmrp.usp.br

Phone/Fax: 55 (16) 3602-3157

\section{Keywords}

CYP1A1*2C allele, Amerindians, Brazilians, Amazon, Ancestry Informative Markers, Large frequency differences 


\begin{abstract}
Ancestry informative markers (AIMs) are genetic loci showing alleles with large frequency differences $(\delta>30 \%)$ between populations. CYP1A1*2C allele (Ile462Val polymorphism of CYP1A1 gene) is very rare among Caucasians and Africans and was observed at higher frequencies in Brazilian Amerindians. The presence of this variant was investigated in four tribes of Brazilian Amazon ( $\mathrm{n}=297$ individuals) in order to corroborate the high $\delta$ values observed elsewhere. These values were compared to an urban sample from the State of São Paulo (Southeastern Brazil, n=90) and the quilombo remnant of Valongo (Southern Brazil, $\mathrm{n}=52)$. CYP1A1*2C was analyzed by the PCR-RFLP method before digestion with BsrDI. Its presence ranged from $80 \%$ to $93 \%$ among the indigenous tribes, in accordance with previous reported data for other Brazilian tribes. This variant was absent in Valongo, probably related to the low frequencies observed in African populations. The frequency $(8.3 \%)$ of the urban sample was lower than those observed to other Afro-derived Brazilians previously studied, and can be explained by different Amerindian contribution to them. The large frequency differences between the Amazon tribes studied and African and European populations indicate that $C Y P 1 A 1 * 2 C$ could be used as an AIM to distinguish Amerindian contribution to tri-hybrid Brazilian populations.
\end{abstract}

\title{
Acknowledgements:
}

This work was supported by grants from the National Counsel of Technological and Scientific Development (CNPq / Brazil). 


\section{Introdução}

Marcadores Informativos de Ancestralidade (AIMs, do inglês Ancestry Informative Markers) são loci que possuem alelos com grandes diferenciais de freqüência $(\delta>30 \%)$ entre os principais grupos étnicos (Shriver et al., 2003). Estes são considerados ferramentas eficientes na determinação de estimativas mais precisas de mistura étnica e na detecção de estrutura populacional (Bonilla et al., 2005; Choudhry et al., 2006). Considerando a natureza tri-híbrida da população Brasileira, faz-se necessário a seleção de marcadores específicos que permitam estimar a contribuição do componente Ameríndio.

O gene CYP1A1 desempenha um papel significativo no metabolismo de hidrocarbonetos aromáticos policíclicos (PAHs), um importante grupo de substâncias carcinogênicas. Uma substituição de base (A2455G) no exon 7 induz a mudança do aminoácido isoleucina para uma valina no codon 462 (Ile462Val). Esta variante, denominada alelo $C Y P 1 A 1 * 2 C$, tem sido associada com o risco aumentado para alguns tipos de câncer (Cascorbi et al., 1996, Esteller et al., 1997, Garte 1998).

As presença do alelo CYP1A1*2C é muito rara dentre os Europeus (de 2,8\% a 6\%; Cascorbi et al., 1996, Esteller et al., 1997, Landi et al., 2005) e Africanos (1,3\% em 114 indivíduos; Dandara et al., 2002). Por outro lado, está presente em altas freqüências em Sulameríndios (de 54\% a 97\%; Muñoz et al., 1998, Kvitko et al., 2000, Gaspar et al., 2002a). Portanto, esta variante apresenta grandes valores de $\delta$ entre populações ameríndias e européias ou africanas.

As freqüências do alelo CYP1A1*2C em 297 indivíduos de quatro tribos indígenas da Amazônia Brasileira são aqui relatadas no intuito de confirmar aqueles altos valores de $\delta$ observados. Estas tribos são caracterizadas por baixa mistura com populações não-indígenas, de acordo com a análise de marcadores clássicos (2 a 3\%; Mohrenweiser et al., 1979, Neel et al., 1980) e AIMs (Luizon et al., 2007), e suas freqüências poderiam ser consideradas como 
parentais de populações Ameríndias em estimativas de mistura étnica. Uma amostra urbana da população do Estado de São Paulo (Sudeste do Brasil, n = 90) e da comunidade remanescente de quilombo de Valongo (Sul do Brasil, $\mathrm{n}=52$ ) também foram determinadas para permitir comparações adicionais.

\section{Material e Métodos}

As amostras de quatro tribos indígenas da Amazônia Brasileira (Tikúna, Baníwa, Kashinawa e Kanamarí; Figura 1) foram coletadas em 1976 para estudos de marcadores clássicos (Mestriner et al., 1980). O anel leucocitário foi removido por aspiração e, após a retirada do plasma as hemácias foram então lavadas em solução salina e o sedimento resultante após a última centrifugação foi diluído em tampão glicerol a 30\% e mantido a $20^{\circ} \mathrm{C}$ em nosso laboratório até o presente. As amostras de Valongo, uma comunidade isolada do Sul do Brasil de origem predominantemente da África Sub-Saariana (um remanescente de quilombo), e de indivíduos não aparentados nascidos no estado de São Paulo, Sudeste do Brasil, foram coletadas como descrito na literatura (de Souza e Culpi 2005 e Ferreira et al., 2006, respectivamente).

\section{Figura 1}

O DNA genômico foi isolado a partir de uma alíquota de $300 \mu$ de sangue total (incluindo leucócitos). $\mathrm{O}$ alelo $C Y P 1 A 1 * 2 C$ foi detectado por PCR seguida de digestão pela endonuclease de restrição BsrDI, segundo os primers e condições de reação descritas por Cascorbi et al., (1996). Os fragmentos de DNA foram então separados por eletroforese em géis de poliacrilamida a $6 \%$ e visualizados por coloração com nitrato de prata. As freqüências alélicas foram estimadas por contagem gênica e as análises estatísticas realizadas pelo software GENEPOP (Raymond \& Rousset 1995, versão 3.4), disponível em http://wbiomed.curtin.edu.au/genepop. As diferenças entre os nossos dados e as freqüências 
alélicas obtidas na literatura foram estimadas pelo teste exato de Fisher. Os procedimentos realizados no presente trabalho foram revisados e aprovados pelo Comitê Nacional de Ética em Pesquisa (CONEP, Processo 25000.097241.2001-83).

\section{Resultados e discussão}

O presente trabalho apresenta altas freqüências do alelo $C Y P 1 A 1 * 2 C$ em sete aldeias de quatro tribos da Amazônia Brasileira, a ausência desta variante em uma comunidade remanescente de quilombo do Sul do Brasil, e sua baixa freqüência em uma amostra urbana do Sudeste do Brasil (Figura 1 e Tabela 1).

As freqüências da aldeia Vendaval, e da tribo Tikúna como um todo, não apresentaram aderência ao equilíbrio de Hardy-Weinberg. Estes desvios podem estar relacionados. Eles são causados pelo déficit de heterozigotos que, por sua vez, poderia ser ocasionado por consangüinidade, heterogeneidade populacional (efeito de Wahlund) ou seleção natural.

Um cenário provável para o aumento da freqüência deste alelo em Ameríndios pode ter ocorrido quando da travessia do estreito de Behring. Uma pequena parcela da variabilidade total da população Asiática contida na população migrante apresentaria, ao acaso, freqüências mais altas do alelo $C Y P 1 A 1 * 2 C$. No entanto, dada as baixas freqüências observadas atualmente em Asiáticos (Tabela 1), fatores seletivos também poderiam ter atuado em regiões e/ou momentos de gargalo a partir do qual teriam emergido populações com altas freqüências do alelo espalhando-se pelo continente onde não mais estariam presentes tais fatores seletivos. O aumento da freqüência do CYP $1 A 1 * 2 C$ na América do Sul teria sido, portanto, uma mistura de seleção natural e efeito do fundador.

O tipo sangüíneo $\mathrm{O}$ e alguns haplogrupos do mtDNA são exemplos de marcadores característicos de ameríndios por terem suas freqüências significativamente maiores entre eles do que nos outros grupos populacionais. A mesma razão ou motivo que provocou o 
aparecimento de tais marcadores pode ter motivado o aparecimento do alelo CYP1A1*2C com alta freqüência em ameríndios.

Por outro lado, estas comunidades indígenas isoladas são particularmente sensíveis ao efeito da deriva genética (Salzano 2002). No entanto, o alto valor médio observado nos ameríndios Sul-americanos (Tabela 1) em relação a Europeus, Africanos e Asiáticos não poderia ser explicado pela deriva. Seu efeito teria provocado uma variação em torno desta freqüência média alta, o que pode ser constatado para alguns valores relatados na literatura (Tabela 1).

A média ponderada das freqüências aqui descritas (90,9\%) é maior do que a observada para as demais tribos $(73,2 \%)$ relatadas na literatura (Tabela 1). As primeiras são provavelmente mais representativas, pois as tribos apresentam baixa mistura com populações não indígenas de acordo com marcadores clássicos (2-3\%; Mohrenweiser et al., 1979, Neel et al., 1980) e AIMs (Luizon et al., 2007). Estas freqüências também são muito maiores do que as descritas para populações européias e mais ainda em relação às freqüências de populações africanas (Tabela 1).

Com o objetivo de comparar as freqüências deste marcador em diferentes segmentos da população brasileira, uma amostra urbana e um remanescente de quilombo foram aqui incluídos.

Em princípio, um remanescente de quilombo deve ter grande proporção de seus genes derivados de estoques africanos. De fato, o quilombo de Valongo demonstrou ausência de contribuição ameríndia e a africana foi estimada em 97,33\% \pm 10,41 por marcadores clássicos (de Souza e Culpi 2005). Isto explica a ausência do alelo CYP1A1*2C nesta comunidade, tendo em vista a baixa freqüência $(1,3 \%)$ observada em populações africanas (Tabela 1; Dandara et al., 2002). 
A freqüência de $C Y P 1 A 1 * 2 C$ na amostra urbana analisada $(8,3 \%$; Tabela 1$)$ é concordante com a contribuição ameríndia estimada para a mesma a partir de STRs autossômicos (7\%; Ferreira et al., 2006). Esta freqüência também é maior do que a freqüência africana (Tabela 1), e pode ser atribuída à contribuição indígena para esta amostra.

A comparação das freqüências alélicas pelo teste exato de Fisher revela diferença estatística $(p=0,014)$ entre a amostra urbana aqui analisada e a amostra de Afro-brasileiros de Porto Alegre (Gaspar et al., 2002b), mas não com relação a outras amostras urbanas brasileiras relatadas na literatura (Tabela 1). A contribuição ameríndia nas amostras Afrobrasileiras analisadas por Gaspar et al., (2002b) foi estimada em 0\% a 7\% para Porto Alegre (Bortolini et al., 1999), em 7\% para o Rio de Janeiro (Palatnik et al., 2000), e em 4\% a 11\% para Salvador (Bortolini et al., 1999). A menor contribuição ameríndia em Porto Alegre poderia explicar a diferença estatística com relação a amostra urbana analisada no presente trabalho.

\section{Conclusões}

As freqüências do alelo $C Y P 1 A 1 * 2 C$ nas tribos indígenas da Amazônia analisadas apresentam grande diferencial $(\delta>70 \%)$ em relação as de Africanos e Europeus e são concordantes com aquelas observadas em outras tribos indígenas da América do Sul, o que confirma os altos valores de $\delta$ observados na literatura. Este grande valor de $\delta$ indica que o alelo $C Y P 1 A 1 * 2 C$ poderia ser útil como um AIM na determinação das contribuição Ameríndia em estimativas de mistura envolvendo as populações tri-híbridas Brasileiras. Além disso, a alta heterogenidade das freqüências observadas entre os principais grupos étnicos que participaram da formação da população Brasileira deve ser levada em consideração no delineamento de estudos de associação caso-controle devido a possibilidade de ocorrência de estratificação populacional entre casos e controles, o que levaria a resultados falso-positivos. 


\section{Referências}

Bonilla C, Gutierrez G, Parra EJ, Kline C, Shriver MD (2005) Admixture analysis of a rural population of the state of Guerrero, Mexico. Am J Phys Anthropol 128(4):861-9

Bortolini MC, Da Silva WA Junior W, De Guerra DC, Remonatto G, Mirandola R,Hutz MH, Weimer TA, Silva MC, Zago MA, Salzano FM (1999) African-derived South American populations: A history of symmetrical and asymmetrical matings according to sex revealed by bi- and uni-parental genetic markers. Am J Hum Biol 11(4):551-563

Boyapati SM, Shu XO, Gao YT, Cai Q, Jin F, Zheng W (2005) Polymorphisms in CYP1A1 and breast carcinoma risk in a population-based case-control study of Chinese women. Cancer. 2005 Jun 1;103(11):2228-35.

Cascorbi I, Brockmoller J, Roots I (1996) A C4887A polymorphism in exon 7 of human CYP1A1: population frequency, mutation linkages, and impact on lung cancer susceptibility. Cancer Res 56(21):4965-9

Choudhry S, Coyle NE, Tang H, Salari K, Lind D, Clark SL, Tsai HJ, Naqvi M, Phong A, Ung N, Matallana H, Avila PC, Casal J, Torres A, Nazario S, Castro R, Battle NC, PerezStable EJ, Kwok PY, Sheppard D, Shriver MD, Rodriguez-Cintron W, Risch N, Ziv E, Burchard EG; Genetics of Asthma in Latino Americans GALA Study (2006) Population stratification confounds genetic association studies among Latinos. Hum Genet 118(5):652-64

Dandara C, Sayi J, Masimirembwa CM, Magimba A, Kaaya S, De Sommers K, Snyman JR, Hasler JÁ (2002) Genetic polymorphism of cytochrome P450 1A1 (Cyp1A1) and glutathione transferases (M1, T1 and P1) among Africans. Clin Chem Lab Med 40(9):9527

de Souza IR, Culpi L (2005) Valongo, genetic studies on an isolated Afro-brazilian community. Genet Mol Biol 28(3):402-406

Duzhak T, Mitrofanov D, Ostashevskii V, Gutkina N, Chasovnikova O, Posukh O, Osipova L, Lyakhovich VV (2000) Genetic polymorphisms of CYP2D6, CYP1A1, GSTM1 and p53 genes in a unique Siberian population of Tundra Nentsi. Pharmacogenetics 10(6):531537

Esteller MA, Garcia JM, Martínez-Palones et al., (1997) Susceptibility to endometrial cancer: Influence of allelism at p53, glutathione S-transferase (GSTm1 and GST1) and cyochrome P-450 (CYP1A1) loci. Br J Cancer 75:1385-1388

Ferreira LB, Mendes-Junior CT, Wiezel CE, Luizon MR, Simoes AL (2006) Genomic ancestry of a sample population from the state of Sao Paulo, Brazil. Am J Hum Biol 18(5):702-5

Garte S (1998) The role of ethnicity in cancer susceptibility gene polymorphisms: the example of CYP1A1. Carcinogenesis 19(8):1329-32

Gaspar PA, Hutz MH, Salzano FM, Hill K, Hurtado AM, Petzl-Erler ML, Tsuneto LT, Weimer TA (2002a) Polymorphisms of CYP1a1, CYP2e1, GSTM1, GSTT1, and TP53 genes in Amerindians. Am J Phys Anthropol 119(3):249-56

Gaspar PA, Kvitko K, Papadópolis LG, Hutz MH, Weimer TA (2002b) High frequency of CYP1A1*2C allele in Brazilian populations. Hum Biol 74(2):235-242 
Kvitko K, Nunes JC, Weimer TA, Salzano FM, Hutz MH (2000) Cytochrome P4501A1 polymorphisms in South American Indians. Hum Biol 72(6):1039-43

Landi MT, Bergen AW, Baccarelli A, Patterson DG Jr, Grassman J, Ter-Minassian M, Mocarelli P, Caporaso N, Masten SA, Pesatori AC, Pittman GS, Bell DA (2005) CYP1A1 and CYP1B1 genotypes, haplotypes, and TCDD-induced gene expression in subjects from Seveso, Italy. Toxicology 207(2):191-202

Luizon MR, Mendes-Junior CT, de Oliveira SF, Simões AL (2007) Ancestry Informative Markers in Amerindians from Brazilian Amazon. Am J Hum Biol (aceito para publicação).

Mestriner MA, Simões AL, Salzano FM (1980) New studies on the esterase D polymorphism in South American Indians. Am J Phys Anthropol 52(1):95-101

Mohrenweiser H, Neel JV, Mestriner MA, Salzano FM, Migliazza E, Simões AL, Yoshihara CM (1979) Electrophoretic variants in three Amerindian tribes: the Baníwa, Kanamari, and Central Pano of western Brazil. Am J Phys Anthropol 50(2):237-46

Muñoz S, Vollrath V, Vallejos MP, Miquel JF, Covarrubias C, Raddatz A, Chianale J (1998) Genetic polymorphisms of CYP2D6, CYP1A1 and CYP2E1 in the South-Amerindian population of Chile. Pharmacogenetics 8(4):343-51

Neel JV, Gershowitz H, Mohrenweiser HW, Amos B, Kostyu DD, Salzano FM, Mestriner MA, Lawrence D, Simoes AL et al., (1980) Genetic studies on the Ticuna, an enigmatic tribe of Central Amazonas. Ann Hum Genet 44(Pt 1):37-54

Palatnik M, Silva Jr. WA, Estalote AC et al., (2000) Gene admixture and type 2 diabetes mellitus (type 2 DM) in Rio de Janeiro, Brazil. Genet Mol Biol 23 (Suppl 3):608

Raymond M, Rousset F (1995) GENEPOP (version 1.2): population genetics software for exact tests and ecumenicism. J Hered 86:248-249

Salzano FM (2002) Molecular variability in Amerindians: widespread but uneven information. An Acad Bras Cienc 74(2):223-63

Shriver MD, Parra EJ, Dios S, Bonilla C, Norton H, Jovel C, Pfaff C, Jones C, Massac A, Cameron N, Baron A, Jackson T, Argyropoulos G, Jin L, Hoggart CJ, McKeigue PM, Kittles RA (2003) Skin pigmentation, biogeographical ancestry and admixture mapping. Hum Genet 112(4):387-99 
Figura 1. Mapa indicando a localização das tribos analisadas.

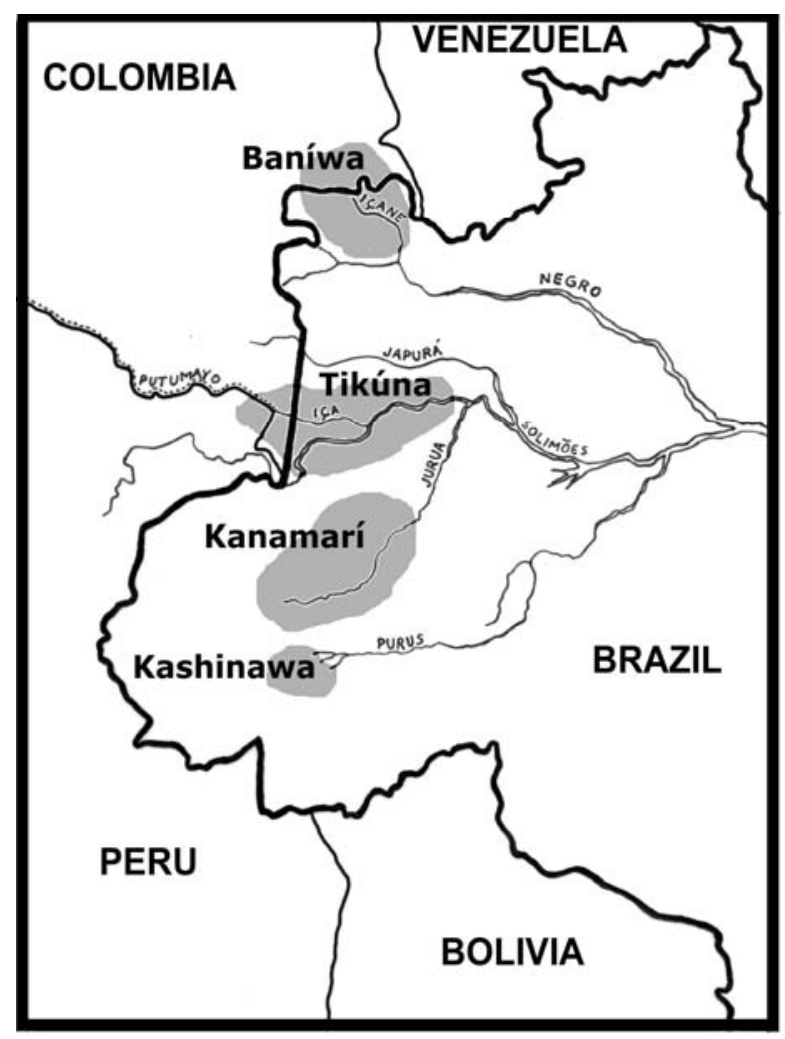


Tabela 1. Freqüências do alelo $C Y P 1 A 1 * 2 C(\%)$ em populações mundiais.

\begin{tabular}{|c|c|c|c|}
\hline População & $2 n$ & $* 2 C$ & Referências \\
\hline África $^{a}$ & 228 & 1,3 & Dandara et al., 2002 \\
\hline Europa & 924 & $2,8-5,8$ & Cascorbi et al., 1996, Esteller et al., 1997 \\
\hline Itália & 242 & 6 & Landi et al., 2005 \\
\hline \multicolumn{4}{|l|}{ Ásia } \\
\hline China & 2454 & 24,8 & Boyapati et al., 2005 \\
\hline Sibéria & 102 & 35 & Duzhak et al., 2000 \\
\hline \multicolumn{4}{|l|}{ América } \\
\hline Aché & 134 & 100 & Gaspar et al., 2002a \\
\hline Baníwa & 98 & 89,8 & present study \\
\hline Gavião & 60 & 59 & Kvitko et al., 2000 \\
\hline Guarani & 102 & 90,2 & Gaspar et al., 2002a \\
\hline Kanamarí & 68 & 92,6 & presente estudo \\
\hline Kashinawa & 50 & 80 & presente estudo \\
\hline Mapuche & 168 & 77 & Muñoz et al., 1998 \\
\hline Suruí & 48 & 54 & Kvitko et al., 2000 \\
\hline Tikúna (4 aldeias) & 378 & 92,1 & presente estudo \\
\hline Umariaçú & 100 & 94 & presente estudo \\
\hline Feijoal & 98 & 95,9 & presente estudo \\
\hline Vendaval & 90 & 82,2 & presente estudo \\
\hline Belém & 90 & 95,6 & presente estudo \\
\hline Xavante & 42 & 97 & Kvitko et al., 2000 \\
\hline Wai Wai & 52 & 81 & Kvitko et al., 2000 \\
\hline Zoró & 60 & 76 & Kvitko et al., 2000 \\
\hline \multicolumn{4}{|l|}{ Afro-brasileiros } \\
\hline Porto Alegre & 274 & 15,7 & Gaspar et al., 2002b \\
\hline Rio de Janeiro & 128 & 11,7 & Gaspar et al., 2002b \\
\hline Salvador & 60 & 15 & Gaspar et al., 2002b \\
\hline São Paulo & 180 & 8,3 & presente estudo \\
\hline Valongo & 104 & 0 & presente estudo \\
\hline \multicolumn{4}{|l|}{ Euro-brasileiros } \\
\hline Porto Alegre & 172 & 11,6 & Gaspar et al., 2002b \\
\hline
\end{tabular}

aTanzânia, os Venda da África do Sul, e Zimbábue 